Portland State University

PDXScholar

Fall 1-1-2012

\title{
Use of Two-Dimensional Agarose-Gel Analysis to Characterize Processing of UV-Irradiated Plasmids and the Composition of the Replisome Following UV- induced Arrest
}

Harout Arthur Jeiranian

Portland State University

Follow this and additional works at: https://pdxscholar.library.pdx.edu/open_access_etds

Part of the Biology Commons, and the Other Cell and Developmental Biology Commons Let us know how access to this document benefits you.

\section{Recommended Citation}

Jeiranian, Harout Arthur, "Use of Two-Dimensional Agarose-Gel Analysis to Characterize Processing of UV-Irradiated Plasmids and the Composition of the Replisome Following UV-induced Arrest" (2012). Dissertations and Theses. Paper 921.

https://doi.org/10.15760/etd.921

This Dissertation is brought to you for free and open access. It has been accepted for inclusion in Dissertations and Theses by an authorized administrator of PDXScholar. Please contact us if we can make this document more accessible: pdxscholar@pdx.edu. 
Use of Two-Dimensional Agarose-Gel Analysis to Characterize Processing of UV-Irradiated Plasmids and the Composition of the Replisome Following UVinduced Arrest

\author{
by \\ Harout Arthur Jeiranian
}

A dissertation submitted in partial fulfillment of the requirements for the degree of

\author{
Doctor of Philosophy \\ in \\ Biology
}

Dissertation Committee:

Justin Courcelle, Chair

Michael Bartlett

Jeffrey Singer

Todd W. Rosenstiel

Dirk Iwata-Reuyl

\author{
Portland State University \\ 2012
}




\begin{abstract}
In this thesis, I address two fundamental questions related to our understanding of how DNA damage is processed and repaired during replication. Using Two-dimensional (2-D) agarose gel analysis, I first examine whether DNA damage on plasmids introduced by transformation is processed in a manner similar to that observed on endogenously replicating plasmids and the chromosome. The original intent for using this approach was to develop a technique that could examine how different DNA adducts would be repaired in various sequence contexts. However, I found that distinct differences exist between the processing of DNA damage on transforming plasmids and the chromosome. The 2-D agarose gel analysis shows that RecA-mediated processing does not contribute to the survival of transforming plasmids and that this effect is likely due to inefficient replication of the plasmids after they are initially introduced into cells. These observations, while important, place limitations on the usefulness of transforming plasmids to characterize cellular repair processes.

In a second question, I characterize the composition of the replisome following arrest by UV-induced DNA damage. Using 2-D agarose gel analysis the structural changes that occur in DNA during processing and repair have been well characterized, however, little is known about the fate of the replisome itself during these events. I used thermosensitive replication mutants to compare the
\end{abstract}


DNA structural intermediates induced after disruption of specific components of the replisome to those observed after UV damage. The results show that dissociation of subunits required for polymerase stabilization are sufficient to induce the same processing events observed after UV damage. By contrast, disruption of the helicase-primase complex induces abnormal structures and a loss of replication integrity, suggesting that these components remain intact and bound to the template following replication arrest. I propose that polymerase dissociation provides a mechanism that allows repair proteins to gain access to the lesion while retention of the helicase serves to maintain the integrity and licensing of the fork so that replication can resume from the appropriate site once the lesion has been processed. 
Table of Contents

Page

Abstract

List of Tables

V

List of Figures

vi

Chapter 1. Introduction

Introduction

References

Chapter 2. Inefficient Replication Reduces RecA-mediated Repair of UVdamaged Plasmids Introduced into Competent Escherichia coli 28

Introduction ............................................... 29

Materials and Methods ....................................... 33

Strain Construction ................................. 33

Plasmids ............................................. 35

Plasmid Purification and Irradiation .................... 35

Preparation of Competent Cells and Transformation ... 36

Quantification of Induced DNA Damage ................ 37

Two-dimensional Agarose Gel Electrophoresis ........ 37

Results

Several RecA-mediated pathways that contribute to cell survival after UV irradiation do not contribute to survival of UV-irradiated plasmids introduced into competent cells

UvrA is nearly essential for survival of plasmids containing UV-induced damage following transformation

RecA-dependent processing intermediates are observed on endogenously replicating plasmids, but not when plasmids are first introduced into cells

SOS induction or plasmid homology does not enhance survival of the transforming plasmid DNA

Discussion

References 
Chapter 3. Fate of the Replisome Following Arrest by DNA Damage in Escherichia coli

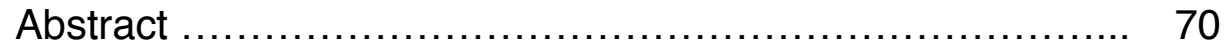

Introduction .............................................. 71

Materials and Methods ......................................... 73

Strain Construction .................................. 73

Tracking Rate of DNA Synthesis via $\left[{ }^{3} \mathrm{H}\right]-$

Thymidine Incorporation .............................. 73

Two-dimensional Agarose Gel Electrophoresis ........ 74

Nascent DNA Degradation Assay ...................... 75

Results ................................................... 76

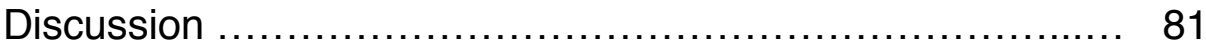

References ................................................ 90

Chapter 4. Concluding Remarks

Concluding Remarks ...................................... 94

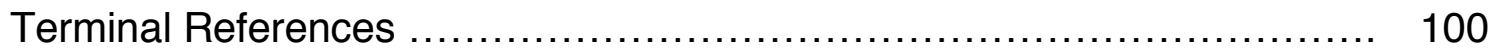

Appendix A. Visualization of UV-induced replication intermediates in

E. coli using two-dimensional agarose-gel analysis

Abstract .................................................. 119

Materials and Methods ..................................... 120

Growth and UV Irradiation .......................... 120

DNA isolation ......................................... 121

2D gel and southern analysis ....................... 123

Discussion .................................................. 126

References .............................................. 130

Appendix B. Damage-Inducible Polymerases Contribute to the DNA

Synthesis that Occurs Following Disruption of Pol III in Escherichia coli

Introduction ............................................... 132

Materials and Methods ..................................... 134

Strain Construction ................................... 134

Tracking Rate of DNA Synthesis via $\left[{ }^{3} \mathrm{H}\right.$ ]-Thymidine ... 134

Results and Discussion .................................... 135

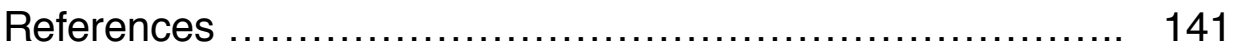




\section{List of Tables}

Table

Page

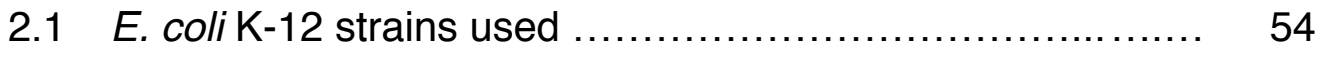

3.1 E. coli strains used ........................................ 84 


\section{List of Figures}

Figure $\quad$ Page

1.1 A schematic of the structural intermediates observed following 2-D agarose gel analysis of a low-copy plasmid with a unidirectional origin

1.2 A model for the DNA structural intermediates generated at each step during processing of the arrested replication fork

1.3 A schematic of the replisome indicating the function of each group of subunits or components

2.1 Schematic of transformation assay $\ldots \ldots \ldots \ldots \ldots \ldots \ldots \ldots \ldots$

2.2 Many RecA-mediated processes that contribute to cell survival do not contribute to the survival of transforming plasmids

2.3 UvrA is nearly essential for the survival of transforming plasmids containing UV-induced damage

2.4 Replication- and RecA-dependent processing intermediates are not observed on newly introduced plasmids

2.5 Constitutive recA expression does not enhance the survival of transforming UV-damaged plasmids

2.6 The presence of a homologous plasmid does not enhance the survival of transforming UV-damaged plasmids

3.1 Replication is disrupted by UV-induced damage or following inactivation of the polymerase, tau complex, 
or helicase-primase complex

3.2 Dissociation of the DNA polymerase or $\alpha$ complex, but not the helicase complex, induces replication fork processing intermediates similar to UV-induced damage

3.3 Similar to after UV, the integrity of the replication fork DNA is maintained after polymerase dissociation, and the formation of the replication fork intermediates are mediated by RecF

3.4 Model of Replisome at UV-induced damage . 88

3.5 Persistence of structural intermediates that accumulate following UV exposure or inactivation by temperature shift 


\section{Chapter 1}

\section{INTRODUCTION}

\section{Repair of UV-induced DNA damage in Escherichia coli}

UV irradiation causes the formation of cyclobutane pyrimidine dimers (CPD) and 6-4 photoproducts in DNA that can block polymerases and prevent replication of the genome (Setlow et al., 1963). In E. coli, the nucleotide excision repair complex, encoded by the $u v r A$, uvrB and $u v r C$ genes, serves to remove these lesions from DNA and allows replication to continue (Rupp and HowardFlanders, 1968). Cells deficient in nucleotide excision repair exhibit elevated levels of mutagenesis, strand exchange, rearrangements and cell lethality (Horii and Suzuki, 1968; Howard-Flanders et al., 1969).

Following the arrest of replication in the presence of UV-induced DNA damage, several proteins, including $\operatorname{RecA}$ and $\mathrm{RecF}$, are required to stabilize the DNA at the replication fork and process the nascent DNA prior to repair (Chow and Courcelle, 2004; Courcelle and Hanawalt, 1999). Upon arrest of the replication fork at a lesion, the fork undergoes transient regression, displacing the nascent DNA strands and returning the DNA at the site of the lesion to duplex form in order to allow nucleotide excision repair to function on the lesion. The displaced nascent lagging strand is then processed to a limited extent by the RecJ nuclease and RecQ helicase (Courcelle and Hanawalt, 1999). The RecFOR complex prevents extensive processing of the nascent DNA and recruits RecA to 
the site of the stalled replication fork (Chow and Courcelle, 2004). RecA forms a nucleoprotein filament at the site of the stalled replication fork pairing the displaced nascent leading strand with its homologous duplex (Cox et al., 1984; Schutte and Cox, 1987). RecA protein in this state becomes activated and induces the SOS response driving the expression of several repair genes (Little et al., 1981). Cells lacking either RecA or any of several RecF pathway proteins are hypersensitive to UV-induced damage and fail to recover replication following disruption by lesions (Clark and Margulies, 1965).

These processing events involve extensive alterations to the DNA at the stalled replication fork. In some studies, the functions of the various DNA processing proteins have been further characterized based on their ability to alter the structure of the DNA strands at replication blocking lesions. The structural modifications that occur in DNA during these processing events can be visualized using a number of techniques. One common and powerful approach is the use of two-dimensional agarose gel analysis, which can be used to resolve various structures that arise in DNA molecules. Although many types of lesions have been studied using this system, several important questions remain to be addressed. In this thesis, I examine the processing of exogenously irradiated plasmids in order to determine whether they are a suitable model for chromosomal repair processes and I characterize the role of the replisome during processing events in vivo using the 2-D agarose gel analysis. 


\section{Two-Dimensional Agarose Gel Analysis}

Two-dimensional (2-D) agarose gel analysis is a technique that allows one to visualize the structure of DNA fragments and has provided valuable insights into our understanding of replication and repair processes. In 1983, Bell and Byers showed that by excising an agarose gel slice containing various species of DNA following an initial round of electrophoresis, rotating the gel slice such that it would be perpendicular to its previous orientation and subjecting this DNA to a second round of electrophoresis, one could resolve branched DNA molecules, such as those produced during replication or recombination, from unbranched molecules of the same size. Historically, the technique has been applied to characterize processes that involve either structural modifications or accumulation of specific structures in DNA. An early study used this technique to identify replication origins in yeast plasmids. In this study, it was observed that the origin of replication mapped to the ARS element in a recombinant plasmid and included the first visual confirmation of a site for the initiation of DNA synthesis in vivo (Brewer and Fangman, 1987). A later study showed that the accumulation of specific intermediates could be used to identify replication pause sites. This study showed that a protein-DNA complex at the centromere could block the replication fork and that the resulting structural intermediates accumulated to levels high enough to be detected (Greenfeder and Newlon, 1992). Another study used this technique to examine the structural intermediates generated during unidirectional replication of a plasmid molecule. This study 
further compared the migration patterns of plasmids with unidirectional origins and those with bidirectional origins (Martin-Parras et al., 1992). As the potential of the 2-D agarose gel technique was realized, it progressively began to replace the use of the electron microscope to identify and resolve DNA structural intermediates.

The versatility of this assay allows DNA to be harvested either from replicating cells in vivo or from biochemical reactions. Typically, the DNA is then linearized or restricted to sizes ranging from $2-10 \mathrm{~kb}$, and resolved by electrophoresis in a low percentage agarose gel at low voltage, to separate the DNA species primarily based on size. Following adequate separation, the lane containing the DNA is excised, rotated $90^{\circ}$, recast in a high percentage agarose gel and resolved rapidly using high voltage (Bell and Byers, 1983). The migration of DNA under these conditions separates DNA fragments based on both size and shape (Bell and Byers, 1983; Friedman and Brewer, 1995; Martin-Parras et al., 1991). The migration pattern of a specific fragment can then be observed following a standard Southern blot procedure.

DNA harvested in vivo typically contains a mixture of replicating and nonreplicating fragments which can be detected using 2-D agarose gel analysis (Brewer and Fangman, 1988; Martin-Parras et al., 1991). The mode of replication can be distinguished in plasmids and viruses as well (Martin-Parras et al., 1991; Martin-Parras et al., 1992; Severini et al., 1996). A DNA fragment linearized near its unidirectional origin produces a Y-shaped structure which can be resolved 
from linear, non-replicating molecules (Courcelle et al., 2003; Martin-Parras et al., 1991). A fragment containing a bidirectional replication origin yields an X-shaped molecule following restriction, which can be further resolved from either Y-shaped or non-replicating molecules (Bell and Byers, 1983; Friedman and Brewer, 1995; Martin-Parras et al., 1991). If a replication origin is contained near the center of the linearized fragment, replication creates a bubble-like structure within the fragment and has a unique migration pattern (Brewer and Fangman, 1987; Martin-Parras et al., 1991). The degree of coiling can also be viewed under these or similar conditions (Martin-Parras et al., 1998).

In order for the technique to be capable of detecting replication on fragments of the chromosome in yeast or mitochondria, purification strategies typically involving conditions that enrich for single-stranded DNA molecules, such as BND-cellulose fractionation or the use of a single-stranded nuclease, are employed (Brewer and Fangman, 1987; Greenfeder and Newlon, 1992; Kajander et al., 2001). The DNA is then concentrated by precipitation to increase sensitivity and enable the detection of rare events. However, these enrichment methods can lead to artifacts in which new structures are generated when the molecules are brought together during precipitation or selection against relevant molecules if they lack single-stranded regions.

To circumvent these shortcomings when examining questions related to replication, plasmids that have moderate copy numbers in bacterial hosts can be isolated and examined directly without the need for precipitation or enrichment 
(Courcelle et al., 2003). Replicating plasmids with unidirectional origins produce a characteristic image that contains a prominent spot consisting of non-replicating molecules and an arc extending away from this spot toward the well of the gel representing the replicating fragments ((Courcelle et al., 2003; Friedman and Brewer, 1995; Martin-Parras et al., 1991) and Figure 1.1). The replicating fragments contain between one and two times as much DNA as their nonreplicating counterparts, as well as branches, which further slows their migration, producing this arc pattern. This technique, as it applies to analysis of plasmid molecules replicating in E. coli cells, is outlined in Appendix A of this thesis and contains a link to an instructional video published in JoVE.

The DNA structures that can be resolved by 2-D agarose gel analysis are not limited to those generated during normal replication. This technique can also be used to reveal how replication behaves when challenged by various impediments. Studies have shown that if a barrier to replication such as bound protein complex or a termination sequence exists on the DNA template, the structural intermediates that result from a stalled replication fork accumulate at the blocked site to levels high enough to be detected (Duggin and Bell, 2009; Greenfeder and Newlon, 1992; Viguera et al., 1996). In 1997, Cordeiro-Stone et al. showed that the structural intermediates that accumulated following exposure to UV-induced lesions could be detected and used to determine whether tolerance mechanisms were to bypass the lesion. Additionally, structural intermediates associated with recombination, which often involve branched 
molecules, have also been characterized. In one study by Kajander et al., the authors examined mitochondrial DNA prepared from human heart muscle cells and observed a prominent subset of structural intermediates most consistent with those generated during recombination (Kajander et al., 2001). The authors interpreted these results to suggest that a constant basal level of recombination intermediates may exist in mitochondria due to repair processes acting on oxidative lesion produced by the oxygen rich environment. Recent uses of this technique have also examined the method by which mitochondrial DNA is replicated. In 2000, Holt et al. revealed that replication intermediates in mammalian mitochondrial DNA included Y-shaped molecules suggesting that synthesis of both the leading and lagging strand occur simultaneously. However, a prior study using SEM and pulse-chase labeling experiments originally established that mitochondrial DNA replicates via a strand displacement mechanism in which synthesis of each strand is initiated separately from one another (Berk and Clayton 1974). A more recent study by Brown et al. which used a combination of atomic force microscopy and 2-D agarose gel analysis, lent further support to the strand displacement model and has led to a debate regarding the method by which mitochondrial DNA replicates.

\section{Structural Intermediates Observed During Processing of a Stalled Replication Fork}


Many of the steps outlined above for the repair of UV lesions are consistent with the structures observed in replicating plasmids following UV irradiation when analyzed by 2-D agarose gel analysis. Following UV irradiation, structural intermediates are generated that migrate in a region of the gel consistent with DNA having two branch points but shorter than a fully replicated molecules (Courcelle et al., 2003). These UV-induced intermediates persist until a time that correlates with the removal of the majority of UV-induced lesions (Courcelle et al., 2003). In RecF mutants, characterized by their inability to process and maintain DNA at the replication fork following arrest, the UV-induced intermediates are not observed (Chow and Courcelle, 2004). However, these intermediates can be restored in the absence of RecQ or RecJ, which are the enzymes responsible for degrading nascent DNA following arrest, indicating that at least a portion of the intermediates are formed by the regression of the replication fork and displacement of nascent DNA (Courcelle et al., 2003); (Donaldson et al., 2006).

\section{Questions Remaining to be Addressed Regarding the Relationship Between DNA Replication and Repair}

The use of 2-D agarose gel analysis can be used to address fundamental questions involving the mechanism by which DNA damage is processed when encountered by replication. First, it is important to determine whether differences in processing exist between lesions encountered on the leading strand and those 
encountered on the lagging strand. In vitro, when replication is reconstituted from purified components or extracts, lesions in the leading strand block the progression of the replisome, whereas lesions in the lagging strand can be skipped over when a new Okazaki fragment is initiated, leaving behind a single strand gap (Higuchi et al., 2003; Mclnerney and O'donnell, 2007; Svoboda and Vos, 1995). In vivo, a number of studies have shown that replication is transiently inhibited following DNA damage (Khidhir et al., 1985;Courcelle et al., 1997; Setlow et al., 1963). In addition, using sucrose gradients, it has been shown that the small amount of DNA synthesized after DNA damage contains gaps (Rupp and Howard-Flanders, 1968;West et al., 1982). Gaps have also been observed in DNA isolated following UV-irradiation using electron microscopy (Cunningham et al., 1980;Webb et al., 1999). While these observations would be consistent with the in vitro observations, it has proven difficult to experimentally obtain strandspecific information in vivo. In an effort to answer this question directly, in vivo, one could introduce site-specific lesions into a single strand of a plasmid and subsequently introduce the plasmid into host cells and examine the processing that occurs on leading- versus lagging-strand lesions via 2-D agarose gel analysis. In the next chapter of this thesis, I examine whether transformation of E. coli cells with UV-damaged plasmids can be adapted to address this question of strand-specific processing. The initial goal was to establish that damaged DNA introduced into cells would be processed and repaired in a manner similar to processing and repair of endogenous plasmids or the chromosome. However, 
our observations indicated that distinct differences exist between repair processes that operate on newly introduced plasmids and those that operate on DNA that had been previously established in the host.

A second question examines how the composition of the replisome is altered during processing and recovery following an encounter with replicationblocking lesions. Whereas processing events that occur in DNA at arrested replication forks are well characterized, the fate of the replisome itself during these events remains unknown. The replisome is a multi-subunit complex of functional components responsible for carrying out accurate replication of the genome. The replisome in E. coli consists of a triple polymerase core, a primasehelicase complex and a clamp-loader that coordinates simultaneous leading- and lagging-strand synthesis ((Chang and Marians, 2000; Mclnerney and O'Donnell, 2004; Mclnerney et al., 2007) and Figure 3). During synthesis, each of the polymerase cores is associated with a 5'-3' proofreading subunit as well as a processivity factor which greatly reduce the frequency of misincorporations and spontaneous disruptions (Horiuchi et al., 1978; Paz-Elizur et al., 1996). The concurrent synthesis of both leading and lagging strands is maintained by the tau factor, which holds the polymerases in a single complex, reloads the processivity factors on the lagging strand template and tethers the polymerase to the helicase complex (Maki and Kornberg, 1988; Leu et al., 2003; Kim et al., 1996; Yao et al., 2000). The primase-helicase complex denatures the two parental strands, retains licensing of the replication origin and initiates the discontinuous synthesis of the 
nascent lagging strand (Allen and Kornberg, 1991; Chang and Marians, 2000; Fujimura et al., 1979; LeBowitz and McMacken, 1986; Lu et al., 1996). Defects in any one of these functions result in either the inability of the replisome to continue synthesis, the inability of the cell to initiate a new round of replication or an increase in mutation frequency (Carl, 1970; Couch and Hanawalt, 1967; Fangman and Novick, 1968; Horiuchi et al., 1978; Kohiyama, 1968; Scheuermann et al., 1983).

Although the replisome is a relatively large complex and an efficient machine, its function can be compromised in the presence of damage to the DNA template. Following exposure to a modest UV dose $\left(20-25 \mathrm{~J} / \mathrm{m}^{2}\right)$, the rate of replication decreases rapidly (Courcelle et al., 2005; Setlow et al., 1963). However, in wild type cultures, replication rates begin to recover within minutes and essentially all cells remain viable (Courcelle and Hanawalt, 2003). Prior to recovery, little degradation of the genomic DNA is observed (Courcelle et al., 1997; Horii and Suzuki, 1968). Thus, the lack of degradation and the rapid resumption of synthesis suggest that cells have mechanisms to efficiently deal with lesions rather than degrading the nascent DNA and reinitiating synthesis at the origin.

Several models have been proposed to describe the role of the replisome during these brief moments. One model suggests that the integrity of the replication machinery upon encounter with an UV-lesion is lost and the replisome collapses, only to be reestablished and resume synthesis downstream from the 
site of the lesion (Heller and Marians, 2006; Michel, 2000). Support for this model comes from in vitro studies in which PriA protein was required to rebuild the replisome downstream from a region of the template containing a replicationblocking lesion suggesting that this mechanism is primase dependent (Heller and Marians, 2006; Jaktaji and Lloyd, 2003; Marians, 2000). However, other studies have suggested that the replisome remains stably bound when it is blocked by DNA damage (Mclnerney and O'donnell, 2007). In this study, a rolling circle template was used to show that the repair complex RecFOR works in conjunction with RecA to actively displace the DNA polymerase from the template when arrested. More recent studies have suggested the replisome may be far more dynamic than previously thought (Georgescu et al., 2009; Indiani et al., 2009; Langston et al., 2009).

In the third chapter, I attempt to characterize how the composition of the replisome is altered during repair and processing events. Thermosensitive alleles of each of the components of the replisome exist and are used to compare which of the components play a role in processing events that are either similar to or distinct from those observed when the replisome encounters UV-induced DNA damage. The results demonstrate a dynamic replisome that is capable of partial disassembly to allow access to the lesion while retaining components to maintain fork integrity and licensing of the origin. I propose that this allows the replisome to be reassembled at the appropriate location prior to resumption. 
In Appendix B, I use the data collected in Chapter 3 to further examine the kinetics by which DNA synthesis is disrupted following inactivation of various components of the replisome. The data suggest that at least one polymerase, other than Pol III, contributes significantly to DNA synthesis following disruption of the replicative polymerase in the absence of DNA damage, in vivo. 


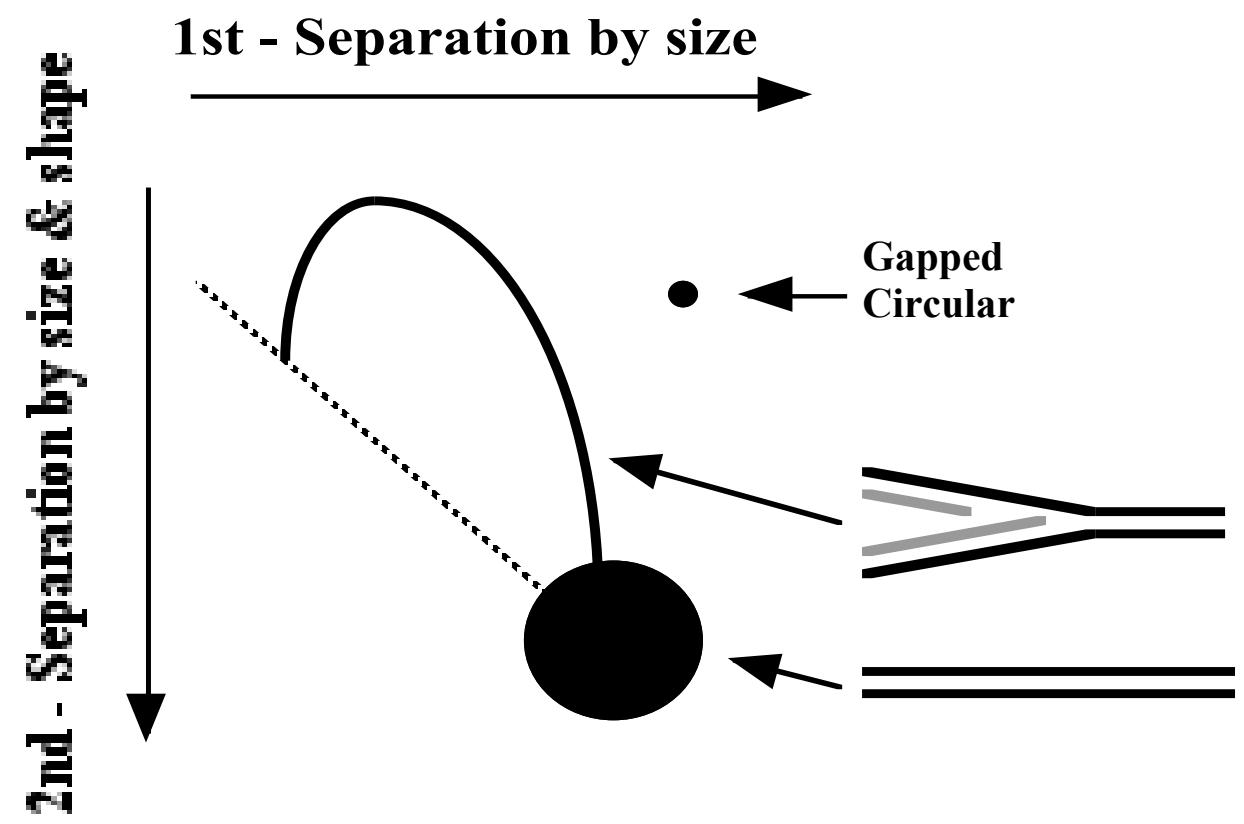

Figure 1.1. A schematic of the structural intermediates observed following 2-D agarose gel analysis of a low-copy plasmid with a unidirectional origin. Grey lines represent nascent DNA. 


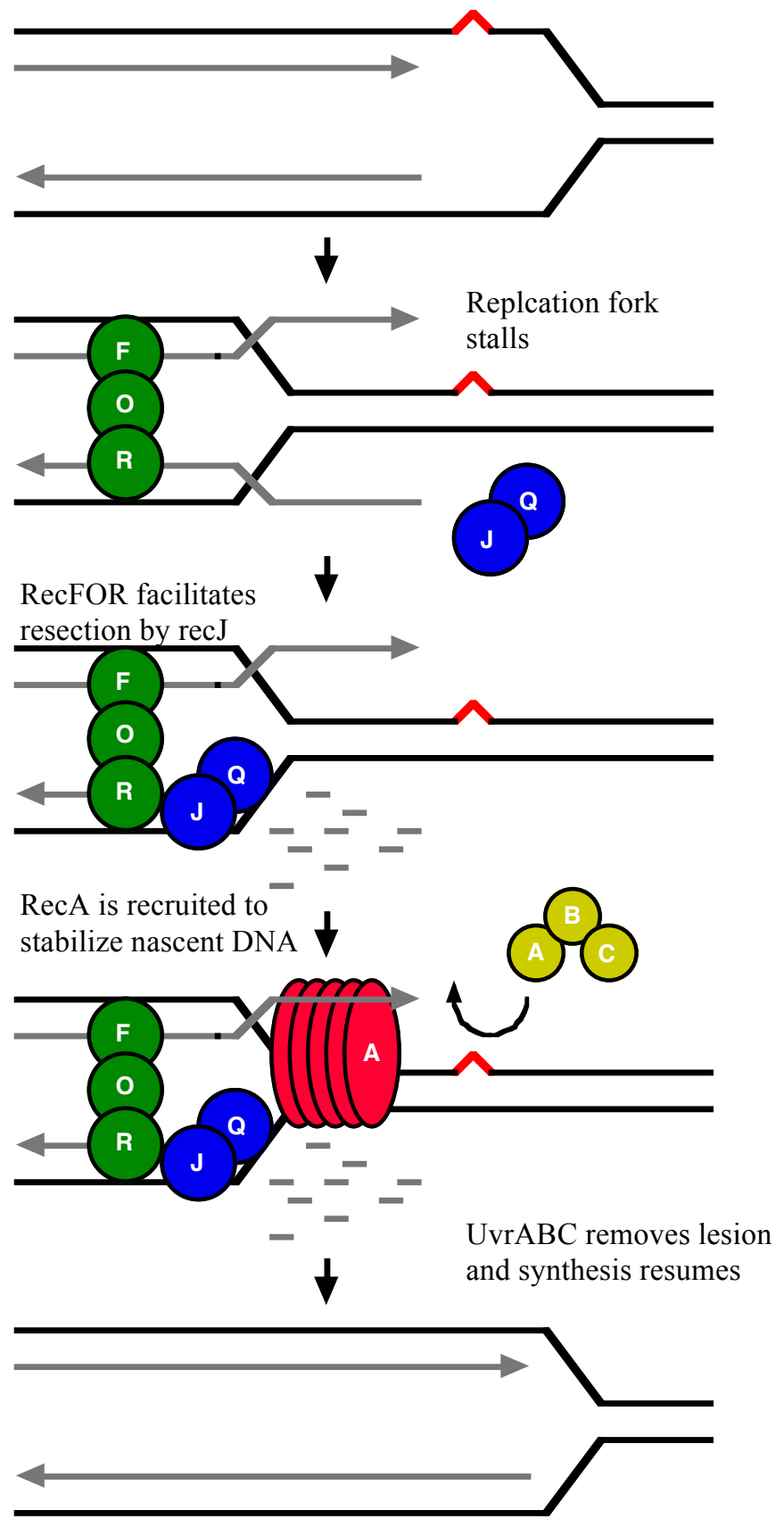

Figure 1.2. A model for the DNA structural intermediates generated at each step during processing of the arrested replication fork. 


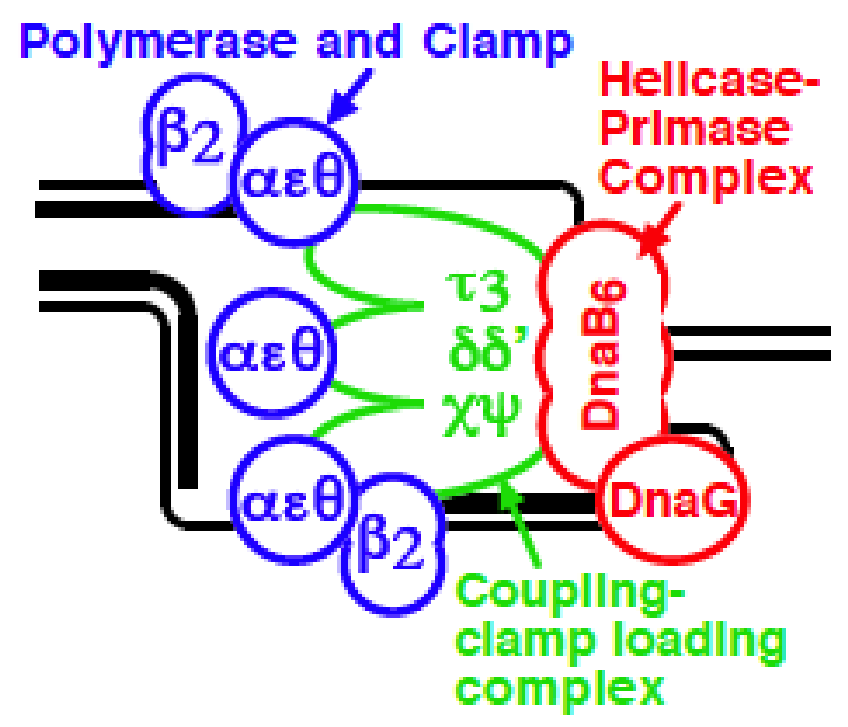

Figure 1.3. A schematic of the replisome indicating the function of each group of subunits or components 


\section{References}

Allen, G.C.J. \& Kornberg, A. 1991. Fine balance in the regulation of DnaB helicase by DnaC protein in replication in Escherichia coli. J Biol Chem. 266, 22096-22101.

Bell, L. \& Byers, B. 1983. Separation of branched from linear DNA by twodimensional gel electrophoresis. Anal Biochem. 130, 527-535.

Berk, A.J. \& Clayton, D.A. 1974. Mechanisms of mitochondrial DNA replication in mouse L-cells: Asynchronous replication of strands, segregation of daughter moolecules, aspecets of topology and turnover of an initiation sequence. $J$ Mol Bio. 86, 801-824

Bork, J.M., Cox, M.M. \& Inman, R.B. 2001. The RecOR proteins modulate RecA protein function at 5 ' ends of single- stranded DNA. Embo J. 20, 7313-7322.

Brewer, B.J. \& Fangman, W.L. 1987. The localization of replication origins on ARS plasmids in S. cerevisiae. Cell. 51, 463-471.

Brewer, B.J. \& Fangman, W.L. 1988. A replication fork barrier at the 3 ' end of yeast ribosomal RNA genes. Cell. 55, 637-643.

Brown, T.A., Cecconi, C., Tkachuk, A.N., Bustamante, C. \& Clayton, D.A. 2005. Replication of mitochondrial DNA occurs by strand displacement with alternative light-strand origins, not via a strand-coupled mechanism. Genes and Dev. 19, 2466-2476 
Carl, P.L. 1970. Escherichia coli mutants with temperature-sensitive synthesis of DNA. Mol Gen Genet. 109, 107-122.

Chang, P. \& Marians, K.J. 2000. Identification of a region of Escherichia coli DnaB required for functional interaction with $\mathrm{DnaG}$ at the replication fork. $\mathrm{J}$ Biol Chem. 275, 26187-26195.

Chow, K.H. \& Courcelle, J. 2004. RecO Acts with RecF and RecR to Protect and Maintain Replication Forks Blocked by UV-induced DNA Damage in Escherichia coli. J Biol Chem. 279, 3492-3496.

Clark, A.J. \& Margulies, A.D. 1965. Isolation and Characterization of Recombination-Deficient Mutants of Escherichia coli K12. Proc Natl Acad Sci U S A. 53, 451-459.

Couch, J. \& Hanawalt, P.C. 1967. DNA repair replication in temperature-sensitive DNA synthesis deficient bacteria. Biochem Biophys Res Commun. 26, 779784.

Courcelle, C.T., Belle, J.J. \& Courcelle, J. 2005. Nucleotide excision repair or polymerase V-mediated lesion bypass can act to restore UV-arrested replication forks in Escherichia coli. J Bacteriol. 187, 6953-6961.

Courcelle, C.T., Chow, K.H., Casey, A. \& Courcelle, J. 2006. Nascent DNA processing by RecJ favors lesion repair over translesion synthesis at arrested replication forks in Escherichia coli. Proc Natl Acad Sci U S A. 103, 9154-9159. 
Courcelle, J., Crowley, D.J. \& Hanawalt, P.C. 1999. Recovery of DNA replication in UV-irradiated Escherichia coli requires both excision repair and recF protein function. J Bacteriol. 181, 916-922.

Courcelle, J., Donaldson, J.R., Chow, K.H. \& Courcelle, C.T. 2003. DNA

Damage-Induced Replication Fork Regression and Processing in Escherichia coli. Science. 299, 1064-1067.

Courcelle, J. \& Hanawalt, P.C. 1999. RecQ and RecJ process blocked replication forks prior to the resumption of replication in UV-irradiated Escherichia coli. Mol Gen Genet. 262, 543-551.

Courcelle, J. \& Hanawalt, P.C. 2003. RecA-dependent recovery of arrested DNA replication forks. Annu Rev Genet. 37, 611-646.

Courcelle, J., Carswell-Crumpton, C. \& Hanawalt, P.C. 1997. recF and recR are required for the resumption of replication at DNA replication forks in Escherichia coli. Proc Natl Acad Sci U S A. 94, 3714-3719.

Cox, M.M., Morrical, S.W. \& Neuendorf, S.K. 1984. Unidirectional branch migration promoted by nucleoprotein filaments of RecA protein and DNA. Cold Spring Harb Symp Quant Biol. 49, 525-533.

Cunningham, R.P., DasGupta, C., Shibata, T. \& Radding, C.M. 1980. Homologous pairing in genetic recombination: recA protein makes joint molecules of gapped circular DNA and closed circular DNA. Cell. 20, 223235. 
Donaldson, J.R., Courcelle, C.T. \& Courcelle, J. 2006. RuvABC is required to resolve holliday junctions that accumulate following replication on damaged templates in Escherichia coli. J Biol Chem. 281, 28811-28821.

Duggin, I.G. \& Bell, S.D. 2009. Termination structures in the Escherichia coli chromosome replication fork trap. J Mol Biol. 387, 532-539.

Fangman, W.L. \& Novick, A. 1968. Characterization of two bacterial mutants with temperature-sensitive synthesis of DNA. Genetics. 60, 1-17.

Friedman, K.L. \& Brewer, B.J. 1995. Analysis of replication intermediates by twodimensional agarose gel electrophoresis. Methods Enzymol. 262, 613-627.

Fujimura, F.K., Zyskind, J.W. \& Smith, D.W. 1979. The Escherichia coli dnaB protein is required for initiation of chromosomal DNA replication. Cold Spring Harb Symp Quant Biol. 43 Pt 1, 559-562.

Georgescu, R.E., Kurth, I., Yao, N.Y., Stewart, J., Yurieva, O. \& O'Donnell, M. 2009. Mechanism of polymerase collision release from sliding clamps on the lagging strand. EMBO J.

Greenfeder, S.A. \& Newlon, C.S. 1992. Replication forks pause at yeast centromeres. Mol Cell Biol. 12, 4056-4066.

Heller, R.C. \& Marians, K.J. 2006. Replication fork reactivation downstream of a blocked nascent leading strand. Nature. 439, 557-562.

Higuchi, K., Katayama, T., Iwai, S., Hidaka, M., Horiuchi, T. \& Maki, H. 2003. Fate of DNA replication fork encountering a single DNA lesion during oriC plasmid DNA replication in vitro. Genes Cells. 8, 437-449. 
Holt, I.J., Lorimer H.E. \& Jacobs, I.T. 2000. Coupled leading and lagging strand synthesis of mammalian mitochondrial DNA. Trends Biochem Sci. 28, 355356

Horii, Z.I. \& Suzuki, K. 1968. Degradation of the DNA of Escherichia coli K12 rec(JC1569b) after irradiation with ultraviolet light. Photochem photobiol. 8, 93105.

Horiuchi, T., Maki, H. \& Sekiguchi, M. 1978. A new conditional lethal mutator (dnaQ49) in Escherichia coli K12. Molecular and General Genetics MGG. $163,277-283$.

Howard-Flanders, P., Theriot, L. \& Stedeford, J.B. 1969. Some properties of excision-defective recombination-deficient mutants of Escherichia coli K-12. J Bacteriol. 97, 1134-1141.

Howard-Flanders, P. \& Theriot, L. 1966. Mutants of Escherichia coli K-12 defective in DNA repair and in genetic recombination. Genetics. 53, 11371150.

Indiani, C., Langston, L.D., Yurieva, O., Goodman, M.F. \& O'Donnell, M. 2009. Translesion DNA Polymerases Remodel the Replisome and Alter the Speed of the Replicative Helicase. Proc Natl Acad Sci U S A. X, XX-XX.

Jaktaji, R.P. \& Lloyd, R.G. 2003. PriA supports two distinct pathways for replication restart in UV-irradiated Escherichia coli cells. Mol Microbiol. 47, 1091-1100. 
Kajander, O.A., Karhunen, P.J., Holt, I.J. \& Jacobs, H.T. 2001. Prominent mitochondrial DNA recombination intermediates in human heart muscle. EMBO Rep. 2, 1007-1012.

Khidhir, M.A., Casaregola, S. \& Holland, I.B. 1985. Mechanism of transient inhibition of DNA synthesis in ultraviolet-irradiated E. coli: inhibition is independent of recA whilst recovery requires RecA protein itself and an additional, inducible SOS function. Mol Gen Genet. 199, 133-140.

Kim, S., Dallmann, H.G., McHenry, C.S. \& Marians, K.J. 1996. Coupling of a replicative polymerase and helicase: a tau-DnaB interaction mediates rapid replication fork movement. Cell. 84, 643-650.

Kohiyama, M. 1968. DNA synthesis in temperature sensitive mutants of Escherichia coli. Cold Spring Harb Symp Quant Biol. 33, 317-324.

Kornberg, T. \& Gefter, M.L. 1971. Purification and DNA synthesis in cell-free extracts: properties of DNA polymerase II. Proc Natl Acad Sci U S A. 68, 761-764.

Langston, L.D., Indiani, C. \& O'Donnell, M. 2009. Whither the replisome: emerging perspectives on the dynamic nature of the DNA replication machinery. Cell Cycle. 8, 2686-2691.

LeBowitz, J.H. \& McMacken, R. 1986. The Escherichia coli dnaB replication protein is a DNA helicase. J Biol Chem. 261, 4738-4748.

Leu, F.P., Georgescu, R. \& O'Donnell, M. 2003. Mechanism of the E. coli tau processivity switch during lagging-strand synthesis. Mol Cell. 11, 315-327. 
Little, J.W., Mount, D.W. \& Yanisch-Perron, C.R. 1981. Purified lexA protein is a repressor of the recA and lexA genes. Proc Natl Acad Sci U S A. 78, 41994203.

Lu, Y.B., Ratnakar, P.V., Mohanty, B.K. \& Bastia, D. 1996. Direct physical interaction between DnaG primase and DnaB helicase of Escherichia coli is necessary for optimal synthesis of primer RNA. Proc Natl Acad Sci U S A. 93, $12902-12907$.

Maki, S. \& Kornberg, A. 1988. DNA polymerase III holoenzyme of Escherichia coli. I. Purification and distinctive functions of subunits tau and gamma, the dnaZX gene products. J Biol Chem. 263, 6547-6554.

Marians, K.J. 2000. PriA-directed replication fork restart in Escherichia coli. Trends Biochem Sci. 25, 185-9.

Martin-Parras, L., Hernandez, P., Martinez-Robles, M.L. \& Schvartzman, J.B. 1992. Initiation of DNA replication in ColE1 plasmids containing multiple potential origins of replication. J Biol Chem. 267, 22496-22505.

Martin-Parras, L., Lucas, I., Martinez-Robles, M.L., Hernandez, P., Krimer, D.B., Hyrien, O. \& Schvartzman, J.B. 1998. Topological complexity of different populations of pBR322 as visualized by two-dimensional agarose gel electrophoresis. Nucleic Acids Res. 26, 3424-3432.

Martin-Parras, L., Hernandez, P., Martinez-Robles, M.L. \& Schvartzman, J.B. 1991. Unidirectional replication as visualized by two-dimensional agarose gel electrophoresis. J Mol Biol. 220, 843-853. 
Masker, W., Hanawalt, P. \& Shizuya, H. 1973. Role of DNA polymerase II in repair replication in Escherichia coli. Nat New Biol. 244, 242-243.

Mazin, A.V. \& Kowalczykowski, S.C. 1999. A novel property of the RecA nucleoprotein filament: activation of double- stranded DNA for strand exchange in trans. Genes Dev. 13, 2005-2016.

Mclnerney, P., Johnson, A., Katz, F. \& O'Donnell, M. 2007. Characterization of a triple DNA polymerase replisome. Mol Cell. 27, 527-538.

McInerney, P. \& O'Donnell, M. 2004. Functional Uncoupling of Twin Polymerases: MECHANISM OF POLYMERASE DISSOCIATION FROM A LAGGING-STRAND BLOCK. J Biol Chem. 279, 21543-21551.

Mclnerney, P. \& O'donnell, M. 2007. Replisome Fate upon Encountering a Leading Strand Block and Clearance from DNA by Recombination Proteins. J Biol Chem. 282, 25903-25916.

Michel, B. 2000. Replication fork arrest and DNA recombination. Trends Biochem Sci. 25, 173-178.

Paz-Elizur, T., Skaliter, R., Blumenstein, S. \& Livneh, Z. 1996. Beta*, a UVinducible smaller form of the beta subunit sliding clamp of DNA polymerase III of Escherichia coli. I. Gene expression and regulation. J Biol Chem. 271, 2482-2490.

Ramdas, J., Mythili, E. \& Muniyappa, K. 1989. RecA protein promoted homologous pairing in vitro. Pairing between linear duplex DNA bound to 
HU Protein (nucleosome cores) and nucleoprotein filaments of recA proteinsingle-stranded DNA. J Biol Chem. 264, 17395-17400.

Reuven, N.B., Arad, G., Maor-Shoshani, A. \& Livneh, Z. 1999. The mutagenesis protein UmuC is a DNA polymerase activated by UmuD', RecA, and SSB and is specialized for translesion replication. J Biol Chem. 274, 3176331766.

Rupp, W.D. \& Howard-Flanders, P. 1968. Discontinuities in the DNA synthesized in an excision-defective strain of Escherichia coli following ultraviolet irradiation. J Mol Biol. 31, 291-304.

Scheuermann, R., Tam, S., Burgers, P.M., Lu, C. \& Echols, H. 1983. Identification of the epsilon-subunit of Escherichia coli DNA polymerase III holoenzyme as the dnaQ gene product: a fidelity subunit for DNA replication. Proc Natl Acad Sci U S A. 80, 7085-7089.

Schutte, B.C. \& Cox, M.M. 1987. Homology-dependent changes in adenosine 5'triphosphate hydrolysis during recA protein promoted DNA strand exchange: evidence for long paranemic complexes. Biochemistry. 26, 56165625.

Seigneur, M., Ehrlich, S.D. \& Michel, B. 1997. Blocking rolling circle replication with a UV lesion creates a deletion hotspot. Mol Microbiol. 26, 569-580.

Setlow, R.B., Swenson, P.A. \& Carrier, W.L. 1963. Thymine dimers and Inhibition of DNA synthesis by ultraviolet irradiation of cells. Science. 142, 1464-1466. 
Severini, A., Scraba, D.G. \& Tyrrell, D.L. 1996. Branched structures in the intracellular DNA of herpes simplex virus type 1. J Virol. 70, 3169-3175.

Svoboda, D.L. \& Vos, J.M. 1995. Differential replication of a single, UV-induced lesion in the leading or lagging strand by a human cell extract: fork uncoupling or gap formation. Proc Natl Acad Sci U S A. 92, 11975-11979.

Van Houten, B., Gamper, H., Hearst, J.E. \& Sancar, A. 1988. Analysis of sequential steps of nucleotide excision repair in Escherichia coli using synthetic substrates containing single psoralen adducts. J Biol Chem. 263, 16553-16560.

Viguera, E., Hernandez, P., Krimer, D.B., Boistov, A.S., Lurz, R., Alonso, J.C. \& Schvartzman, J.B. 1996. The ColE1 unidirectional origin acts as a polar replication fork pausing site. J Biol Chem. 271, 22414-22421.

Wagner, J., Gruz, P., Kim, S.R., Yamada, M., Matsui, K., Fuchs, R.P. \& Nohmi, T. 1999. The dinB gene encodes a novel E. coli DNA polymerase, DNA pol IV, involved in mutagenesis. Mol Cell. 4, 281-286.

Webb, B.L., Cox, M.M. \& Inman, R.B. 1997. Recombinational DNA repair: the RecF and RecR proteins limit the extension of RecA filaments beyond single-strand DNA gaps. Cell. 91, 347-356.

Webb, B.L., Cox, M.M. \& Inman, R.B. 1999. ATP hydrolysis and DNA binding by the Escherichia coli RecF protein. J Biol Chem. 274, 15367-15374. 
West, S.C., Cassuto, E. \& Howard-Flanders, P. 1982. Postreplication repair in E. coli: strand exchange reactions of gapped DNA by RecA protein. Mol Gen Genet. 187, 209-217.

Woodgate, R., Rajagopalan, M., Lu, C. \& Echols, H. 1989. UmuC mutagenesis protein of Escherichia coli: purification and interaction with UmuD and UmuD'. Proc Natl Acad Sci U S A. 86, 7301-7305.

Yao, N., Leu, F.P., Anjelkovic, J., Turner, J. \& O'Donnell, M. 2000. DNA structure requirements for the Escherichia coli gamma complex clamp loader and DNA polymerase III holoenzyme. J Biol Chem. 275, 11440-11450.

Yeung, A.T., Mattes, W.B., Oh, E.Y. \& Grossman, L. 1983. Enzymatic properties of purified Escherichia coli uvrABC proteins. Proc Natl Acad Sci U S A. 80, 6157-6161. 


\title{
Chapter 2
}

\section{Inefficient Replication Reduces RecA-mediated Repair of UV-damaged Plasmids Introduced into Competent Escherichia coli}

*This chapter has been published: Plasmid. (2012) 68: 2. pp.113-24

\begin{abstract}
Transformation of Escherichia coli with purified plasmids containing DNA damage is frequently used as a tool to characterize repair pathways that operate on chromosomes. In this study, we used an assay that allowed us to quantify plasmid survival and to compare how efficiently various repair pathways operate on plasmid DNA introduced into cells relative to their efficiency on chromosomal DNA. I observed distinct differences between the mechanisms operating on the transforming plasmid DNA and the chromosome. An average of one UV-induced lesion was sufficient to inactivate ColE1-based plasmids introduced into nucleotide excision repair mutants, suggesting an essential role for repair on newly introduced plasmid DNA. By contrast, the absence of RecA, RecF, RecBC, RecG or RuvAB had a minimal effect on the survival of the transforming plasmid DNA containing UV-induced damage. Neither the presence of an endogenous homologous plasmid nor the induction of the SOS response enhanced the survival of transforming plasmids. Using two-dimensional agarose-gel analysis, both replication- and RecA-dependent structures that were observed on
\end{abstract}


established, endogenous plasmids following UV-irradiation, failed to form on UVirradiated plasmids introduced into E. coli. We interpret these observations to suggest that the lack of RecA-mediated survival is likely to be due to inefficient replication that occurs when plasmids are initially introduced into cells, rather than to the plasmid's size, the absence of homologous sequences, or levels of recA expression.

\section{Introduction}

Transformation of cells with plasmids containing DNA damage is one approach that has been frequently used to characterize cellular repair pathways in both prokaryotic and eukaryotic systems (Bichara et al., 2007; Bichara et al., 2009; Kucherlapati et al., 1984; Roberts and Strike, 1981; Saffran and Cantor, 1984; Schmid et al., 1982; Strike et al., 1979; Wang et al., 2001). UV irradiation of Escherichia coli causes the formation of cyclobutane pyrimidine dimers (CPDs) and 6-4 photoproducts in DNA that can block polymerases and prevent replication of the genome (Setlow et al., 1963). A number of repair and tolerance pathways are known to contribute significantly to survival in the presence of UVinduced lesions on the chromosome. Nucleotide excision repair removes these lesions from the genome reducing the frequency that replication encounters this type of damage, and contributes significantly to cell survival (Courcelle et al., 1999; Courcelle et al., 2005; Courcelle et al., 2006). In the absence of repair, translesion polymerases can incorporate bases opposite to the damage that 
would otherwise prevent replication from being completed (Bagg et al., 1981; Courcelle et al., 1999; Courcelle et al., 2005; Courcelle et al., 2006). Under most conditions, these polymerases have only modest effects on survival, but can have large effects on the frequency of mutagenesis (Bagg et al., 1981; Courcelle et al., 1999; Courcelle et al., 2006; Radman, 1975). A large number of these processing events are dependent on RecA, and the absence of the protein renders cells hypersensitive to UV irradiation (Courcelle et al., 1999; Courcelle et al., 2003; Keller et al., 2001; West, 1996). RecA along with several RecFpathway proteins are involved in processing replication forks that encounter DNA damage and are required for replication to resume (Courcelle et al., 1997; Courcelle et al., 1999; Courcelle et al., 2003). In addition, RecA along with RecBC- pathway proteins are needed to repair double-strand break intermediates that arise following several forms of DNA damage (Chow and Courcelle, 2007; Keller et al., 2001; Willetts and Clark, 1969). Strand exchange and Holliday junction intermediates that form during these RecA-mediated events are processed and resolved by the RuvABC and RecG resolvases (Donaldson et al., 2004; Lloyd and Sharples, 1993; Lloyd, 1991; West, 1996). Mutations inactivating $\operatorname{rec} B C$, recF, ruvABC, or recG reduce cellular resistance to UVirradiation to varying degrees (Courcelle et al., 1997; Courcelle et al., 1999; McGlynn and Lloyd, 2001; McGlynn and Lloyd, 2002; West, 1996; Willetts and Clark, 1969). 
Plasmids used to transform chemical- or electro-competent $E$. coli are taken up as double-strand circular DNA. Typically, in assays using plasmid transformation, the purified plasmid DNA is exogenously exposed to a damaging agent and then introduced into cells to monitor plasmid survival, DNA repair, or replication using various conditions and mutants. However, quantifying the effect that DNA damage has on plasmid survival can be challenging. Transformation frequencies can vary several-fold between experiments due to small variations in competent cell preparations, DNA-to-cell ratios, temperature, heat shock duration, or recovery times prior to selection (Froger and Hall, 2007; Norgard et al., 1978; Roychoudhury et al., 2009; Yoshida and Sato, 2009). In addition, several mutants, including $\operatorname{rec} A$ and $\operatorname{rec} B C$, are known to affect the cell's ability to take up or maintain plasmids, making it difficult to directly quantify and compare plasmid survival in different strains (Bassett and Kushner, 1984; Biek and Cohen, 1986; Summers and Sherratt, 1984).

A number of reports have suggested that differences exist between the repair pathways that operate on transforming plasmids and chromosomal DNA, but the underlying mechanism and overall conclusions have varied greatly between studies. A series of early studies by Roberts and Strike introduced UVirradiated plasmids and found that plasmid survival depended on UvrA and RecBC, but not on RecA or RecF, irrespective of whether a homologous plasmid was present (Roberts and Strike, 1981; Roberts and Strike, 1986; Strike and Roberts, 1982; Strike et al., 1979). In contrast, a set of more recent studies 
reported that survival of transforming plasmids containing bulky adducts depended on both RecA and RecF function and required the presence of a homologous plasmid (Bichara et al., 2007; Bichara et al., 2009). However, an earlier study involving authors from this same group reported that RecA did not significantly contribute to survival of plasmids containing bulky lesions (Schmid et al., 1982). Another group using a similar approach to characterize repair of interstrand DNA crosslinks observed that a lack of RecA did not affect survival of transforming plasmids and concluded that recombinational processes may not be involved in repairing these lesions (Berardini et al., 1997; Berardini et al., 1999). In subsequent work, it was noted that $r e c A$ mutants were hypersensitive to crosslinking agents and the authors speculated that a lack of homology to the plasmid might account for the observed differences between the plasmid and chromosome (Berardini et al., 1999). All of these studies utilized plasmids containing ColE1-type origins, making it unlikely that differences in replication origins could account for the observed variation in results. However, each of these studies relied on the introduction of a single, damaged plasmid into different preparations and strains of competent cells to draw conclusions about which proteins or pathways were important for survival. In some cases, damaged and undamaged plasmids were required to be prepared separately. Thus, some of the discrepancies between studies could be due to either variations in DNA concentrations, cell preparations, or inherent competency of cells from different genetic backgrounds. 
In light of these issues, we developed an assay that utilizes a control plasmid to normalize for variations in transformation efficiencies between different experiments and strains. We then used this assay to quantify the relative contribution that various repair pathways have on the transforming plasmid's survival. We found that only nucleotide excision repair, but not RecA, RecF, RecBC, RecG or RuvAB, contributes to the survival of transforming plasmids containing UV-induced lesions. Using two-dimensional agarose gel analysis, we observed that both replication-dependent and RecA-dependent processing intermediates are observed on established plasmids replicating endogenously, but not on plasmids that have been newly introduced into competent cells. Homology or SOS induction did not enhance the survival of transforming plasmids containing UV damage in the presence of RecA. Based on these observations, we infer that the inability of RecA-mediated pathways to operate is most likely due to inefficient replication of plasmids when they are initially introduced into cells, rather than to other aspects such as the plasmid's size, the absence of homology, or levels of recA expression.

\section{Materials and Methods}

\section{Strain Construction.}

The strains used in this work are presented in Table 2.1. All strains were derived from the parental strain ER1793 (New England Biolabs) using standard P1 transduction. 
A gene replacement of polB was constructed using the recombineering strain DY351 (Yu et al., 2000). The tetracycline resistance cassette was inserted into polB using primers polBF-tetF and polBR-tetR, 5'CAAGCCTGGTTTTTTGATGGATTTTCAGCGTGGCGCAGGCACTCGACATCT TGGTTACCG and 5'TTGCTCAAAATAGCCCAAGTTGCCCGGTCATAAGTGTAGCCAAGAGGGTC ATTATATTTCG, respectively, to amplify the tet ${ }^{R}$ cassette from Tn10. The PCR product was used to transform DY351 to generate CL1016 (polB::tet,). CL1317 (ER1793 polB::tet) was constructed by $\mathrm{P} 1$ transduction of the polB::tet allele from CL1016 into ER1793.

A gene replacement of $s u l A$ was constructed using the recombineering strain DY329 (Yu et al., 2000). The chloramphenicol resistance cassette flanked by FRT sequences was inserted into sulA using primers sulA-frtFOR and sulAfrtREV, 5'CTGTACATCCATACAGTAACTCACAGGGGCTGGATTGATTGTGTAGGCTGG AGCTGCTTCG and 5'TGGGCGACAAAAAAAGTTCCAGGATTAATCCTAAATTTACCATATGAATATC CTCCTTA, respectively, to amplify the frt-cam-frt cassette from pKD3 (Datsenko and Wanner, 2000). The PCR product was then used to transform DY329 to generate CL1922 (sulA::frt-cam-frt). CL1919 (ER1793 sulA::frt-cam-frt) was constructed by P1 transduction of the sulA::frt-cam-frt allele from CL1922 into ER1793. CL1921 (ER1793 sulA::frt-cam-frt lexA71::Tn5) was constructed by P1 
transduction of the lexA71::Tn5 allele from HL940 into CL1919. To generate a markerless sulA mutant, CL1923 (ER1793 sulA::frt lexA71::Tn5), the helper plasmid pCP20 (Cherepanov and Wackernagel, 1995) was introduced into CL1921 and FLP recombinase expression was induced to eliminate the chloramphenicol resistance cassette as described previously (Datsenko and Wanner, 2000).

Transductants were verified following selection with the appropriate antibiotic and by their sensitivity to UV irradiation when appropriate. Antibiotics were used at the following concentrations: Ampicillin $100 \mu \mathrm{g} / \mathrm{mL}$, Chloramphenicol $20 \mu \mathrm{g} / \mathrm{mL}$, Kanamycin 30 or $70 \mu \mathrm{g} / \mathrm{mL}$, Tetracycline $16 \mu \mathrm{g} / \mathrm{mL}$.

Plasmids. pBR322, pBluescriptll SK (pSK+) and the pBluescriptll KS (pKS+/-) vectors confer resistance to ampicillin and have been described previously(Alting-Mees et al., 1992; Watson, 1988). pBluescript BC SK+ (pBC, Fermentas) contains a chloramphenicol marker. pET30 (Novagen) contains a kanamycin resistance cassette.

Plasmid Purification and Irradiation. All plasmids used in this study were prepared and purified from JM109 cells using the Eppendorf Fastplasmid Mini kit and then gel purified (0.5X TAE, $0.5 \%$ Agarose, $0.3 \mu \mathrm{g} / \mathrm{mL}$ ethidium bromide ran at $1.5 \mathrm{~V} / \mathrm{cm}$ ) to obtain supercoiled circular DNA. For survival experiments, $1 \mathrm{mg}$ of purified plasmid in TE was UV irradiated at the indicated dose, using a Sylvania 
$15 \mathrm{~W}$ germicidal light bulb $(254 \mathrm{~nm})$ at an incidence rate of $0.9 \mathrm{~J} / \mathrm{m}^{2} / \mathrm{s}$. For all experiments, an equal molar amount of unirradiated, purified plasmid (pBC) was mixed with the UV-irradiated plasmids prior to the transformation analysis.

Preparation of Competent Cells and Transformation. Fresh overnight cultures of each strain were diluted 1:100 in $50 \mathrm{ml}$ of Luria-Bertani medium (LB) and grown to an $\mathrm{OD}_{600}$ of 0.4 . Cells were then pelleted, washed with $50 \mathrm{ml}$ of 80 $\mathrm{mM} \mathrm{MgCl}, 20 \mathrm{mM} \mathrm{CaCl}_{2}$ solution, repelleted and then resuspended in $1 \mathrm{ml}$ of $100 \mathrm{mM} \mathrm{CaCl}_{2}$ and $10 \%$ glycerol. Cells were stored at $-80^{\circ} \mathrm{C}$ until needed.

Competent cells that were induced for the SOS response were prepared by irradiating the culture with $20 \mathrm{~J} / \mathrm{m}^{2} \mathrm{UV}$ light, and allowing the culture to recover at $37^{\circ} \mathrm{C}$ for $20 \mathrm{~min}$ before cells were pelleted and prepared using the protocol described above.

To measure transformation frequency of damaged plasmids, a single mixture of UV-lesion containing pKS or pBR322, was mixed with undamaged pBC in a 1:1 molar ratio. This same mixture was then used to transform wild-type cells and all mutants to be compared. For transformation, $200 \mu \mathrm{l}$ competent cells were thawed on ice, mixed with $10 \mathrm{ng}$ of the $\mathrm{pKS} / \mathrm{pBC}$ plasmid mixture and heat shocked at $42^{\circ} \mathrm{C}$ for $90 \mathrm{sec}$. The mixture was then returned to ice for $1-2 \mathrm{~min}$ before $800 \mu \mathrm{l}$ of fresh LB was added and the mixture was incubated at $37^{\circ} \mathrm{C}$ for $30 \mathrm{~min}$. At this time, cultures were serially diluted and duplicate $100-\mu \mathrm{l}$ aliquots were spread on LB plates containing ampicillin $(100 \mu \mathrm{g} / \mathrm{ml})$ or chloramphenicol 
(20 $\mu \mathrm{g} / \mathrm{ml})$. Plates were incubated overnight at $37^{\circ} \mathrm{C}$ before the number of surviving colonies on each plate was counted. The ratio of ampicillin-resistant colonies to chloramphenicol-resistant colonies was then determined for each mutant and compared to wild-type cultures.

Quantification of Induced DNA Damage. Lesion frequency on plasmids was measured by sensitivity to T4 endonuclease V (TEV, Epicentre), which cleaves DNA at sites containing cyclobutane pyrimidine dimers, generating a single strand nick. $20 \mathrm{U}$ of TEV was added to $1 \mathrm{mg}$ of purified, irradiated or unirradiated plasmid DNA in $25 \mu \mathrm{l}$ TE buffer and incubated at $37^{\circ} \mathrm{C}$ for one hour. Reactions were stopped by the addition of an equal volume of chloroform and the DNA was separated on a $0.7 \%$ agarose gel containing ethidium bromide. Supercoiled plasmids containing lesions were thus converted to a nicked, open circle conformation that can be resolved on an agarose gel. For each dose, the number of lesions per plasmid molecule was then calculated from the fraction of plasmids that remained lesion free (the zero class), based on the Poisson expression, $\mathrm{P}_{(0}$ lesions) $=-\ln (\mathrm{n})$, where $\mathrm{n}$ represents the average number of lesions per plasmid.

Two-dimensional Agarose Gel Electrophoresis. For transformation experiments, electrocompentent cells were prepared by growing cultures in $50 \mathrm{ml}$ LBthy media to an $\mathrm{OD}_{600}$ of 0.6 before they were washed $4 \mathrm{X}$ with ice-cold water and resuspended in $500 \mathrm{ml}$ of ice-cold $10 \%$ glycerol. $40 \mu \mathrm{l}$ of cells were then 
transformed via electroporation with $500 \mathrm{ng}$ of pBR322, washed with $1 \mathrm{ml}$ of LB media, pelleted, resuspended in $1 \mathrm{ml} \mathrm{LB}$ media, and allowed to recover at $37^{\circ} \mathrm{C}$. During the recovery, $0.15-\mathrm{ml}$ aliquots of the transformed cell culture were taken at the indicated times and transferred to $0.75-\mathrm{ml}$ ice-cold NET buffer $(100 \mathrm{mM} \mathrm{NaCl}$, 20 mM EDTA, pH 8.0, 10 mM Tris, pH 8.0).

For experiments with cells containing an endogenous pBR322 plasmid, cultures were grown overnight in Davis medium supplemented with $0.4 \%$ glucose, $0.2 \%$ casamino acids (DGC), and $40 \mathrm{mg} / \mathrm{ml}$ each of histidine (his) and tryptophan (trp) in the presence of $100 \mathrm{mg} / \mathrm{ml}$ ampicillin. $0.2 \mathrm{ml}$ of the overnight cultures were pelleted and resuspended in 20-mI DGC medium supplemented with his and trp in the absence of ampicillin and grown in a $37^{\circ} \mathrm{C}$ shaking water bath to an $\mathrm{OD}_{600}$ of 0.5 . At this time, cultures were irradiated with $55 \mathrm{~J} / \mathrm{m}^{2}$ of UV light, which produces an average of 1 lesion per strand of the plasmid, and allowed to recover at $37^{\circ} \mathrm{C}$. At the times indicated, a $0.75-\mathrm{ml}$ aliquot of culture was removed and transferred to an equal volume of NET buffer.

To purify genomic and plasmid DNA, cells were pelleted, resuspended in $0.15 \mathrm{ml}$ of lysis buffer $(1.5 \mathrm{mg} / \mathrm{ml}$ lysozyme, $0.5 \mathrm{mg} / \mathrm{ml}$ RNAseA in $10 \mathrm{mM}$ Tris, $\mathrm{pH}$ 8.0, $1 \mathrm{mM}$ EDTA, $\mathrm{pH} 8.0$ ) and incubated at $37^{\circ} \mathrm{C}$ for $30 \mathrm{~min}$. Then, $10 \mathrm{ml}$ each of $10 \mathrm{mg} / \mathrm{ml}$ Proteinase $\mathrm{K}$ and $20 \%$ Sarkosyl was added to the samples and returned to $37^{\circ} \mathrm{C}$ for $30 \mathrm{~min}$. Samples were then extracted with 4 volumes of phenol:chloroform (1:1), followed by an extraction with 4 volumes of chloroform, dialyzed against $200 \mathrm{ml}$ of TE (2 mM Tris, pH 8.0, $1 \mathrm{mM}$ EDTA, pH 8.0) for one 
hour on a floating 47-mm Whatman 0.05-mm pore disk, and digested with Pvull (Fermentas) overnight at $37^{\circ} \mathrm{C}$. Samples were extracted with an equal volume of chloroform and loaded directly onto a gel.

Genomic DNA was separated initially on a $0.4 \%$ agarose gel in 1 X TBE at $1 \mathrm{~V} / \mathrm{cm}$ for $15 \mathrm{~h}$. For the second dimension, lanes were excised from the gel, rotated $90^{\circ}$, recast in a $1 \%$ agarose gel in $1 \mathrm{X} \mathrm{TBE}$ and electrophoresed at $7 \mathrm{~V} / \mathrm{cm}$ for $6 \mathrm{~h}$. DNA in the gels was transferred to Hybond N+ (GE BioSciences) membrane using standard Southern blotting protocols. The plasmid DNA was detected by probing with ${ }^{32} \mathrm{P}$-labeled pBR322 that was prepared using nick translation (Roche) and visualized using a Storm 840 phosphorimager (GE Biosciences) and its associated ImageQuant analysis software.

\section{Results}

\section{Several RecA-mediated pathways that contribute to cell survival after UV irradiation do not contribute to survival of UV-irradiated plasmids introduced into competent cells.}

To characterize the repair pathways that operate on transforming plasmid DNA, we employed an assay in which the survival of plasmids containing DNA damage could be compared directly between different strains and transformation experiments (Fig. 2.1). In this assay, a mixture containing equal molar amounts 
of a UV-irradiated plasmid (pBR322 or pKS, as indicated) and an undamaged control plasmid $(\mathrm{pBC})$ were used to transform wild-type and various mutant cells. Duplicate aliquots of each transformation were then plated on both ampicillin and chloramphenicol media. Survival of the damaged plasmid in each mutant was determined by calculating the ratio of surviving UV-damaged plasmids (Amp ${ }^{\mathrm{R}}$ colonies) to undamaged control plasmids (Cam ${ }^{R}$ colonies). The inclusion of the second, undamaged plasmid served to normalize for differences in the transformation frequency due to genetic mutations that affect DNA uptake and maintenance as well as to control for variations between experiments due to cell competence, DNA-cell concentrations, or heat shock durations (Berry and Kropinski, 1986; Dower et al., 1988).

We used ER1793, which lacks the two restriction endonucleases encoded by the E. coli genome, as our parental strain. Isogenic mutants in genes known to be involved in processing UV-induced damage on the chromosome were then constructed in this background. For the purpose of comparison to the plasmid assay, the survival of each strain relative to the parental strain is shown following irradiation with $25 \mathrm{~J} / \mathrm{m}^{2}$ (Fig. 2.2A). In strains lacking UvrA, RecA, RecF, RecBC, RuvAB, or RuvC, cell survival was reduced by greater than two orders of magnitude relative to wild-type cells after a dose of $25 \mathrm{~J} / \mathrm{m}^{2}$. In recG mutants, survival was more than one order of magnitude lower relative to wild-type cells. At this dose, an average of 1 lesion per 10-kb DNA strand is induced ((Courcelle 
et al., 2003) and Fig. 2.3A) and approximately $70 \%$ of wild-type cells survive to form colonies.

To measure the survival of introduced plasmid DNA in these strains, a purified preparation of pBR322 was UV-irradiated with $110 \mathrm{~J} / \mathrm{m}^{2}$. This dose produces an average of 2 lesions per plasmid strand ((Courcelle et al., 2003) and Fig. 2.3A). The irradiated plasmid was then mixed with an equal amount of a purified preparation of undamaged pBC plasmid and $20 \mathrm{ng}$ of this mixture was then used to transform each strain, as described above. Based on the ratio of transformants obtained when selecting for single or double antibiotic resistances, less than $5 \%$ of the transformants received both plasmids. In addition, at the DNA concentrations used, the overall transformation frequency was typically in the range of $<1$ transformant per 1000 colony-forming units (cfu). These transformation frequencies suggest that cells generally received only a single plasmid and argue that plasmid incompatibility or homology-based repair processes would not affect plasmid survival rates.

When transformation efficiency was normalized to the undamaged control plasmid, we observed that the survival of plasmids containing UV-induced damage in recA mutants was similar to that in wild-type cells (Fig. 2.2B). By contrast, in uvrA mutants, which are deficient in nucleotide excision repair, plasmid survival was reduced by approximately 2 orders of magnitude relative to the parental strain. 
Consistent with the results described above, the absence of other RecAdependent repair processes also did not contribute to the survival of plasmids containing UV-induced damage. UV-irradiated plasmids introduced into recF, recJ, recQ, or recBC mutants survived as well as those introduced into the parental strain (Fig. 2.2B). Similarly, plasmid survival was also unaffected by mutations inactivating RecG, RuvAB or RuvC (Fig. 2.2B).

No effect on plasmid survival was observed in the absence of any single translesion DNA polymerase gene, umuC, polB or dinB. However, of the translesion DNA polymerase genes, only UmuC contributes to cell survival after high doses of UV (Courcelle et al., 2006). Similar results were obtained when survival of UV-irradiated Phi X 174 was examined following infection of wild-type, uvrA and recA cells (data not shown). Taken together, these results suggest that nucleotide excision repair, but not recA-mediated processes contribute to the survival of introduced DNA containing UV-induced damage.

\section{UvrA is nearly essential for survival of plasmids containing UV-induced damage following transformation.}

To further characterize the role of nucleotide excision repair and recAmediated pathways in processing introduced DNA, we examined the survival of plasmids over a range of UV doses. To this end, aliquots of a purified plasmid preparation of pKS+ were either mock irradiated or irradiated with $40,80,160$ or $240 \mathrm{~J} / \mathrm{m}^{2}$ of UV to produce an average of $0,1,2,4$ and 6 CPDs on the 3-kb 
plasmid, respectively. The lesion frequency was confirmed by treating the irradiated samples with T4 endonuclease V (TEV), which incises DNA at sites containing CPDs. Following incision by TEV, supercoiled plasmids containing UV lesions are converted to a relaxed open circular conformation that can be monitored in an agarose gel (Fig. 2.3A). The UV-irradiated plasmid preparations were then mixed with an unirradiated control pBC plasmid and the mixture was used to transform a set of wild-type, recA, or uvrA cultures as described above. As shown in Fig. 2.3B, the survival of UV-irradiated plasmids in recA mutants (filled bar) was similar to wild-type cells up to doses of $160 \mathrm{~J} / \mathrm{m}^{2}$. By comparison, plasmid survival in uvrA mutants (unfilled bar) decreased relative to survival in wild-type cultures as the lesion frequency increased.

To assess plasmid survival within each strain as a function of UV dose, we also plotted plasmid survival relative to the survival of a mock-irradiated plasmid in each strain. Because we are not comparing survival to wild-type cultures, this type of analysis does not control for differences in transformation efficiencies that may exist between strains. However, the use of the undamaged control plasmid still normalizes for differences in transformation efficiencies that occur between experiments and allows one to determine how survival is reduced within each strain as a function of UV dose. By this type of analysis, plasmid survival in wildtype cells decreased linearly as the number of lesions on the plasmid increased over the doses we examined (Fig. 2.3C). In recA mutants, plasmid survival decreased at the same rate as that observed in wild-type cells. The lack of any 
RecA dependence on plasmid survival across the range of doses examined argues that the observed effect is not a result of the lesion frequency being below or beyond the capacity of RecA pathways to operate.

In contrast to recA cultures, plasmid survival in uvrA and recA uvrA mutants decreased more rapidly than wild-type cultures as the UV dose increased. At each dose examined, the percent plasmid survival was approximately equal to the fraction of plasmids that, by chance, remained lesionfree within the UV-irradiated samples (compare Figs. 2.3A and 2.3C). The result indicates that when lesions are present on the newly introduced DNA, nucleotide excision repair is nearly essential for survival. Other mutants that were examined, including $r e c B C$, recF and $u m u C$, did not exhibit dose-dependent hypersensitivity to UV-induced damage on plasmid DNA (data not shown), consistent with the idea that other RecA-dependent processes are not contributing to plasmid survival.

\section{RecA-dependent processing intermediates are observed on endogenously} replicating plasmids, but not when plasmids are first introduced into cells.

The inability of RecA-mediated pathways to contribute to survival of transforming plasmid DNA may be due either to the plasmid's small size, its structure, or some aspect associated with the transformation process. To differentiate between these possibilities, we compared the processing intermediates observed on newly introduced plasmids following transformation to 
those observed on established, endogenously replicating plasmids using twodimensional (2D) agarose-gel electrophoresis. This technique is able to differentiate and identify the structural properties of plasmids during repair and replication. To examine the structures induced on established, endogenous plasmids, cultures of $E$. coli containing the plasmid pBR322 were UV irradiated with $55 \mathrm{~J} / \mathrm{m}^{2}$ and then allowed to recover. To examine structures on newly introduced plasmids, purified pBR322 was first UV-irradiated with $110 \mathrm{~J} / \mathrm{m}^{2}$ and then used to transform competent preparations of $E$. coli. In both cases, samples were then taken at various times during the recovery period and total genomic DNA (plasmid and chromosomal) was purified. The genomic DNA was then digested with Pvull to linearize the plasmid at its unidirectional origin of replication and analyzed by 2D agarose-gel electrophoresis.

On endogenous plasmids in the absence of DNA damage, nonreplicating plasmid molecules migrate as a linear 4.4-kb fragment and form the prominent spot observed in this analysis. Replicating, Y-shaped molecules migrate more slowly due to their larger size and nonlinear structure and appear as an arc that extends out from the prominent nonreplicating spot (Fig. 2.4A and D). In the presence of UV-induced DNA damage, a unique class of intermediates is transiently observed that migrates more slowly than the replicating $\mathrm{Y}$-arc, forming a cone region. These intermediates represent molecules having four arms or two branch points and have been shown to be resolved at a time that correlates with repair of the lesion and resumption of replication (Courcelle et al., 2003). 
When we analyzed the structure of plasmids following transformation, we observed a distinct absence of both replicating structures and processing intermediates. We did observe a prominent $4.4 \mathrm{~kb}$ linear spot that corresponded to nonreplicating molecules (Fig. 2.4B). To estimate the amount of plasmid DNA that was not taken up by cells but detected in these assays, non-transformed samples were also analyzed after plasmid DNA was simply mixed with competent cell preparations. Based on the amount of plasmid detected in these mock-transformed samples, more than $96 \%$ of the signal detected in the Southern analysis represents plasmids taken up by cells, suggesting that plasmids not taken up by cells were effectively removed from the media by the washing step before DNA was prepared from the culture (Fig. 2.4A). To determine whether the lack of any observed intermediates was due to the presence of DNA damage on the transforming plasmid DNA, we also examined undamaged plasmids using the same approach and observed a similar lack of replication intermediates on plasmids newly introduced to competent cells (Fig. 2.4B). These observations suggest that newly introduced plasmids do not replicate efficiently and therefore fail to generate replication intermediates associated with processing lesions at replication forks.

On established, endogenous plasmids, the formation of the transient UVinduced structural intermediates requires ongoing replication and depends on RecA. By contrast, the UV-induced intermediates fail to resolve in uvrA mutants when the lesions cannot be removed. Thus, in these mutants, the intermediates 
are not transient but are seen to persist and accumulate. Similarly, in ruvAB mutants, which are unable to resolve these replication intermediates, the structures have been shown to accumulate, and go on to form higher order structures when other RecA-dependent processes are absent ((Courcelle et al., 2003;Donaldson et al., 2006) and Fig. 2.4C). Thus, if the transient nature of these intermediates prohibited their detection following transformation in wildtype cells, we reasoned that we should observe them in uvrA or ruvAB mutants where they are not resolved and continue to accumulate. However, as shown in Fig. 2.4C, when we examined the structure of newly introduced plasmids in each of these mutants, only nonreplicating linear fragments were detected in transformed uvrA, recA or ruvAB mutants. The lack of intermediate structures seen in these mutants argues that these replication-dependent processing events are not occurring at high frequencies following transformation.

We interpret these observations to be consistent with the idea that the inability of RecA-mediated processes to contribute to survival is due to an aspect of the transformation process. The presence of RecA-dependent intermediates on endogenous plasmids argues against the idea that the plasmid is either too small or is otherwise inappropriate as a substrate for RecA-mediated processes to operate. The absence of any replication-associated structural intermediates on the newly introduced plasmids suggests that the plasmid replicates inefficiently when it is initially introduced into host cells and that this is likely to account for the lack of processing by RecA-mediated pathways. 


\section{SOS induction or plasmid homology does not enhance survival of the transforming plasmid DNA.}

Following DNA damage on the chromosome, RecA is upregulated as part of the SOS response (Radman, 1975; Sassanfar and Roberts, 1990). Thus, it is possible that higher levels of RecA expression are required to observe RecAmediated survival or processing on the newly introduced UV-irradiated plasmids. To address this possibility, we constructed wild-type and uvrA mutants that lacked the LexA repressor, allowing constitutive expression of RecA and all other SOS-regulated gene products. We then examined pKS plasmid survival following transformation as a function of UV dose in each of these strains as described before. By this type of analysis, constitutive expression of recA and other SOS-regulated genes had no effect on plasmid survival at any of the doses examined compared to their LexA+ counterparts (Fig. 2.5), indicating that the inability of RecA-mediated processes to operate in transforming plasmid DNA is not due to the expression level of $r e c A$ or other SOS-regulated genes.

A second possible reason that RecA-dependent survival is not observed on newly introduced plasmids is the lack of established homologous sequences in the cell at the time of transformation. In the case of endogenously replicating plasmids, the plasmid is present in multiple copies inside the cell. Thus, it is possible that RecA-dependent survival would increase significantly if homologous sequences were present inside the cell at the time of transformation. To test this 
possibility, we used a mixture of a UV-irradiated plasmid, pSK+, and control plasmid, pET30, to transform competent preparations of wild-type, recA, and uvrA cells that either contained no homologous plasmid, or contained an endogenous, homologous plasmid, $\mathrm{pBC}$. The $\mathrm{pBC}$ plasmid is entirely homologous to the UV-irradiated pSK+ plasmid except for its antibiotic resistance cassette but is not homologous to pET30. As shown in Fig. 2.6, the survival of UV-irradiated plasmids in uvrA cultures was reduced to the same extent regardless of whether or not cells contained the homologous plasmid and no RecA-dependent survival was observed. We interpret these results to indicate that the presence of homology does not limit the ability of RecA-mediated processes from operating on plasmids following transformation.

\section{Discussion}

We demonstrate that distinct differences exist between the battery of repair processes that operate on newly introduced plasmids as compared to those that operate on established, endogenous plasmids or the chromosome. On newly introduced plasmid DNA containing UV-induced damage, nucleotide excision repair is nearly essential for survival, whereas RecA-mediated processes do not significantly contribute to survival. The presence of replication and processing intermediates on endogenous plasmids, but not on newly introduced plasmids suggests that the lack of RecA-mediated processing is due to inefficient replication when plasmids are initially introduced into cells, rather 
than to other aspects such as the plasmid's size, the presence of homology, or levels of RecA expression. Delayed or inefficient replication of the plasmid would allow more time for lesion repair to occur, obviating the need for RecA-mediated processing of arrested replication forks, as originally postulated by Strike and Roberts (Strike and Roberts, 1982).

The inefficient replication and processing by RecA-mediated pathways following transformation could reflect the need to establish additional protein factors on the purified DNA before replication or RecA-mediated processing can occur. Endogenous plasmids contain a number of associated structural proteins, including histone-like factors such as $\mathrm{Hu}$, Ihf, or topoisomerases that are known to impair replication of plasmids when absent (Baker et al., 1986; Biek and Cohen, 1992; Gamas et al., 1986; Hwang and Kornberg, 1992; van der Ende et al., 1985). It is reasonable to consider that the newly introduced DNA may not replicate or be recognized efficiently by some enzymatic processes until these topology-altering factors are established.

A key difference between this study and previous studies involving the transformation of plasmids containing DNA damage involves the inclusion of an undamaged reference plasmid to normalize for transformation frequencies between different experiments and strains. This may help clarify a number of previous studies that have reached differing conclusions when characterizing repair mechanisms on transforming DNA. Strike and Roberts initially found that plasmid survival was dependent on $\operatorname{RecBC}$, but curiously, it did not depend on 
RecA or RecF (Roberts and Strike, 1986). When normalized to an undamaged reference plasmid, we found that the survival of introduced plasmids containing UV-induced damage in recBC mutants was similar to wild-type cells and did not depend on RecA. A number of studies subsequent to Strike and Roberts work have shown that mutants defective in the RecBCD pathway have an impaired ability to maintain plasmids, which may account for the reduced survival that was observed in these early studies (Biek and Cohen, 1986; Niki et al., 1988; Summers and Sherratt, 1984).

Two previous studies also reached different conclusions as to whether a resident homologous plasmid enhances survival. Strike and Roberts concluded that RecA did not enhance survival of introduced plasmids even in the presence of homology (Strike and Roberts, 1982). Curiously, they did observe a modest increase in plasmid survival that was dependent on UvrA and UvrB, but not UvrC. In contrast, Bichara et al. using plasmids containing an AAF adduct, reported that survival depended on both RecA and RecF, required the presence of homology and involved a pathway that could be coupled to lesion removal by nucleotide excision repair (Bichara et al., 2007; Bichara et al., 2009). The RecA- and RecFdependent survival was initially observed when using single-strand plasmids (Bichara et al., 2007). In a subsequent study, the authors suggested that the RecA-mediated effect also occurred when using double-strand plasmids, although survival of the transforming plasmid DNA was not specifically examined in this study (Bichara et al., 2009). An earlier study from this group reported that 
RecA did not contribute to survival following introduction of double-stranded plasmids containing either UV or AAF adducts (Schmid et al., 1982). When normalized to the reference plasmid, we did not observe any enhanced survival that was dependent on RecA or homology, consistent with the early results reported by Strike and Roberts, and Schmid et al. (Schmid et al., 1982; Strike and Roberts, 1982). Considering the essential role for nucleotide excision repair on transforming plasmids, it is likely that both RecA and the presence of a second, homologous template plays a more important role in the survival of single-stranded plasmids than on double-stranded plasmids following introduction into the cell, which may in part explain the discrepancies between these studies (Bichara et al., 2007; Bichara et al., 2009; Roberts and Strike, 1981; Schmid et al., 1982; Strike and Roberts, 1982). On double-stranded plasmids, a range of genetic and cellular observations suggest that arrested replication forks are processed by RecA to restore the region to a double-stranded form that can be repaired by nucleotide excision repair (Courcelle and Hanawalt, 2001; Courcelle et al., 1997; Courcelle et al., 1999; Courcelle et al., 2001; Courcelle et al., 2003). However, on single-stranded plasmids, repair of the lesion following the arrest of replication would require a second homologous plasmid to provide a template that can restore the lesion-containing region to a double-stranded form, as Bichara et al. observed (Bichara et al., 2007). 


\section{Acknowledgements}

We thank Dr. Iwata-Reuyl and Dr. Fred Heffron for providing plasmids used in this study. This work was supported by the National Science Foundation (CAREER award MCB0551798); and the National Institute of General Medical

Sciences, National Institutes of Health (AREA grant R15GM86839). 
TABLE 2.1. E. coli $\mathrm{K}-12$ strains used

\begin{tabular}{|c|c|c|}
\hline Strain & Relevant Genotype & Source, Reference or Construction \\
\hline ER1793 & $\begin{array}{l}\mathrm{F}^{-} \text {fhuA2 } \Delta(\text { lacZ)r1 gln44e14 } \\
\left(\mathrm{McrA}^{-}\right) \text {trp13-31 his-1 } \\
\text { rpsL104 xyl-7 mtl-2 metB1 } \\
\Delta(\mathrm{mcrC}-\mathrm{mrr}) 114:: / \mathrm{IS10}\end{array}$ & New England Biolabs \\
\hline KM21 & $\Delta($ recBCD)::kan & (Murphy, 1998) \\
\hline TP539 & recG6201:: kan & (Murphy et al., 2000) \\
\hline TP605 & sulA6209::tet & (Murphy et al., 2000) \\
\hline TP638 & recQ6216::tet & (Murphy et al., 2000) \\
\hline DY329 & $\begin{array}{l}\Delta \text { (lacU169) nadA::Tn10, } \\
\text { gal490, Lambda cl857, } \Delta \\
\text { (cro-bioA) }\end{array}$ & (Yu et al., 2000) \\
\hline CL1922* & sulA::frt-cam-frt & $\begin{array}{l}\text { DY329 x linear PCR product } \\
\text { Primers sulA-frtFOR and sulA- } \\
\text { frtREV }\end{array}$ \\
\hline DY351 & $\begin{array}{l}\text { 4lacU169, gal490, } \Delta c / 857, \Delta \\
\text { (cro-bioA), D(kil-git::cam) }\end{array}$ & (Yu et al., 2000) \\
\hline CL1016* & polB::tet & $\begin{array}{l}\text { DY351 x linear PCR product } \\
\text { Primers polBF-tetF and polBR-tetR }\end{array}$ \\
\hline HL759 & uvrA6, zjd::Tn5 & Dr. Ann Ganesan \\
\hline HL921 & recA::tet & (Courcelle et al., 1997) \\
\hline HL924 & recJ284::Tn10 & (Courcelle and Hanawalt, 1999) \\
\hline HL940 & lexA71::Tn5 & (Crowley and Hanawalt, 1998) \\
\hline HL952 & uvrA::Tn 10 & (Courcelle et al., 1999) \\
\hline CL575 & umuC122::Tn5 & (Courcelle et al., 2005) \\
\hline CL577 & ruvC53eda-51::Tn10 & (Donaldson et al., 2006) \\
\hline CL578 & ruvAB6204::kan & (Donaldson et al., 2004) \\
\hline CL579 & recF6206::tet & (Courcelle et al., 2003) \\
\hline CL634 & dinB::kan & (Courcelle et al., 2005) \\
\hline \multicolumn{3}{|c|}{ Strains isogenic to ER1793: } \\
\hline CL1312 & recJ284::Tn10 & ER1793 x P1 (HL924) \\
\hline CL1313 & recA::tet & ER1793 x P1 (HL921) \\
\hline CL1314 & ruvC53eda-51::Tn10 & ER1793 x P1 (CL577) \\
\hline CL1315 & uvrA::Tn 10 & ER1793 x P1 (HL952) \\
\hline CL1316 & recQ6216::tet & ER1793 x P1 (TP638) \\
\hline CL1317 & polB::tet & ER1793 x P1 (CL1016) \\
\hline CL1318 & $\operatorname{din} B:: k a n$ & ER1793 x P1 (CL634) \\
\hline CL1319 & recF6206::tet & ER1793 x P1 (CL579) \\
\hline CL1320 & ruvAB6204::kan & ER1793 x P1 (CL578) \\
\hline CL1321 & recG6201:: kan & ER1793 x P1 (TP539) \\
\hline
\end{tabular}




\begin{tabular}{|l|l|l|}
\hline CL1323 & umuC122::Tn5 & ER1793 x P1 (CL575) \\
\hline CL1473 & $\Delta($ recBCD)::kan & ER1793 x P1 (KM21) \\
\hline CL1605 & sulA6209::tet & ER1793 x P1 (TP605) \\
\hline CL1623 & sulA6209::tet lexA71::Tn5 & CL1605 x P1 (HL940) \\
\hline CL1919 & sulA::frt-cam-frt & ER1793 x P1 (CL1922) \\
\hline CL1921 & sulA::frt-cam-frt lexA71::Tn5 & CL1919 x P1 (HL940) \\
\hline CL1923* & sulA::frt lexA71::Tn5 & $\begin{array}{l}\text { CL1921 x pCP20 (Cherepanov and } \\
\text { Wackernagel, 1995) }\end{array}$ \\
\hline CL 1507 & uvrA6, zjd::Tn5 & ER1793 x P1 (HL759) \\
\hline CL 1566 & uvrA6, zjd::Tn5, recA::tet & CL1313 x P1 (HL759) \\
\hline CL1736 & $\begin{array}{l}\text { sulA::frt lexA71::Tn5 } \\
\text { uvrA::Tn10 }\end{array}$ & CL1923 x P1 (HL952) \\
\hline
\end{tabular}




\section{(A)}

(B)

(C)

(D)

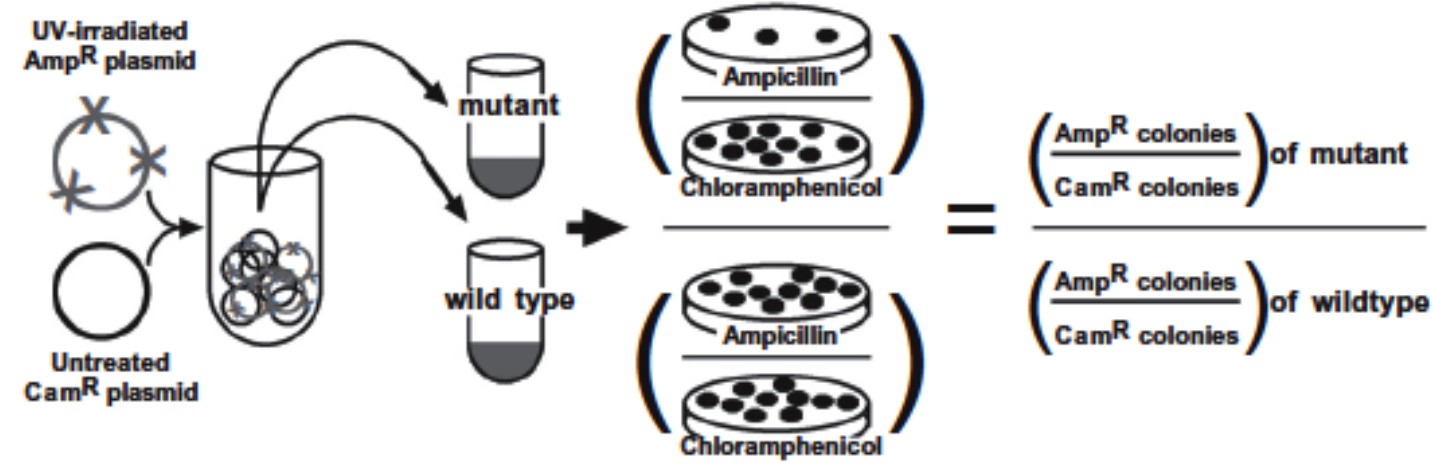

Figure 2.1. Schematic of transformation assay. A) Equal amounts of UV-damaged and untreated plasmids are mixed and used to B) transform a set of competent wild-type and mutant cells. C) The ratio of colonies formed on ampicillin plates (UV-damaged) to those formed on chloramphenicol plates (untreated) are determined for each mutant and $\mathrm{D}$ ) normalized to the ratio observed in wild-type. 
(A)

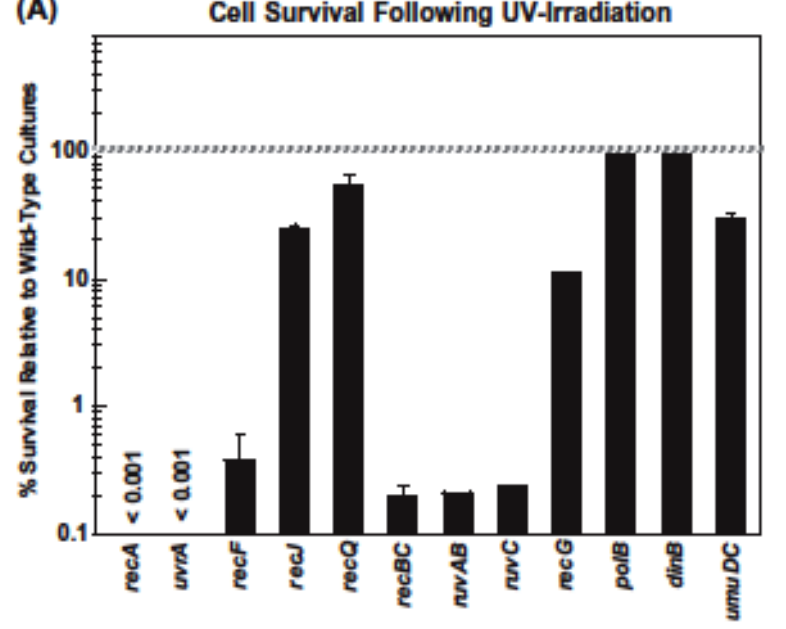

(B)

UV-Irradiated Plasmid Survival

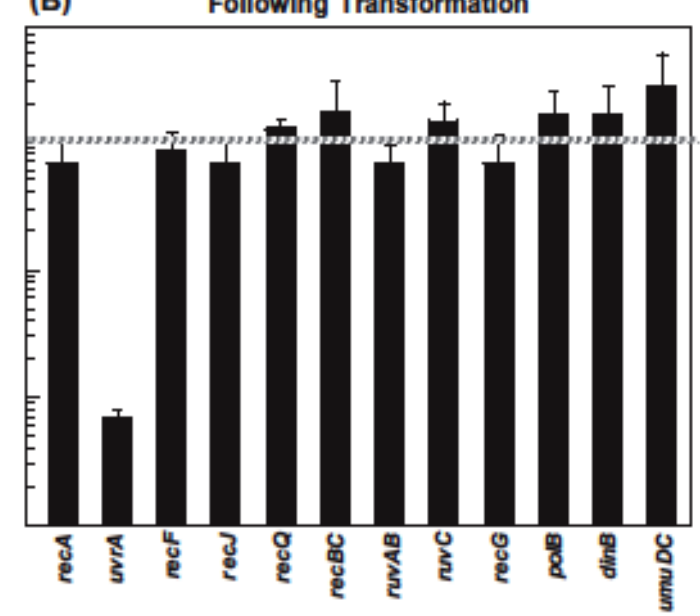

Figure 2.2. Many RecA-mediated processes that contribute to cell survival do not contribute to the survival of transforming plasmids. A) The survival of each mutant is plotted relative to the survival of wild-type cells following irradiation with $25 \mathrm{~J} / \mathrm{m}^{2}$ of UV. B) The survival of UV-irradiated plasmids $\left(160 \mathrm{~J} / \mathrm{m}^{2}\right)$ introduced into each mutant is plotted relative to the survival of plasmids introduced into wild-type cells. Data represents an average of at least 3 independent experiments. Error bars represent standard error of the mean. 

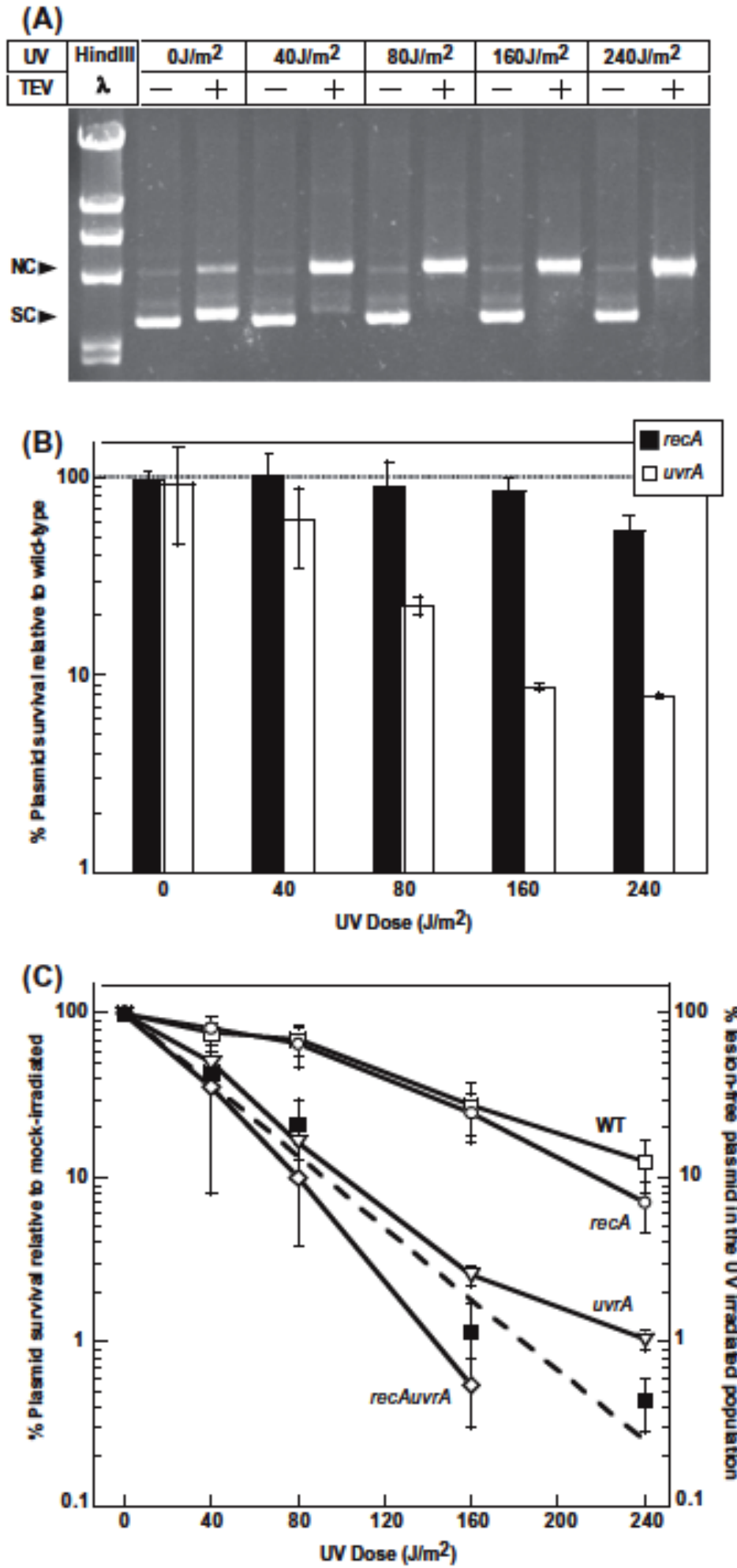

Figure 2.3. UvrA is nearly essential for the survival of transforming plasmids containing UV-induced damage. A) The formation of the predominant UV-induced lesion, the cyclobutane pyrimidine dimer (CPD), increases linearly with UV dose. The presence of lesions was determined by sensitivity to T4 Endonuclease V (TEV), which cleaves DNA at sites containing CPDs converting supercoiled plasmid (SC) to a nicked open circular form (NC). These forms are differentiated by their migration pattern following agarose-gel electrophoresis ${ }^{54}$. B) The survival of UV-irradiated plasmids following transformation in recA (filled bars) and uvrA (unfilled bars) mutants is plotted relative to the survival of plasmids introduced into wild-type cells at each dose. Survival was calculated as described in Figure 2.1. Plots represent an average of at least 2 independent experiments. Error bars represent standard error of the mean. C) The survival of UV-irradiated transforming plasmid is plotted relative to the survival of the mock-irradiated plasmid for wildtype (open squares), recA (open circles), uvrA (open triangles) and recA uvrA (open diamonds) at the indicated doses. The predicted (dashed line) and measured (filled squares) fraction of lesion-free plasmids in the UV-irradiated population is plotted. Measured lesion-free fractions were calculated from the amount of plasmid remaining resistant to TEV cleavage as shown in Figure 2.3A. Predicted lesion-free

plasmids were calculated as the zero-class of plasmids using the Poisson expression. Graphs represent an average of at least 2 independent experiments. Error bars represent standard error of the mean. 

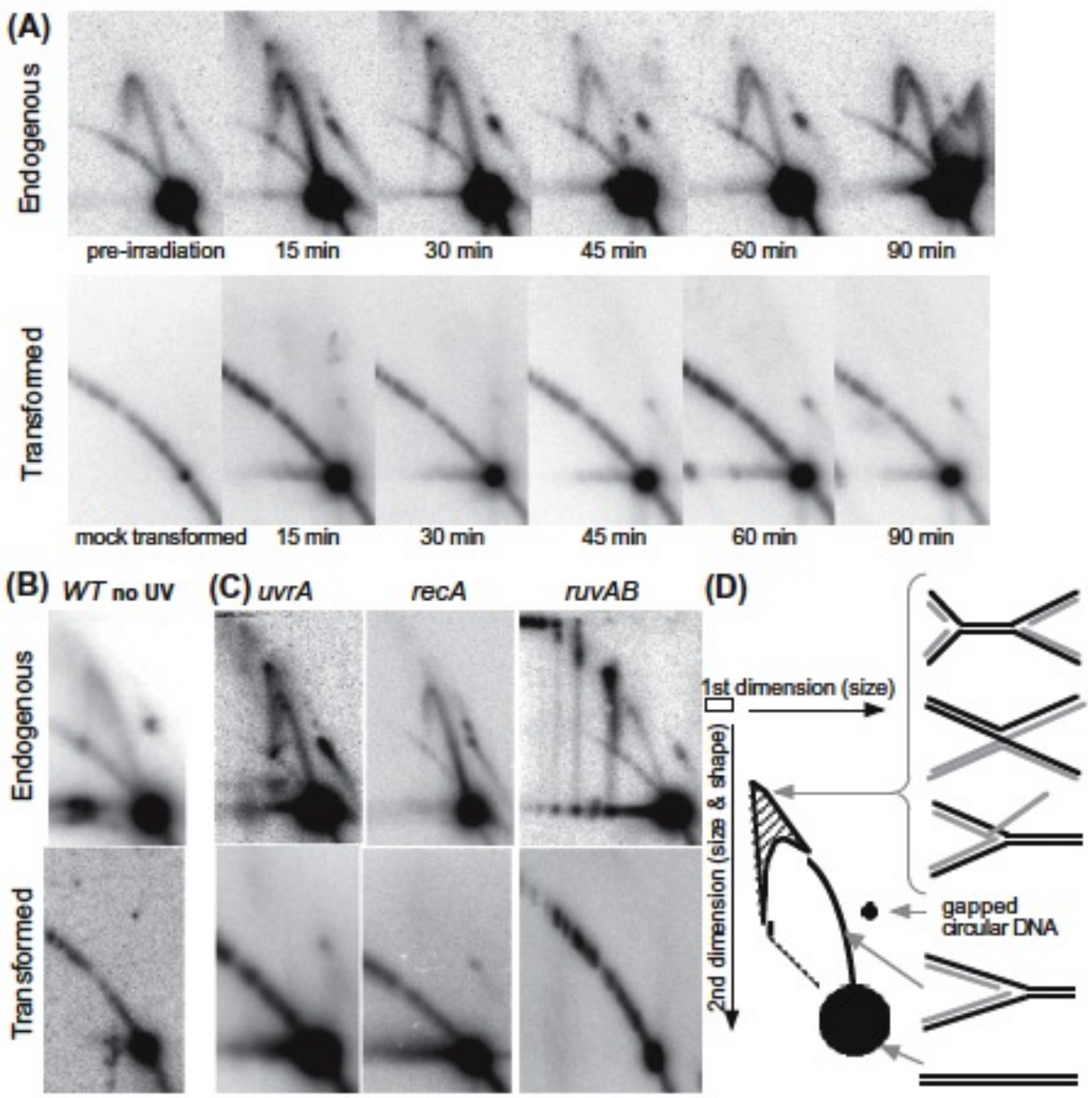

Figure 2.4. Replication- and RecA-dependent processing intermediates are not observed on newly introduced plasmids. A) Replication-associated structural intermediates observed on endogenous plasmids containing UV-induced DNA damage are not observed on plasmids following transformation. Wild-type cells containing an endogenous plasmid pBR322 were UVirradiated with $55 \mathrm{~J} / \mathrm{m}^{2}$ (top) or wild-type cells were transformed with a plasmid that was UVirradiated with $110 \mathrm{~J} / \mathrm{m}^{2}$ (bottom). Genomic DNA was then purified, digested with Pvull, and analyzed by two-dimensional agarose-gel analysis at the times indicated. B) Non-damaged plasmids also fail to generate replication intermediates when first introduced into cells. Wild-type cells containing an endogenous plasmid pBR322 were mock UV-irradiated (top) or wild-type cells were transformed with a plasmid that was mock UV-irradiated, and then analyzed as in $(A)$ following a 60-min recovery period. C) On endogenous plasmids containing DNA damage, RecAdependent structural intermediates persist and accumulate in uvrA and ruvAB mutants (top), but are not observed when UV-irradiated plasmids are introduced into these mutants (bottom). uvrA, recA, and ruvAB mutants were analyzed as described in (A) following UV irradiation of cultures containing an endogenous plasmid or following introduction with UV-irradiated plasmid, pBR322. 
uvrA and recA mutants were analyzed at 30 min following treatment, ruvAB mutants were analyzed 60 min following treatment. D) Migration pattern of replication- and UV-induced structural intermediates following Pvull digestion of pBR322 during two-dimensional agarose-gel analysis. Nonreplicating plasmids run as a linear $4.4-\mathrm{kb}$ fragment. Normal replicating fragments form Y-shaped structures and migrate more slowly because of their larger size and nonlinear shape, forming an arc that extends out from the linear fragment. Double $\mathrm{Y}$ - or $\mathrm{X}$-shaped molecules migrate in the cone region and are observed after UV-induced damage on endogenous plasmids. 


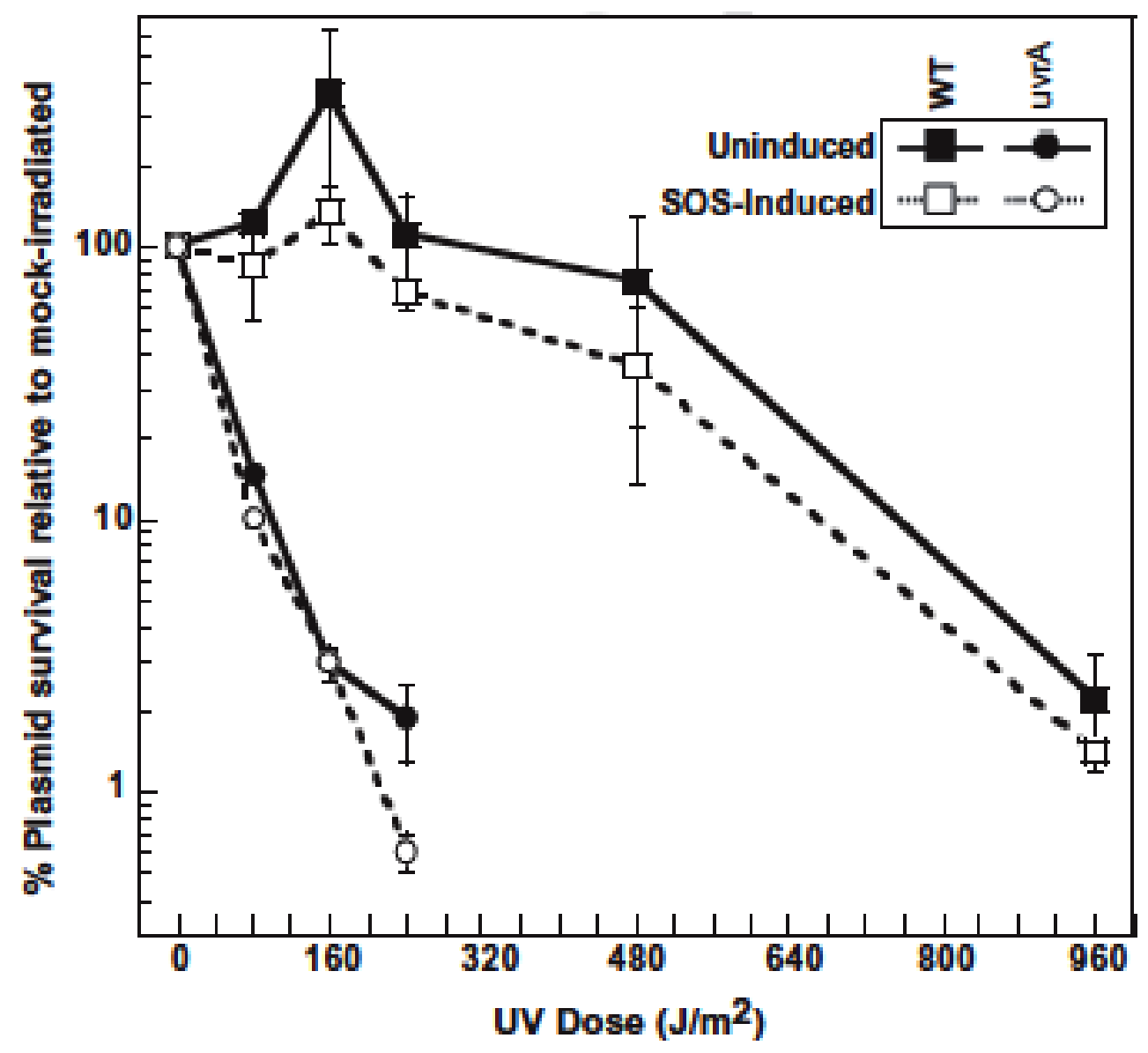

Figure 2.5. Constitutive recA expression does not enhance the survival of transforming UV-damaged plasmids. The survival of UV-irradiated plasmids following introduction into wildtype (filled squares), lexA (open squares, dotted lines), uvrA (filled circles), and uvrA lexA (open circles, dotted lines) cells is plotted relative to the survival of mock-irradiated plasmids. Plots represent an average of at least 2 experiments. Error bars represent standard error of the mean. 


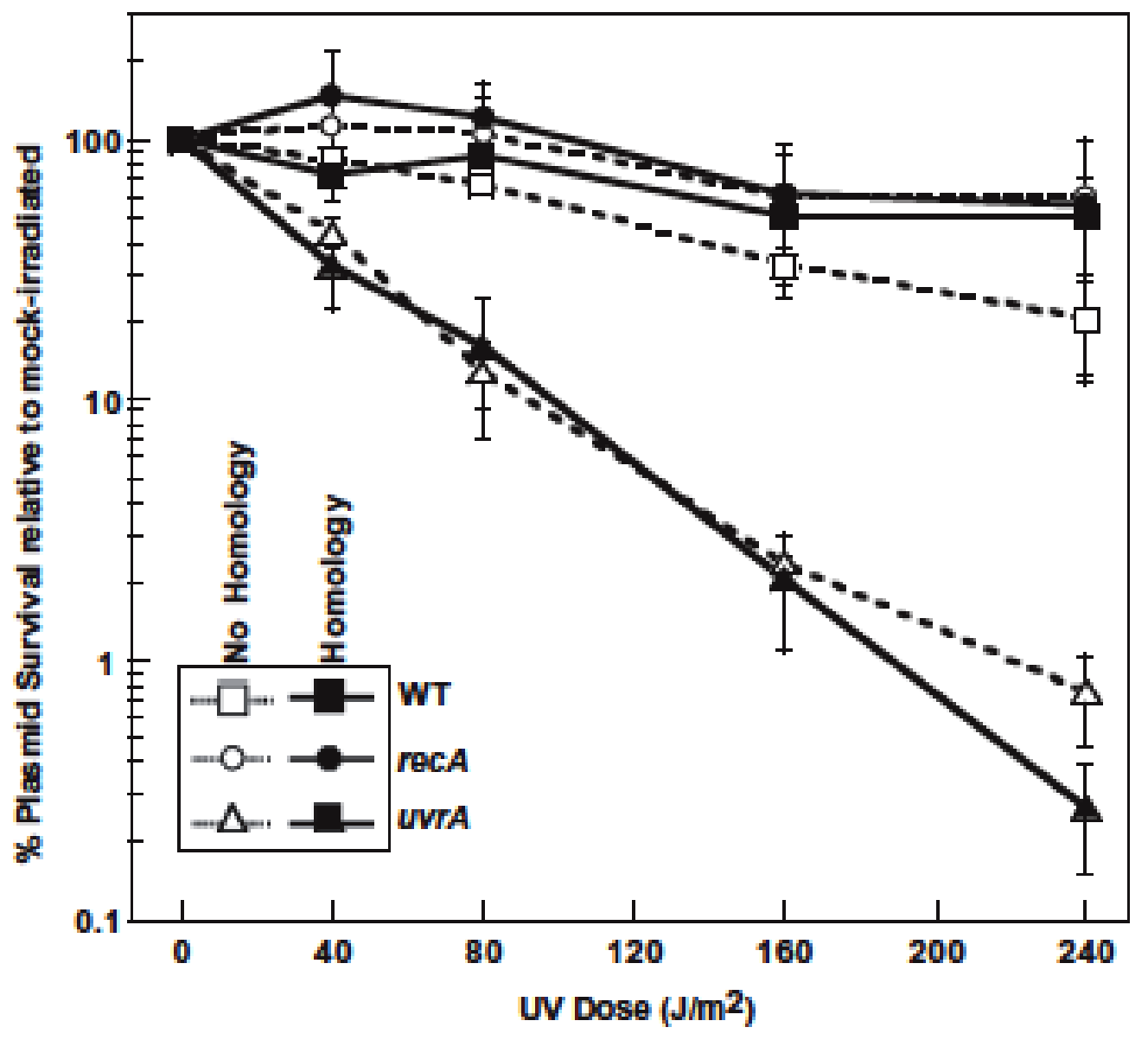

Figure 2.6. The presence of a homologous plasmid does not enhance the survival of transforming UV-damaged plasmids. The survival of UV-irradiated plasmids following introduction into wild-type (squares), recA (circles) and uvrA (triangles) cells is plotted relative to the survival of mock-irradiated plasmids at each dose. The cells either contained an endogenous homologous plasmid (filled symbols) or no homologous plasmid (open symbols, dotted lines). Plots represent an average of at least 2 experiments. Error bars represent standard error of the mean. 


\section{References}

Alting-Mees, M.A., Sorge, J.A. \& Short, J.M. 1992. pBluescriptll: multifunctional cloning and mapping vectors. Methods Enzymol. 216, 483-495.

Bagg, A., Kenyon, C.J. \& Walker, G.C. 1981. Inducibility of a gene product required for UV and chemical mutagenesis in Escherichia coli. Proc Natl Acad Sci U S A. 78, 5749-5753.

Baker, T.A., Sekimizu, K., Funnell, B.E. \& Kornberg, A. 1986. Extensive unwinding of the plasmid template during staged enzymatic initiation of DNA replication from the origin of the Escherichia coli chromosome. Cell. 45, 5364.

Bassett, C.L. \& Kushner, S.R. 1984. Exonucleases I, III, and V are required for stability of ColE1-related plasmids in Escherichia coli. J Bacteriol. 157, 661664.

Berardini, M., Foster, P.L. \& Loechler, E.L. 1999. DNA polymerase II (polB) is involved in a new DNA repair pathway for DNA interstrand cross-links in Escherichia coli. J Bacteriol. 181, 2878-2882.

Berardini, M., Mackay, W. \& Loechler, E.L. 1997. Evidence for a recombinationindependent pathway for the repair of DNA interstrand cross-links based on a site-specific study with nitrogen mustard. Biochemistry. 36, 3506-3513.

Berry, D. \& Kropinski, A.M. 1986. Effect of lipopolysaccharide mutations and temperature on plasmid transformation efficiency in Pseudomonas aeruginosa. Can J Microbiol. 32, 436-438. 
Bichara, M., Fuchs, R.P., Cordonnier, A. \& Lambert, I.B. 2009. Preferential postreplication repair of DNA lesions situated on the leading strand of plasmids in Escherichia coli. Mol Microbiol. 71, 305-314.

Bichara, M., Pinet, I., Lambert, I.B. \& Fuchs, R.P. 2007. RecA-mediated excision repair: a novel mechanism for repairing DNA lesions at sites of arrested DNA synthesis. Mol Microbiol. 65, 218-229.

Biek, D.P. \& Cohen, S.N. 1986. Identification and characterization of recD, a gene affecting plasmid maintenance and recombination in Escherichia coli. J Bacteriol. 167, 594-603.

Biek, D.P. \& Cohen, S.N. 1992. Propagation of pSC101 plasmids defective in binding of integration host factor. J Bacteriol. 174, 785-792.

Cherepanov, P.P. \& Wackernagel, W. 1995. Gene disruption in Escherichia coli: TcR and KmR cassettes with the option of Flp-catalyzed excision of the antibiotic-resistance determinant. Gene. 158, 9-14.

Chow, K.H. \& Courcelle, J. 2007. RecBCD and RecJ/RecQ initiate DNA degradation on distinct substrates in UV-irradiated Escherichia coli. Radiat Res. 168, 499-506.

Courcelle, C.T., Belle, J.J. \& Courcelle, J. 2005. Nucleotide excision repair or polymerase V-mediated lesion bypass can act to restore UV-arrested replication forks in Escherichia coli. J Bacteriol. 187, 6953-6961.

Courcelle, C.T., Chow, K.H., Casey, A. \& Courcelle, J. 2006. Nascent DNA processing by RecJ favors lesion repair over translesion synthesis at 
arrested replication forks in Escherichia coli. Proc Natl Acad Sci U S A. 103, 9154-9159.

Courcelle, J., Crowley, D.J. \& Hanawalt, P.C. 1999. Recovery of DNA replication in UV-irradiated Escherichia coli requires both excision repair and recF protein function. J Bacteriol. 181, 916-922.

Courcelle, J., Donaldson, J.R., Chow, K.H. \& Courcelle, C.T. 2003. DNA

Damage-Induced Replication Fork Regression and Processing in Escherichia coli. Science. 299, 1064-1067.

Courcelle, J., Ganesan, A.K. \& Hanawalt, P.C. 2001. Therefore, what are recombination proteins there for? Bioessays. 23, 463-470.

Courcelle, J. \& Hanawalt, P.C. 2001. Participation of recombination proteins in rescue of arrested replication forks in UV-irradiated Escherichia coli need not involve recombination. Proc Natl Acad Sci U S A. 98, 8196-8202.

Courcelle, J., Carswell-Crumpton, C. \& Hanawalt, P.C. 1997. recF and recR are required for the resumption of replication at DNA replication forks in Escherichia coli. Proc Natl Acad Sci U S A. 94, 3714-3719.

Datsenko, K.A. \& Wanner, B.L. 2000. One-step inactivation of chromosomal genes in Escherichia coli K-12 using PCR products. Proc Natl Acad Sci U S A. $97,6640-6645$.

Donaldson, J.R., Courcelle, C.T. \& Courcelle, J. 2004. RuvAB and RecG Are Not Essential for the Recovery of DNA Synthesis Following UV-Induced DNA Damage in Escherichia coli. Genetics. 166, 1631-1640. 
Donaldson, J.R., Courcelle, C.T. \& Courcelle, J. 2006. RuvABC is required to resolve holliday junctions that accumulate following replication on damaged templates in Escherichia coli. J Biol Chem. 281, 28811-28821.

Dower, W.J., Miller, J.F. \& Ragsdale, C.W. 1988. High efficiency transformation of E. coli by high voltage electroporation. Nucleic Acids Res. 16, 6127-6145.

Froger, A. \& Hall, J.E. 2007. Transformation of plasmid DNA into E. coli using the heat shock method. J Vis Exp. 253.

Gamas, P., Burger, A.C., Churchward, G., Caro, L., Galas, D. \& Chandler, M. 1986. Replication of pSC101: effects of mutations in the E. coli DNA binding protein IHF. Mol Gen Genet. 204, 85-89.

Hwang, D.S. \& Kornberg, A. 1992. Opening of the replication origin of Escherichia coli by DnaA protein with protein HU or IHF. J Biol Chem. 267, 23083-23086.

Keller, K.L., Overbeck-Carrick, T.L. \& Beck, D.J. 2001. Survival and induction of SOS in Escherichia coli treated with cisplatin, UV-irradiation, or mitomycin C are dependent on the function of the RecBC and RecFOR pathways of homologous recombination. Mutat Res. 486, 21-29.

Kucherlapati, R.S., Eves, E.M., Song, K.Y., Morse, B.S. \& Smithies, O. 1984. Homologous recombination between plasmids in mammalian cells can be enhanced by treatment of input DNA. Proc Natl Acad Sci U S A. 81, 31533157. 
Lloyd, R.G. \& Sharples, G.J. 1993. Dissociation of synthetic Holliday junctions by E. coli RecG protein. Embo J. 12, 17-22.

Lloyd, R.G. 1991. Conjugational recombination in resolvase-deficient ruvC mutants of Escherichia coli K-12 depends on recG. J Bacteriol. 173, 54145418.

McGlynn, P. \& Lloyd, R.G. 2001. Action of RuvAB at replication fork structures. J Biol Chem. 276, 41938-41944.

McGlynn, P. \& Lloyd, R.G. 2002. Genome stability and the processing of damaged replication forks by RecG. Trends Genet. 18, 413-419.

Niki, H., Ichinose, C., Ogura, T., Mori, H., Morita, M., Hasegawa, M., Kusukawa, N. \& Hiraga, S. 1988. Chromosomal genes essential for stable maintenance of the mini-F plasmid in Escherichia coli. J Bacteriol. 170, 5272-5278.

Norgard, M.V., Keem, K. \& Monahan, J.J. 1978. Factors affecting the transformation of Escherichia coli strain chi1776 by pBR322 plasmid DNA. Gene. 3, 279-292.

Radman, M. 1975. SOS repair hypothesis: phenomenology of an inducible DNA repair which is accompanied by mutagenesis. Basic Life Sci. 5A, 355-367.

Roberts, R.J. \& Strike, P. 1981. Efficiency of Escherichia coli repair processes on uv-damaged transforming plasmid DNA. Plasmid. 5, 213-220.

Roberts, R.J. \& Strike, P. 1986. Repair in E. coli of transforming plasmid DNA damaged by psoralen plus near-ultraviolet irradiation. Mutat Res. 165, 8188. 
Roychoudhury, A., Basu, S. \& Sengupta, D.N. 2009. Analysis of comparative efficiencies of different transformation methods of E. coli using two common plasmid vectors. Indian J Biochem Biophys. 46, 395-400.

Saffran, W.A. \& Cantor, C.R. 1984. Mutagenic SOS repair of site-specific psoralen damage in plasmid pBR322. J Mol Biol. 178, 595-609.

Sassanfar, M. \& Roberts, J.W. 1990. Nature of the SOS-inducing signal in Escherichia coli. The involvement of DNA replication. J Mol Biol. 212, 79-96.

Schmid, S.E., Daune, M.P. \& Fuchs, R.P. 1982. Repair and mutagenesis of plasmid DNA modified by ultraviolet irradiation or N-acetoxy-N-2acetylaminofluorene. Proc Natl Acad Sci U S A. 79, 4133-4137.

Setlow, R.B., Swenson, P.A. \& Carrier, W.L. 1963. Thymine dimers and Inhibition of DNA synthesis by ultraviolet irradiation of cells. Science. 142, 1464-1466.

Strike, P., Humphreys, G.O. \& Roberts, R.J. 1979. Nature of transforming deoxyribonucleic acid in calcium-treated Escherichia coli. J Bacteriol. 138, 1033-1035.

Strike, P. \& Roberts, R.J. 1982. Resident enhanced repair: novel repair process action on plasmid DNA transformed into Escherichia coli K-12. J Bacteriol. 150, 385-388.

Summers, D.K. \& Sherratt, D.J. 1984. Multimerization of high copy number plasmids causes instability: ColE1 encodes a determinant essential for plasmid monomerization and stability. Cell. 36, 1097-1103. 
van der Ende, A., Baker, T.A., Ogawa, T. \& Kornberg, A. 1985. Initiation of enzymatic replication at the origin of the Escherichia coli chromosome: primase as the sole priming enzyme. Proc Natl Acad Sci U S A. 82, 39543958.

Wang, X., Peterson, C.A., Zheng, H., Nairn, R.S., Legerski, R.J. \& Li, L. 2001. Involvement of nucleotide excision repair in a recombination-independent and error-prone pathway of DNA interstrand cross-link repair. Mol Cell Biol. $21,713-720$.

Watson, N. 1988. A new revision of the sequence of plasmid pBR322. Gene. 70, 399-403.

West, S.C. 1996. The RuvABC proteins and Holliday junction processing in Escherichia coli. J Bacteriol. 178, 1237-1241.

Willetts, N.S. \& Clark, A.J. 1969. Characteristics of some multiply recombinationdeficient strains of Escherichia coli. J Bacteriol. 100, 231-239.

Yoshida, N. \& Sato, M. 2009. Plasmid uptake by bacteria: a comparison of methods and efficiencies. Appl Microbiol Biotechnol. 83, 791-798.

Yu, D., Ellis, H.M., Lee, E.C., Jenkins, N.A., Copeland, N.G. \& Court, D.L. 2000. An efficient recombination system for chromosome engineering in Escherichia coli. Proc Natl Acad Sci U S A. 97, 5978-5983. 


\title{
Chapter 3
}

Fate of the Replisome Following Arrest by DNA Damage in Escherichia coli

\begin{abstract}
Accurate replication in the presence of DNA damage is critical to maintaining genomic stability and viability in all cells. In Escherichia coli, the DNA at replication forks blocked by UV-induced damage undergoes a partial resection of the nascent lagging strand and RecF-catalyzed regression of its branch point to allow for lesion removal or bypass before synthesis resumes (Courcelle and Hanawalt, 1999; Courcelle et al., 1997; Courcelle et al., 2003). These processing events generate distinct structural intermediates that can be visualized in vivo using 2-dimensional agarose gels. However, the fate and composition of the replisome itself remains a central uncharacterized question. Here, we use thermosensitive mutants to show that following encounters with DNA damage, the polymerases uncouple and transiently dissociate from the replisome, while the DNA helicase complex remains associated with the replication fork. Disruption of either the $\alpha$ (DnaE), $\beta$ (DnaN), or $\tau$ (DnaX) subunits of the replisome is sufficient to induce the DNA structural intermediates and RecFmediated processing that occurs following encounters with UV-induced damage. By contrast, disruption of the DNA helicase (DnaB), or primase (DnaG) leads to abnormal intermediates and events that are not observed following DNA damage, arguing that these subunits remain associated throughout the recovery
\end{abstract}


process. We propose that polymerase dissociation provides a mechanism for access to the obstructing lesion, while the DNA helicase complex retains the licensing and integrity of the fork, directing replisome reassembly to the appropriate location once the obstruction is processed.

\section{Introduction}

The replisome is made up of several multi-subunit protein complexes and is responsible for duplicating the genome. In E. coli, it is comprised of three DNA polymerase complexes tethered to the DNA template by processivity factors, a $\tau$ complex that couples leading and lagging strand synthesis, and a helicaseprimase complex that separates the duplex DNA and primes lagging strand synthesis ((Mclnerney et al., 2007; O'Donnell, 2006; Reyes-Lamothe et al., 2010) and Figure 3.1A). When the replisome encounters DNA damage that blocks its progression, the potential for mutagenesis, rearrangements, and lethality increases significantly. Replication in the presence of DNA damage generates mutations if the wrong base is incorporated, rearrangements if it resumes from the wrong site, or lethality if the obstructing lesion cannot be overcome. Following arrest of replication at UV-induced damage, the nascent lagging strand is partially resected by the combined action of the RecQ helicase and RecJ nuclease, and the RecF-O-R proteins along with RecA limit this degradation and promote a transient regression of the DNA branch point which is thought to be important for restoring the damaged region to a form that can be accessed by repair enzymes 
or translesion polymerases (Courcelle et al., 2003; Courcelle et al., 2006). These processing events generate distinct structural intermediates on the DNA that can be readily visualized using two-dimensional (2-D) agarose gel analysis, a technique that allows one to identify the shape and structure of DNA molecules (Courcelle et al., 2003; Friedman and Brewer, 1995).

Although the processing that occurs on the DNA is well characterized, little is known about the behavior or composition of the replisome itself during these events. If the replisome remains bound to the arresting lesion, it may sterically obstruct repair or bypass from occurring. Conversely, complete dissociation of the replisome would likely abolish the licensing for the replication fork and expose DNA ends that have the potential to recombine- generating deletions, reduplications, or rearrangements on the chromosome. Recent studies in vitro have suggested that dynamic interactions between replisome components play a role in allowing the machinery to overcome specific challenges such as collisions with the transcription machinery (Furukohri et al., 2008; Langston et al., 2009; O'Donnell, 2006). Thus, it seems likely that specific components of the replisome may dissociate upon encountering a blocking DNA lesion, and that this may be necessary or serve as a signal to allow lesion processing to occur. To determine how the replisome behaves or is modified following encounters with DNA damage in vivo, we used thermosensitive mutants to deliberately disrupt specific components of the replisome and then asked if the loss of that component induced replication fork processing, similar to that seen when replication 
encounters DNA damage.

\section{Materials and Methods}

Strain Construction. The strains used in this study are presented in Table 3.1. Our wild type strain has the genotype: lambda-, thyA36, deoC2, IN(rrnD-rrnE)1, rph and has been described previously (Jensen, 1993). Double mutants were constructed using standard P1 transduction. Standard electroporation with $50 \mathrm{ng} / \mu \mathrm{L}$ of pBR322 was used for transformation of these strains. pBR322 has been described previously (Watson, 1988). Transductants were verified via selection using antibiotics and sensitivity to temperature shift when appropriate. Antibiotics used: Ampicillin $100 \mu \mathrm{g} / \mathrm{mL}$ for transformants containing pBR322, Tetracycline $16 \mu \mathrm{g} / \mathrm{mL}$ for transductants.

Tracking Rate of DNA Synthesis via [ $\left.{ }^{3} \mathrm{H}\right]$-Thymidine Incorporation.

For UV experiments, fresh overnight cultures of wild type cells were diluted 1:100 and grown in Davis medium supplemented with $0.4 \%$ glucose, $0.2 \%$ casamino acid, and $10 \mu \mathrm{g} / \mathrm{mL}$ thymine (DGCthy) to an OD600 of 0.4 in a $30^{\circ} \mathrm{C}$ shaking water bath at which time the culture was split in half. Half of the culture was irradiated with $55 \mathrm{~J} / \mathrm{m} 2 \mathrm{UV}$, while the other half was mock irradiated. Duplicate $0.5-\mathrm{mL}$ aliquots of the culture were pulse-labeled with $\left[{ }^{3} \mathrm{H}\right]$ thymidine $(1.0 \mu \mathrm{Ci} / 10$ $\mu \mathrm{g} / \mathrm{mL}$ ) for $2 \mathrm{~min}$ at the indicated times. Following pulse-labeling, the cells were lysed and the DNA was precipitated by addition of $5 \mathrm{~mL}$ of ice-cold $5 \%$ trichloroacetic acid. The precipitate was then collected on Fisherbrand $2.5-\mathrm{cm}$ 
glass fiber filters, and the amount of radioactivity in each sample was measured via liquid scintillation counter. Raw counts were normalized to the -10 min time point in both treatments. For temperature shift experiments, fresh overnight cultures were diluted 1:100 and grown in DGCthy to an OD600 of 0.4 in a $30^{\circ} \mathrm{C}$ shaking water bath at which time the culture was split in half. Half of the culture was immediately filtered and resuspended in fresh media that had been prewarmed to $42{ }^{\circ} \mathrm{C}$ while the other half was filtered and returned to fresh media that had been pre-warmed to $30^{\circ} \mathrm{C}$. Duplicate $0.5-\mathrm{mL}$ aliquots of the culture were pulse-labeled with $\left[{ }^{3} \mathrm{H}\right]$ thymidine $(1.0 \mu \mathrm{Ci} / 10 \mu \mathrm{g} / \mathrm{mL})$ for $2 \mathrm{~min}$ at the indicated times. Following pulse-labeling, the cells were lysed and the DNA was precipitated by addition of $5 \mathrm{~mL}$ of ice-cold $5 \%$ trichloroacetic acid. The precipitate was then collected on Fisherbrand $2.5-\mathrm{cm}$ glass fiber filters, and the amount of radioactivity in each sample was measured via liquid scintillation counter. Raw counts were normalized to the -10 min time point in both treatments.

Two-dimensional Agarose Gel Electrophoresis. Fresh overnight cultures containing pBR322 were grown in Ampicillin. Cultures were then diluted $1 / 100$ and grown in DGCthy without antibiotic to an $\mathrm{OD}_{600}$ of $\sim 0.4$ in a $30^{\circ} \mathrm{C}$ shaking water bath. At this time, cultures were split in half and one half was irradiated with $55 \mathrm{~J} / \mathrm{m}^{2}$ of $\mathrm{UV}$ and returned to the $30^{\circ} \mathrm{C}$ shaking water bath while the other half was filtered, and resuspended in media that had been pre-warmed to $42^{\circ} \mathrm{C}$. During the recovery, $0.15 \mathrm{ml}$ aliquots of the cultures were taken at the 
indicated times and transferred to $0.75 \mathrm{ml}$ ice-cold NET buffer (100 mM NaCl, 20 mM EDTA, pH 8.0, $10 \mathrm{mM}$ Tris, $\mathrm{pH}$ 8.0).

To purify DNA, cells were pelleted, resuspended in $0.15 \mathrm{ml}$ of lysis buffer (1.5 mg/ml lysozyme, $0.5 \mathrm{mg} / \mathrm{ml}$ RNAse A in $10 \mathrm{mM}$ Tris, $\mathrm{pH}$ 8.0, $1 \mathrm{mM}$ EDTA, $\mathrm{pH}$ 8.0) and incubated at $37^{\circ} \mathrm{C}$ for $30 \mathrm{~min}$ at which point $10 \mu \mathrm{l}$ of $10 \mathrm{mg} / \mathrm{ml}$ Proteinase $\mathrm{K}$ and $10 \mu \mathrm{l}$ of $20 \%$ Sarkosyl was added to the samples and returned to $37^{\circ} \mathrm{C}$ for an additional $30 \mathrm{~min}$. Samples were then extracted with 2 volumes of phenol:chloroform (1:1), followed by an extraction with 4 volumes of chloroform. The samples were then dialyzed with $200 \mathrm{ml}$ of TE $(2 \mathrm{mM}$ Tris, $\mathrm{pH} 8.0,1 \mathrm{mM}$ EDTA, $\mathrm{pH}$ 8.0) for 30-45mins on a floating 47-mm Whatman 0.05-mm pore disk, and digested with Pvull (Fermentas) overnight at $37^{\circ} \mathrm{C}$. Samples were extracted with an equal volume of chloroform and loaded directly into a gel.

The DNA was separated initially on a $0.4 \%$ agarose gel in 1 X TBE at 1 V/cm for 16 hours. For the second dimension, lanes were excised from the gel, rotated $90^{\circ}$, recast in a $1 \%$ agarose gel in 1 X TBE and underwent electrophoresis at $7 \mathrm{~V} / \mathrm{cm}$ for 6-7 hours. DNA in the gels was transferred to Hybond N (GE BioSciences) membrane using standard Southern blotting protocols. The plasmid DNA was detected by probing with ${ }^{32} \mathrm{P}$-labeled pBR322 prepared via nick translation kit (Roche) and visualized using a Storm 840 phosphorimager (GE Biosciences) and its associated ImageQuant analysis software.

Nascent DNA Degradation Assay. Fresh overnight cultures were diluted $1: 100$ and grown in DGCthy and $\left[{ }^{14} \mathrm{C}\right]$ thymine $(0.1 \mu \mathrm{Ci} / 10 \mu \mathrm{g} / \mathrm{mL})$ to an OD600 
of 0.4 in a $30^{\circ} \mathrm{C}$ shaking water bath. Cultures were then pulse labeled with $\left[{ }^{3} \mathrm{H}\right]$ thymidine $(1 \mu \mathrm{Ci} / 10 \mu \mathrm{g} / \mathrm{mL})$ for $5 \mathrm{~s}$, filtered on Whatman $0.4-\mu \mathrm{m}$ membrane filters, and washed twice with $3 \mathrm{~mL}$ of cold NET buffer $(100 \mathrm{mM} \mathrm{NaCl}, 10 \mathrm{mM}$ Tris ( $\mathrm{pH}$ 8.0), and $1 \mathrm{mM}$ ethylenediaminetetraacetic acid). For UV experiments, the filter was then resuspended in prewarmed nonradioactive DGCthy media, immediately UV irradiated with $30 \mathrm{~J} / \mathrm{m} 2$ (Sylvania 15-W germicidal lamp, $254 \mathrm{~nm}$, $0.9 \mathrm{~J} / \mathrm{m} 2 / \mathrm{s}$ incident dose), and incubated in a $30^{\circ} \mathrm{C}$ shaking water bath. For temperature shift experiments, the filter was instead immediately resuspended in fresh media that had been pre-warmed to $42^{\circ} \mathrm{C}$. For both experiments, at the times indicated, duplicate $200-\mu \mathrm{L}$ aliquots of the culture (triplicate at time 0 ) were taken. Cells were lysed, and the DNA was precipitated by addition of $5 \mathrm{~mL}$ of icecold $5 \%$ trichloroacetic acid and then collected on Fisherbrand $2.5-\mathrm{cm}$ glass fiber filters. The amount of radioactivity in each filter was determined using a liquid scintillation counter.

\section{Results}

A schematic of each of the components of the replisome tested in this study and their function is presented in Figure 3.1A. Temperature-sensitive mutants exist for each of these components in which viability or functionality is supported at $30^{\circ} \mathrm{C}$, but not at $42^{\circ} \mathrm{C}$ (Figure 3.1B). Although replication proceeds normally at the permissive temperature, it is rapidly disrupted following inactivation of the proteins at the restrictive temperature (Figure 3.1C). The 
exception to this is the proofreading subunit $\varepsilon$, encoded by $d n a Q$, which is mutagenic at the restrictive temperature, but is not essential for viability or replication (Scheuermann et al., 1983).

These thermosensitive mutants were used to visualize the processing intermediates at the replication fork DNA, in vivo, on replicating fragments of the plasmid pBR322 (Figure 3.2A and B). pBR322 replicates using the host's replication machinery, can be linearized at its single origin of replication, and maintains a moderate copy number, making it useful to detect rare events such as replication through a defined fragment (Martin-Parras et al., 1991). Here, we examine the structural intermediates induced following disruption of each of the components of the replisome and compare them to those induced following arrest by UV lesions. To this end, mid-log cultures of each thermosensitive mutant containing the plasmid were either filtered and resuspended in media prewarmed to the restrictive temperature or UV-irradiated with $50 \mathrm{~J} / \mathrm{m}^{2}$, a dose which produces an average of one lesion per plasmid strand and where greater than $90 \%$ of cells survive (Courcelle et al., 2003). Aliquots of the cultures from each treatment were then taken at various times during the recovery period, and total genomic DNA was purified, digested with a restriction endonuclease to linearize the plasmid at its origin of replication, and examined following 2D agarose-gel electrophoresis. In this type of analysis, actively replicating molecules appear as "Y"-shaped structures that migrate in an arc that extends out from the prominent spot of nonreplicating linear molecules (Figure 3.2A and B). When replication 
forks encounter UV-induced damage, the transient regression and other processing events associated with the recovery process generate intermediates having two branch points, forming double-"Y" or "X"-shaped molecules which migrate more slowly due to their nonlinear shape, forming a cone region above the arc of replicating molecules (Figure 3.2A and B).

At the permissive temperature, only normal "Y"-shaped replication intermediates were observed before treatment in all mutants, and normal damage-induced processing of the replication fork occurred after UV damage, as evidenced by the timely appearance of cone region intermediates in each mutant (Figure 3.2 and 3.5). These data show that the existence of any of the thermosensitive alleles do not disrupt normal replication or lesion processing.

Following disruption of either $\alpha$ (DnaE), the catalytic subunit of the DNA polymerase, or $\beta$ (DnaN), the processivity factor that tethers the DNA polymerase to the DNA template, by temperature shift, processing intermediates were induced at the replication fork that appeared similar to those seen after UV irradiation (Figure 3.2C). Both $\alpha$ and $\beta$ are required to maintain DNA polymerase binding to the DNA template (Marians et al., 1998; Stukenberg et al., 1991). These data indicate that processing intermediates were induced specifically by the disruption of the Pol III subunits because no processing intermediates were induced either in wild-type cells at the restrictive temperature or following disruption of the nonessential proofreading subunit, $\varepsilon$ (DnaQ) (Figure 3.2 and 3.5). Similar to the polymerase subunits, UV-like processing intermediates were 
also induced following disruption of $\tau$ (DnaX) (Figure 3.2C), which is responsible for coupling leading and lagging strand synthesis and repetitive cycling of the processivity factors during lagging strand synthesis (Glover et al., 2001). The induction of UV-like intermediates following the disruption of the DNA polymerase or coupling factor indicates that the processing of replication forks at UV-induced damage is likely to involve the dissociation of these subunits from the DNA and replisome.

The helicase-primase complex interacts with $\tau$ and the holoenzyme and tracks along the lagging strand template, serving to unwind and prime it during replication (Glover et al., 2001; LeBowitz and McMacken, 1986). Disruption of either the helicase (DnaB) or primase (DnaG) led to the production of abnormal structural intermediates that were unlike any of those that are induced during the processing of UV lesions suggesting that dissociation of the helicase does not normally occur during the recovery of replication following UV damage (Figure 3.2D and 3.5).

The results described above indicate that the dissociation of the polymerase induces structural intermediates similar to those observed during the recovery of replication after UV irradiation but that dissociation of the helicase does not occur. Following arrest by UV irradiation, the integrity of the replication fork is maintained and the nascent DNA at the arrested replication fork undergoes only limited degradation prior to resumption of replication (Courcelle and Hanawalt, 1999; Hanawalt and Brempelis, 1967). To further characterize the 
events that occur after dissociation of the polymerase or helicase, we examined whether and to what extent the degradation of nascent DNA occurs at the replication fork in these mutants. To this end, wild type, $d n a B$ and $d n a E$ cultures prelabled with $\left[{ }^{14} \mathrm{C}\right]$ thymine, were pulse-labeled with $\left[{ }^{3} \mathrm{H}\right]$ thymidine for 20 seconds, then filtered, resuspended in fresh media and either UV-irradiated or shifted to the restrictive temperature. Following inactivation of DnaE, we observed limited degradation of nascent DNA at the replication fork indicating that polymerase disruption occurs without compromising the integrity of the replication fork. By contrast, following disruption of the helicase complex, we observed extensive degradation of the fork DNA, indicating that helicase disruption leads to a loss of replication fork integrity, suggesting that the abnormal intermediates are associated with the collapse and degradation of the fork (Figure 3.3A). Neither the abnormal structural intermediates nor the extensive degradation of the fork are observed during the processing of replication forks after UV-induced damage, arguing that the helicase complex normally remains associated with the DNA during the recovery process and the fork remains intact.

We have previously shown that the formation of damage-induced intermediates is catalyzed by the RecF pathway gene products, depends on active replication, and resolves at a time that correlates with when the lesions are repaired and replication resumes (Courcelle et al., 2003). In the absence of RecF, the transient regression and structural intermediates fail to form at the 
replication fork following UV-induced damage (Figure 3.3B and 3.3C). To determine if the DNA processing events induced by DNA polymerase dissociation are identical to those occurring after UV-induced damage, we examined whether the intermediates formed after polymerase disruption were also dependent on RecF. Cultures of wild type, $d n a E$ and $d n a B$ mutants containing either a normal copy or a deletion of the recF gene were grown and examined by 2-D agarose gel analysis as described above. In wild type cells, normal UV processing intermediates are observed in the presence of RecF but are not induced in recF mutants indicating that functional RecF protein is required to initiate processing events (Figure 3.3B). Similar to UV, the replication fork processing intermediates induced following temperature shift in $d n a E$ mutants did not appear in the absence of RecF, indicating that dissociation of the polymerase is sufficient and serves as a signal to initiate the RecF-mediated processing that occurs following replication arrest by DNA damage (Figure 3.3B). By contrast, the abnormal intermediates that arise following disruption of the helicase complex appear irrespective of whether RecF is present or absent (Figure 3.3B).

\section{Discussion}

These data indicate that, in vivo, the DNA polymerase transiently dissociates from the replisome, uncoupling leading and lagging strand synthesis, while the helicase-primase complex remains associated with the DNA (Figure 3.4). We propose a model in which polymerase dissociation may be required to 
allow repair enzymes or translesion DNA polymerases to gain access and effect repair as suggested by in vitro and cellular assays (Bichara et al., 2007; Courcelle et al., 2005; Courcelle et al., 2006; Mclnerney and O'Donnell, 2004). Polymerase dissociation can occur without compromising the integrity of the replication fork. Lagging strand synthesis requires constant dissociation and reloading of both the polymerase and the processivity factor (Mclnerney and O'Donnell, 2004). A similar method of dissociation may be required on the leading strand following UV-induced arrest to allow repair of the lesion. Tolerance of the lesion through translesion synthesis can occur but would also require transient dissociation of the replicative polymerase (Indiani et al., 2005). In this scenario, an arrested replicative polymerase would be displaced by a low-affinity translesion polymerase, which would carry out DNA synthesis through the site of the lesion prior to being displaced by the high-affinity replicative polymerase.

In contrast to the polymerases, a number of observations are consistent with the idea that replicative helicases appear to remain associated with the DNA template. One study uses an in vitro model to suggest that compromising the interaction between the helicase and DNA template results in a loss of origin licensing and requires re-initiation at the origin (Nishitani and Lygerou, 2004). Another study has showed that biochemically assembling and maintaining the structure of the replisome is dependent upon the prior assembly of the replicative helicase (Remus et al., 2009). These authors suggest that compromising the assembly of the helicase multimer necessarily compromises the integrity of the 
replisome.

It is also of interest to not that both prokaryotes and eukaryotes tightly regulate helicase loading onto DNA as the limiting step in the mechanism to control replication initiation and licensing regions of DNA for replication (Remus and Diffley, 2009; Sclafani and Holzen, 2007). Once the helicase has been loaded, the remaining components of the replisome are then recruited to this site and replication begins. Retention of the helicase complex at the site of arrest implies cells are able to retain licensing for disrupted replication forks and suggests the helicase serves to signal and recruit replisome reassembly to the correct site once the lesion has been processed.

The broad conservation of replication initiation mechanisms and the replication proteins that comprise the replisome in both prokaryotes and eukaryotes suggest that these results may extend widely to other organisms.

\section{Acknowledgements}

This work was funded by National Institutes of Health/National Institute of Environmental Health research grants (R21ES018940) and (R15ES021594) and an American Heart Association predoctoral fellowship (11PRE6890009) to B.J.S 
Table 3.1. E. coli strains used

\begin{tabular}{|l|l|l|}
\hline $\begin{array}{l}\text { Strain } \\
\text { number }\end{array}$ & Relevant Genotype & $\begin{array}{l}\text { Source, Reference or } \\
\text { Construction }\end{array}$ \\
\hline SR 108 & thyA36, deoC2 & $\begin{array}{l}\text { (Mellon and Hanawalt, } \\
\text { 1989) }\end{array}$ \\
\hline CL 583 & recF6206::tet ${ }^{R}$ & (Courcelle et al., 2003) \\
\hline CRT 266 & dnaB266(ts) & (Kohiyama et al., 1966) \\
\hline E486 & dnaE486(ts) & (Wechsler and Gross, 1971) \\
\hline PC 3 & dnaG3(ts) & (Carl, 1970) \\
\hline MS 101 & dnaN159(ts) & (Sutton, 2004) \\
\hline KH 1366 & dnaQ49(ts) & (Horiuchi et al., 1978) \\
\hline AX 727 & dnaX2016(ts) & (Filip et al., 1974) \\
\hline CL 756 & dnaB266(ts) recF6206:::tet & (Belle et al., 2007) \\
\hline CL 069 & $\begin{array}{l}\text { dnaE486(ts) } \\
\text { recF349tna300::Tn10 }\end{array}$ & $\begin{array}{l}\text { E486 x P1 from HL 919 } \\
\text { (Courcelle et al., 1997) }\end{array}$ \\
\hline pBR322 & & (Bolivar et al., 1977) \\
\hline
\end{tabular}


A)

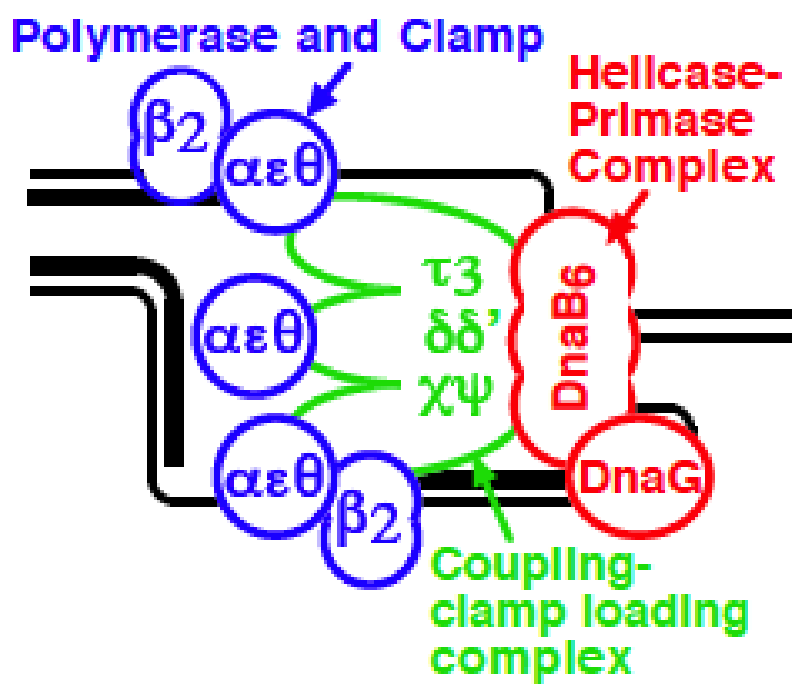

B)

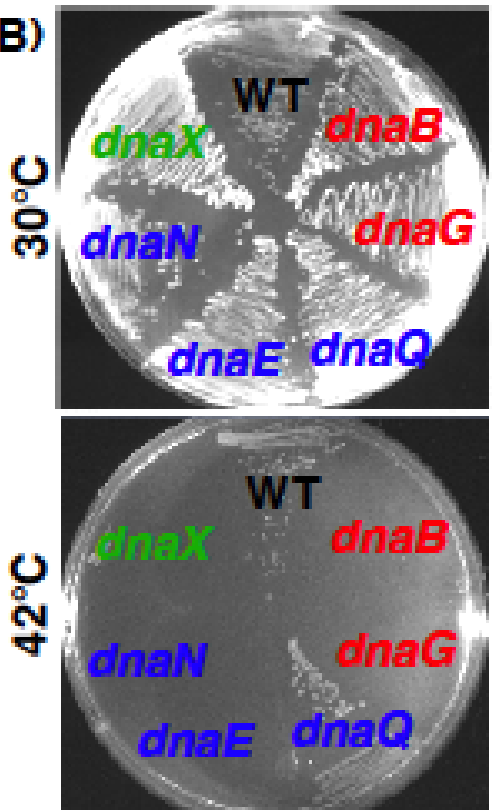

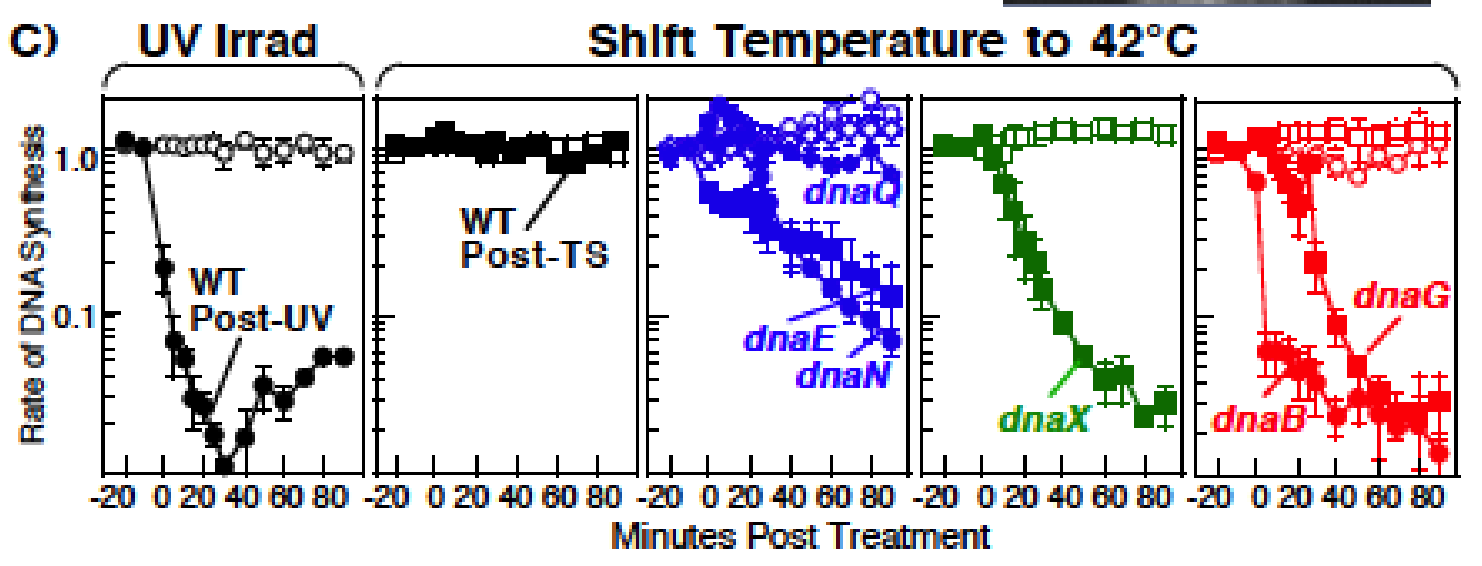

Figure 3.1. Replication is disrupted by UV-induced damage or following inactivation of the polymerase, tau complex, or helicase-primase complex. (A) A diagram of the replisome, indicating the subunits of each protein complex. (B) Thermosensitive mutants that inactivate the polymerase core, tau complex, or helicase complex are viable at $30^{\circ} \mathrm{C}$ but fail to grow at the restrictive temperature of $42^{\circ} \mathrm{C}$ following overnight incubation. (C) The rate of DNA synthesis is inhibited following UV-induced damage or inactivation of the replisome's essential subunits. Wildtype or mutant cultures, grown at $30^{\circ} \mathrm{C}$ were pulse-labeled with 1 "Ci $/ 10^{\prime \prime} \mathrm{g} / \mathrm{ml} 3 \mathrm{H}$-thymidine for two minutes at the indicated times following mock treatment (open symbols), $50 \mathrm{~J} / \mathrm{m} 2 \mathrm{UV}$ irradiation (filled symbols), or a shift to $42^{\circ} \mathrm{C}$ (filled symbols). The amount of radioactivity incorporated into the DNA, relative to pretreated cultures is plotted 8 . Error bars represent standard error of two experiments. 

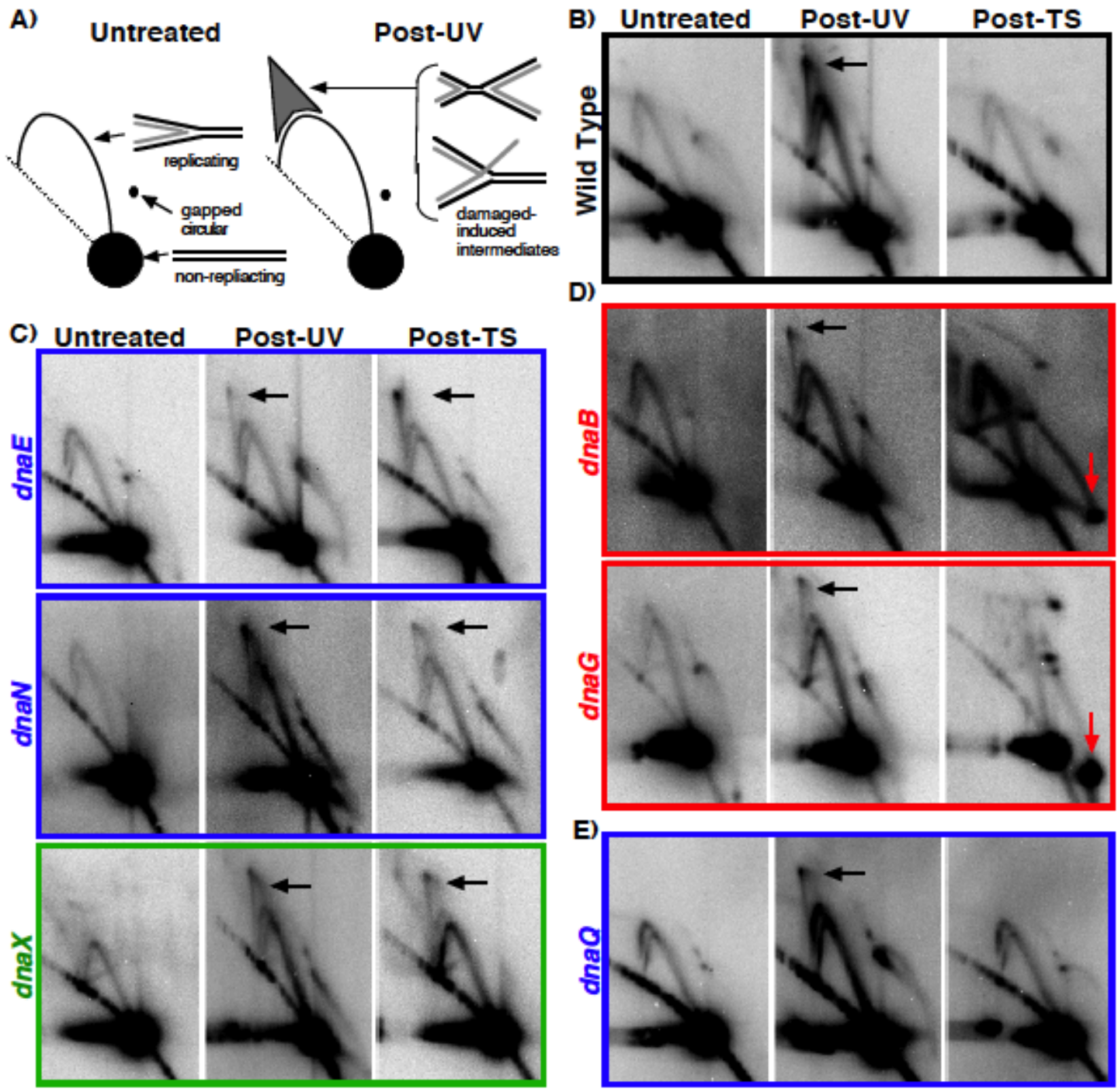

Figure 3.2. Dissociation of the DNA polymerase or $\tau$ complex, but not the helicase complex, induces replication fork processing intermediates similar to UV-induced damage. (A) Diagram depicting the migration pattern of replicating DNA fragments and intermediates associated with processing forks disrupted by UV-induced damage in 2D agarose gels. (B) In wild-type cultures, replication fork processing intermediates are observed after disruption by UV-irradiation but not after a shift to $42^{\circ} \mathrm{C}$. (C) Disruption of the polymerase core (dnaEts), processivity factor ( $d n a N t s)$ or tau $(d n a X t s)$ is sufficient to induce replication fork processing similar to that seen after UV-induced damage. (D) Abnormal intermediates, distinct from any of those associated with processing UVinduced damage, arise after disruption of the helicase ( $d n a B t s)$, or primase (dnaGts). (E) No atypical intermediates are observed following disruption of the nonessential proofreading subunit of the DNA polymerase (dnaQ $t s)$. Strains containing plasmid pBR322 were UV-irradiated with $50 \mathrm{~J} / \mathrm{m} 2$ or filtered and placed in pre-warmed media at $42^{\circ} \mathrm{C}$. Genomic and plasmid DNA was then purified, digested with Pvull, and analyzed by $2 \mathrm{D}$ agarose-gel analysis 15 and 90 min following UV-irradiation or temperature shift, respectively. 

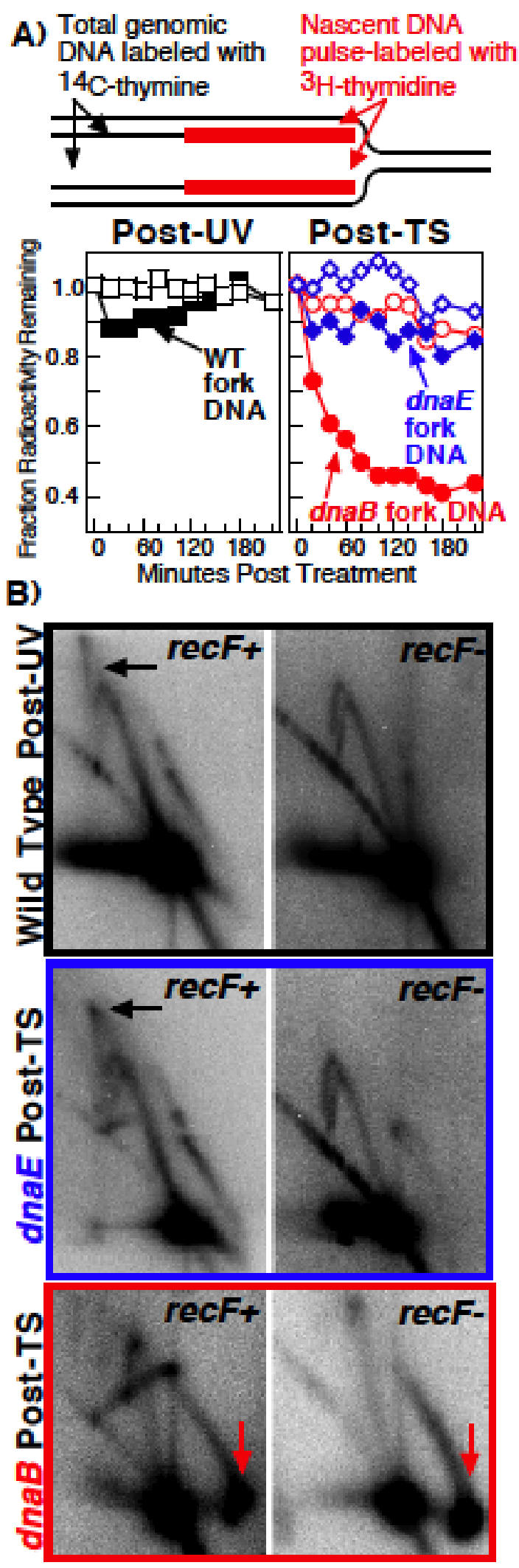

Figure 3.3. Similar to after UV, the integrity of the replication fork DNA is maintained after polymerase dissociation, and the formation of the replication fork intermediates are mediated by RecF. A) The integrity of the replication fork is maintained following arrest by UV irradiation or polymerase dissociation, but collapses after disruption of the helicase. [14C]-thymine prelabeled cultures were pulse-labeled with $\left[{ }^{3} \mathrm{H}\right]$ thymidine for $20 \mathrm{~s}$ before being filtered and placed in nonradioactive media and either UV-irradiated or shifted to $42^{\circ} \mathrm{C}$ as indicated. The amount of radioactivity remaining in the total genomic DNA (open symbols) and nascent DNA at the replicationfork (filled symbols) is plotted over time. B) The formation and processing of the replication intermediates after polymerase dissociation are mediated by RecF, similar to UV. The formation of the abnormal intermediates that arise following helicase disruption are not dependent on RecF. Isogenic wild-type, dnaBts and dnaEts cultures containing a normal or mutated copy of the recF gene were UV-irradiated or temperature shifted and analyzed by $2 \mathrm{D}$ agarose gel analysis as in Figure 3.2. 

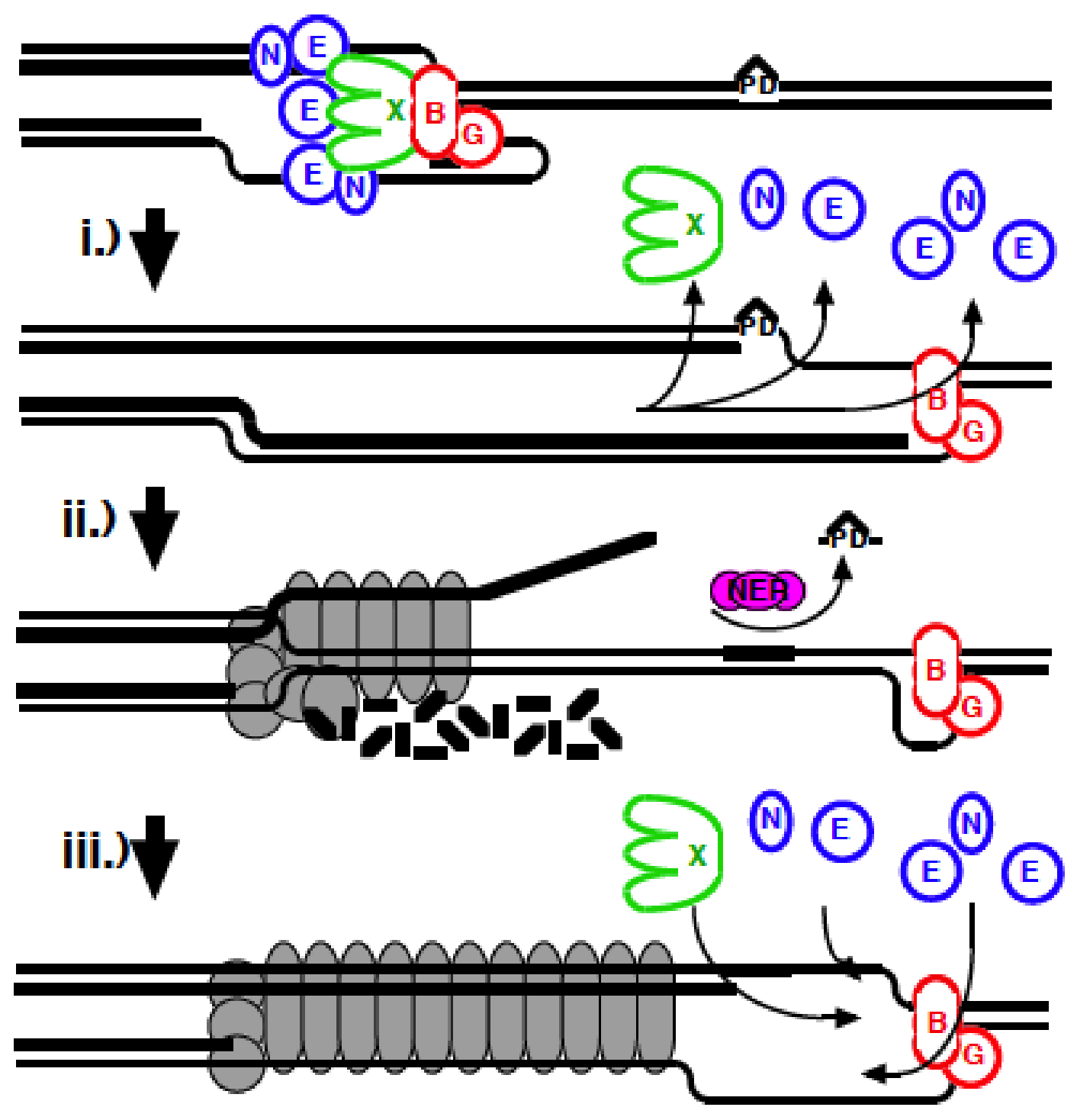

Figure 3.4. Model of Replisome at UV-induced damage. Upon encountering an arresting lesion (i), DNA synthesis becomes uncoupled and the polymerases transiently dissociate. (ii) This serves as a signal to initiate the replication fork DNA processing by the RecF pathway gene products (gray circles) allowing repair enzymes (NER) or translesion polymerases (not shown) to access the lesion. (iii) The helicase-primase complex remains bound to the template DNA and serves to maintain the licensing and integrity of the replication fork, directing replisome reassembly to the correct location once the lesion has been processed. 

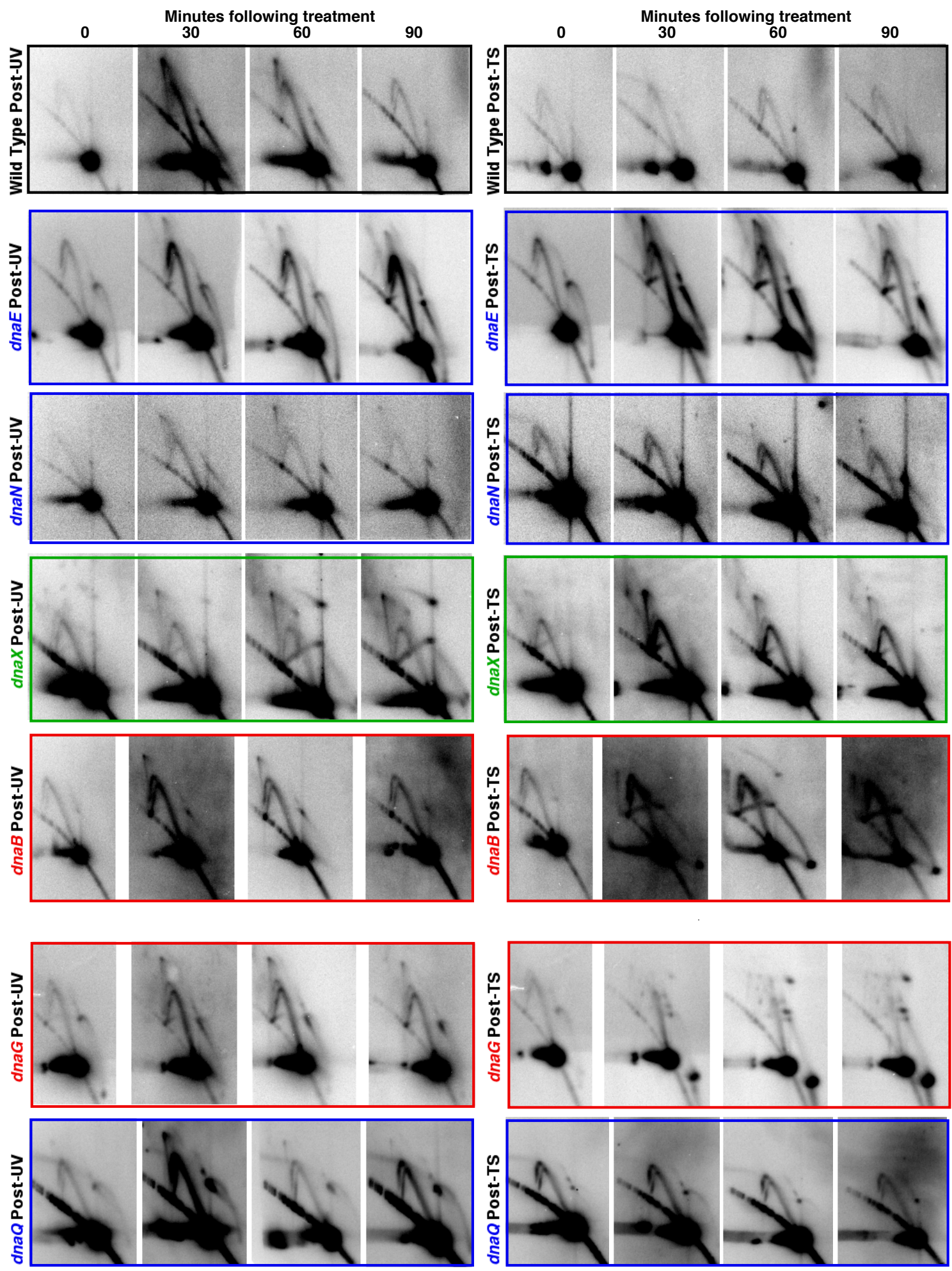

Figure 3.5. Persistence of structural intermediates that accumulate following UV exposure or inactivation by temperature shift. Aliquots each culture were taken at $0,30,60$ and 90 minutes following treatment and subject to 2-D agarose gel analysis. 


\section{References}

Bichara, M., Pinet, I., Lambert, I.B. \& Fuchs, R.P. 2007. RecA-mediated excision repair: a novel mechanism for repairing DNA lesions at sites of arrested DNA synthesis. Mol Microbiol. 65, 218-229.

Clark, J.M. \& Hanawalt, P.C. 1984. Replicative intermediates in UV-irradiated simian virus 40. Mutat Res. 132, 1-14.

Courcelle, C.T., Belle, J.J. \& Courcelle, J. 2005. Nucleotide excision repair or polymerase V-mediated lesion bypass can act to restore UV-arrested replication forks in Escherichia coli. J Bacteriol. 187, 6953-6961.

Courcelle, C.T., Chow, K.H., Casey, A. \& Courcelle, J. 2006. Nascent DNA processing by RecJ favors lesion repair over translesion synthesis at arrested replication forks in Escherichia coli. Proc Natl Acad Sci U S A. 103, 9154-9159.

Courcelle, J., Donaldson, J.R., Chow, K.H. \& Courcelle, C.T. 2003. DNA

Damage-Induced Replication Fork Regression and Processing in Escherichia coli. Science. 299, 1064-1067.

Courcelle, J. \& Hanawalt, P.C. 1999. RecQ and RecJ process blocked replication forks prior to the resumption of replication in UV-irradiated Escherichia coli. Mol Gen Genet. 262, 543-551.

Courcelle, J., Carswell-Crumpton, C. \& Hanawalt, P.C. 1997. recF and recR are required for the resumption of replication at DNA replication forks in Escherichia coli. Proc Natl Acad Sci U S A. 94, 3714-3719. 
Friedman, K.L. \& Brewer, B.J. 1995. Analysis of replication intermediates by twodimensional agarose gel electrophoresis. Methods Enzymol. 262, 613-627.

Furukohri, A., Goodman, M.F. \& Maki, H. 2008. A dynamic polymerase exchange with Escherichia coli DNA polymerase IV replacing DNA polymerase III on the sliding clamp. J Biol Chem. 283, 11260-11269.

Glover, B.P., Pritchard, A.E. \& McHenry, C.S. 2001. tau binds and organizes Escherichia coli replication proteins through distinct domains: domain III, shared by gamma and tau, oligomerizes DnaX. J Biol Chem. 276, 3584235846 .

Hanawalt, P. \& Brempelis, I. 1967. Selective Degradation of Newly-Replicated DNA after Inhibition of DNA synthesis in Escherichia coli. Proceedings of the 7th International Congress of Biochemistry, Japan. 650.

Indiani, C., Mclnerney, P., Georgescu, R., Goodman, M.F. \& O'Donnell, M. 2005. A sliding-clamp toolbelt binds high- and low-fidelity DNA polymerases simultaneously. Mol Cell. 19, 805-815.

Jensen, K.F. 1993. The Escherichia coli K-12 "wild types" W3110 and MG1655 have an rph frameshift mutation that leads to pyrimidine starvation due to low pyrE expression levels. J Bacteriol. 175, 3401-3407.

Langston, L.D., Indiani, C. \& O'Donnell, M. 2009. Whither the replisome: emerging perspectives on the dynamic nature of the DNA replication machinery. Cell Cycle. 8, 2686-2691. 
LeBowitz, J.H. \& McMacken, R. 1986. The Escherichia coli dnaB replication protein is a DNA helicase. J Biol Chem. 261, 4738-4748.

Marians, K.J., Hiasa, H., Kim, D.R. \& McHenry, C.S. 1998. Role of the core DNA polymerase III subunits at the replication fork. Alpha is the only subunit required for processive replication. J Biol Chem. 273, 2452-2457.

Martin-Parras, L., Hernandez, P., Martinez-Robles, M.L. \& Schvartzman, J.B. 1991. Unidirectional replication as visualized by two-dimensional agarose gel electrophoresis. J Mol Biol. 220, 843-853.

Mclnerney, P., Johnson, A., Katz, F. \& O'Donnell, M. 2007. Characterization of a triple DNA polymerase replisome. Mol Cell. 27, 527-538.

Mclnerney, P. \& O'Donnell, M. 2004. Functional Uncoupling of Twin Polymerases: MECHANISM OF POLYMERASE DISSOCIATION FROM A LAGGING-STRAND BLOCK. J Biol Chem. 279, 21543-21551.

Nishitani, H. \& Lygerou, Z. 2004. DNA replication licensing. Front Biosci. 9, 21152132.

O'Donnell, M. 2006. Replisome architecture and dynamics in Escherichia coli. J Biol Chem. 281, 10653-10656.

Remus, D., Beuron, F., Tolun, G., Griffith, J.D., Morris, E.P. \& Diffley, J.F. 2009. Concerted loading of Mcm2-7 double hexamers around DNA during DNA replication origin licensing. Cell. 139, 719-730.

Remus, D. \& Diffley, J.F. 2009. Eukaryotic DNA replication control: lock and load, then fire. Curr Opin Cell Biol. 21, 771-777. 
Reyes-Lamothe, R., Sherratt, D.J. \& Leake, M.C. 2010. Stoichiometry and architecture of active DNA replication machinery in Escherichia coli. Science. 328, 498-501.

Scheuermann, R., Tam, S., Burgers, P.M., Lu, C. \& Echols, H. 1983. Identification of the epsilon-subunit of Escherichia coli DNA polymerase III holoenzyme as the dnaQ gene product: a fidelity subunit for DNA replication. Proc Natl Acad Sci U S A. 80, 7085-7089.

Sclafani, R.A. \& Holzen, T.M. 2007. Cell cycle regulation of DNA replication. Annu Rev Genet. 41, 237-280.

Stukenberg, P.T., Studwell-Vaughan, P.S. \& O'Donnell, M. 1991. Mechanism of the sliding beta-clamp of DNA polymerase III holoenzyme. J Biol Chem. $266,11328-11334$.

Watson, N. 1988. A new revision of the sequence of plasmid pBR322. Gene. 70, 399-403. 


\section{Chapter 4}

\section{Concluding Remarks}

The main objective of this thesis was to address two questions central to repair and replication processes in an E. coli system. First, I examined whether repair processes that occur on exogenously irradiated plasmids are appropriate models for those that occur on the chromosome in vivo and second, I examined the roles of the replisome during the processing of UV lesions. The ability to visualize DNA structural intermediates provided valuable insights into examining either of these questions and 2-D agarose gel analysis remains a powerful technique for the visualization of DNA structures in vivo. It has been used to characterize a number of the intermediates associated with both replication and repair processes, and in conjunction with other assays has helped elucidate the biochemical mechanisms by which DNA damage is repaired.

The ability to introduce damage exogenously in a site-specific manner would provide a tool which could be used to examine a number of questions relating to precise method of processes for lesions in the leading and lagging strand as well as the differences in processing that may occur between various forms of damage. However, I found distinct differences exist between repair processes that operate on established, endogenous DNA versus DNA that was newly introduced via transformation. As stated below, the inherent differences 
would make it difficult to use transformation studies as a model for the processing events that occur in the chromosome.

In order to construct a system in which we could examine the differences between the repair processes that act on strand-specific or site-specific lesions, we would need to control for or remove the differences in replication and topology affecting factors between newly introduced plasmids and their endogenously established counterparts. One method is to introduce UV lesions specifically into endogenous plasmids although it is technically challenging to do so without also causing damage to the chromosome. In theory, this method would allow us to directly quantify the effect that lack of each repair protein would have on plasmid survival during replication endogenously. However, the introduction of additional lesions on the chromosome using this method would influence survival of the cell to a greater extent than lesions on the plasmid, particularly in repair mutants. It is possible that some variations in the system could be implemented in order to address these problems.

Another possibility is to add the replication proteins and topology-affecting factors prior to transformation of the UV damaged plasmid thereby eliminating a key difference between the two systems. A limitation of this approach, however, is that transformation efficiency may decrease dramatically when the plasmid is bound to proteins prior to introduction into the cell making quantification difficult. Agents that make the membrane more permeable could be used to increase 
transformation efficiency of protein-bound plasmids in an effort to overcome this limitation.

Yet another possibility is to use cell free extracts in place of host cells thereby eliminating the need for transformation altogether. The technical challenge would involve clean, efficient and consistent recovery of the plasmids following introduction and incubation. It would be important to include a second, undamaged reference plasmid in order to normalize for variation in the recovery of the plasmids. It may be difficult to determine whether the results of this approach provide appropriate model for the repair processes that occur on the chromosome because of the loss of structural integrity of the cell and membrane and its effect on the structure and compartmentalization of endogenous DNA. In the next chapter, I took advantage of the fact that UV-irradiation induces distinct structural intermediates at arrested replication forks. I used the formation of these structural intermediates to characterize the fate and composition of the replisome during the processing events. To this end, thermosensitive alleles for each of the components were used to disrupt their function under lesion-free conditions. The structural intermediates produced by artificial disruption of each component were then compared to those formed during normal lesion processing. The results indicate that dissociation of the polymerase and uncoupling of leading and lagging strand synthesis is sufficient to initiate the same processing events observed following encounter with a UV-lesion. The results also showed that disruption of the helicase-primase complex leads to the 
induction of structural intermediates not observed during the normal recovery of replication after DNA damage, strongly suggesting that the helicase-primase complex remains intact during processing events. This study demonstrates a dynamic replisome in which each of the functional components has a specific role during the repair process. The key finding that the helicase-primase complex is required to remain intact in order to re-establish synthesis following repair as well as retain licensing of the replication origin has not been demonstrated previously in vivo. The findings imply that rather than the replisome being a static, steric barrier for repair, it can function as a modular unit to facilitate repair without compromising the integrity of the ongoing fork.

We interpret the requirement for RecF in the generation of structural intermediates following polymerase inactivation to indicate the initiation of a repair-associated response. However, an alternative interpretation of this data could be developed. It is possible that a previously unknown function for the RecF protein exists in which RecF is involved in DNA metabolism or structural processing and doesn't require a repair response for this particular function.

We also interpret our data to suggest a specific role for each of the components of the replisome during processing of a UV lesion in a modular manner. It may be of further benefit to attempt a more direct approach in the context of our results. Using a similar system in which UV-irradiated plasmid are examined in vivo, it may be possible to directly examine the presence or absence of each of the components of the replisome following arrest. One could use a 
modified ChIP analysis in which proteins are cross-linked to the plasmid DNA following exposure to UV. The proteins bound to the UV irradiated plasmid DNA would then be compared to those bound to un-irradiated plasmids. It would be advantageous to perform this experiment in a repair deficient cell. This would maximize the number of arrested replisomes undergoing processing but not completing repair. Presumably, the replisome would remain in its partially dissociated state until repair was completed and synthesis was allowed to resume. One limitation of this approach is that some of the components of the replisome are not bound to DNA or interact within sufficient proximity that would result in successful crosslinking. This approach may, however, be quite beneficial for direct examination of the helicase-primase complex following arrest. Although the results of these experiments could be largely confirmatory, the experimental parameters could be further modified to address questions related to sitespecificity or sequence-specificity as well as address the potential differences in the processing of a variety of lesions.

The goal of this thesis was to address very fundamental questions regarding the ability of cells to repair DNA damage using 2-D agarose gel analysis. While it is difficult to examine the effects of leading versus lagging strand lesions directly on the genome due to the lack of any reliable methods to introduce strand-specific lesions in vivo, the approaches mentioned above may provide some insights (with certain caveats) but would still require a way to verify that the repair mechanisms observed to operate on plasmids could be 
extrapolated to genomic repair processes. Questions regarding the precise mechanism by which strand-specific or site-specific repair processes following UV-damage still remain, and answers to these basic questions could potentially provide profound insights into phenomena such as mutagenesis, genomic rearrangements and development of cancer phenotypes. 


\section{Terminal References}

Allen, G.C.J. \& Kornberg, A. 1991. Fine balance in the regulation of DnaB helicase by DnaC protein in replication in Escherichia coli. J Biol Chem. 266, 22096-22101.

Alting-Mees, M.A., Sorge, J.A. \& Short, J.M. 1992. pBluescriptll: multifunctional cloning and mapping vectors. Methods Enzymol. 216, 483-495.

Bagg, A., Kenyon, C.J. \& Walker, G.C. 1981. Inducibility of a gene product required for UV and chemical mutagenesis in Escherichia coli. Proc Natl Acad Sci U S A. 78, 5749-5753.

Baker, T.A., Sekimizu, K., Funnell, B.E. \& Kornberg, A. 1986. Extensive unwinding of the plasmid template during staged enzymatic initiation of DNA replication from the origin of the Escherichia coli chromosome. Cell. 45, 5364.

Bassett, C.L. \& Kushner, S.R. 1984. Exonucleases I, III, and V are required for stability of ColE1-related plasmids in Escherichia coli. J Bacteriol. 157, 661664.

Bell, L. \& Byers, B. 1983. Separation of branched from linear DNA by twodimensional gel electrophoresis. Anal Biochem. 130, 527-535.

Berardini, M., Foster, P.L. \& Loechler, E.L. 1999. DNA polymerase II (polB) is involved in a new DNA repair pathway for DNA interstrand cross-links in Escherichia coli. J Bacteriol. 181, 2878-2882. 
Berardini, M., Mackay, W. \& Loechler, E.L. 1997. Evidence for a recombinationindependent pathway for the repair of DNA interstrand cross-links based on a site-specific study with nitrogen mustard. Biochemistry. 36, 3506-3513.

Berk, A.J. \& Clayton, D.A. 1974. Mechanisms of mitochondrial DNA replication in mouse L-cells: Asynchronous replication of strands, segregation of daughter moolecules, aspecets of topology and turnover of an initiation sequence. $\mathrm{J}$ Mol Bio. 86, 801-824

Berry, D. \& Kropinski, A.M. 1986. Effect of lipopolysaccharide mutations and temperature on plasmid transformation efficiency in Pseudomonas aeruginosa. Can J Microbiol. 32, 436-438.

Bichara, M., Fuchs, R.P., Cordonnier, A. \& Lambert, I.B. 2009. Preferential postreplication repair of DNA lesions situated on the leading strand of plasmids in Escherichia coli. Mol Microbiol. 71, 305-314.

Bichara, M., Pinet, I., Lambert, I.B. \& Fuchs, R.P. 2007. RecA-mediated excision repair: a novel mechanism for repairing DNA lesions at sites of arrested DNA synthesis. Mol Microbiol. 65, 218-229.

Biek, D.P. \& Cohen, S.N. 1986. Identification and characterization of recD, a gene affecting plasmid maintenance and recombination in Escherichia coli. J Bacteriol. 167, 594-603.

Biek, D.P. \& Cohen, S.N. 1992. Propagation of pSC101 plasmids defective in binding of integration host factor. J Bacteriol. 174, 785-792. 
Bork, J.M., Cox, M.M. \& Inman, R.B. 2001. The RecOR proteins modulate RecA protein function at $5^{\prime}$ ends of single- stranded DNA. Embo J. 20, 7313-7322.

Brewer, B.J. \& Fangman, W.L. 1987. The localization of replication origins on ARS plasmids in S. cerevisiae. Cell. 51, 463-471.

Brewer, B.J. \& Fangman, W.L. 1988. A replication fork barrier at the 3 ' end of yeast ribosomal RNA genes. Cell. 55, 637-643.

Brown, T.A., Cecconi, C., Tkachuk, A.N., Bustamante, C. \& Clayton, D.A. 2005. Replication of mitochondrial DNA occurs by strand displacement with alternative light-strand origins, not via a strand-coupled mechanism. Genes and Dev. 19, 2466-2476

Carl, P.L. 1970. Escherichia coli mutants with temperature-sensitive synthesis of DNA. Mol Gen Genet. 109, 107-122.

Chang, P. \& Marians, K.J. 2000. Identification of a region of Escherichia coli DnaB required for functional interaction with DnaG at the replication fork. J Biol Chem. 275, 26187-26195.

Cherepanov, P.P. \& Wackernagel, W. 1995. Gene disruption in Escherichia coli: TcR and KmR cassettes with the option of Flp-catalyzed excision of the antibiotic-resistance determinant. Gene. 158, 9-14.

Chow, K.H. \& Courcelle, J. 2004. RecO Acts with RecF and RecR to Protect and Maintain Replication Forks Blocked by UV-induced DNA Damage in Escherichia coli. J Biol Chem. 279, 3492-3496. 
Chow, K.H. \& Courcelle, J. 2007. RecBCD and RecJ/RecQ initiate DNA degradation on distinct substrates in UV-irradiated Escherichia coli. Radiat Res. 168, 499-506.

Clark, A.J. \& Margulies, A.D. 1965. Isolation and Characterization of Recombination-Deficient Mutants of Escherichia coli K12. Proc Natl Acad Sci U S A. 53, 451-459.

Clark, J.M. \& Hanawalt, P.C. 1984. Replicative intermediates in UV-irradiated simian virus 40. Mutat Res. 132, 1-14.

Couch, J. \& Hanawalt, P.C. 1967. DNA repair replication in temperature-sensitive DNA synthesis deficient bacteria. Biochem Biophys Res Commun. 26, 779784.

Courcelle, C.T., Belle, J.J. \& Courcelle, J. 2005. Nucleotide excision repair or polymerase V-mediated lesion bypass can act to restore UV-arrested replication forks in Escherichia coli. J Bacteriol. 187, 6953-6961.

Courcelle, C.T., Chow, K.H., Casey, A. \& Courcelle, J. 2006. Nascent DNA processing by RecJ favors lesion repair over translesion synthesis at arrested replication forks in Escherichia coli. Proc Natl Acad Sci U S A. 103, 9154-9159.

Courcelle, J., Crowley, D.J. \& Hanawalt, P.C. 1999. Recovery of DNA replication in UV-irradiated Escherichia coli requires both excision repair and recF protein function. J Bacteriol. 181, 916-922. 
Courcelle, J., Donaldson, J.R., Chow, K.H. \& Courcelle, C.T. 2003. DNA

Damage-Induced Replication Fork Regression and Processing in

Escherichia coli. Science. 299, 1064-1067.

Courcelle, J., Ganesan, A.K. \& Hanawalt, P.C. 2001. Therefore, what are recombination proteins there for? Bioessays. 23, 463-470.

Courcelle, J. \& Hanawalt, P.C. 1999. RecQ and RecJ process blocked replication forks prior to the resumption of replication in UV-irradiated Escherichia coli. Mol Gen Genet. 262, 543-551.

Courcelle, J. \& Hanawalt, P.C. 2001. Participation of recombination proteins in rescue of arrested replication forks in UV-irradiated Escherichia coli need not involve recombination. Proc Natl Acad Sci U S A. 98, 8196-8202.

Courcelle, J. \& Hanawalt, P.C. 2003. RecA-dependent recovery of arrested DNA replication forks. Annu Rev Genet. 37, 611-646.

Courcelle, J., Carswell-Crumpton, C. \& Hanawalt, P.C. 1997. recF and recR are required for the resumption of replication at DNA replication forks in Escherichia coli. Proc Natl Acad Sci U S A. 94, 3714-3719.

Cox, M.M., Morrical, S.W. \& Neuendorf, S.K. 1984. Unidirectional branch migration promoted by nucleoprotein filaments of RecA protein and DNA. Cold Spring Harb Symp Quant Biol. 49, 525-533.

Cunningham, R.P., DasGupta, C., Shibata, T. \& Radding, C.M. 1980. Homologous pairing in genetic recombination: recA protein makes joint 
molecules of gapped circular DNA and closed circular DNA. Cell. 20, 223235.

Datsenko, K.A. \& Wanner, B.L. 2000. One-step inactivation of chromosomal genes in Escherichia coli K-12 using PCR products. Proc Natl Acad Sci U S A. $97,6640-6645$.

Donaldson, J.R., Courcelle, C.T. \& Courcelle, J. 2004. RuvAB and RecG Are Not Essential for the Recovery of DNA Synthesis Following UV-Induced DNA Damage in Escherichia coli. Genetics. 166, 1631-1640.

Donaldson, J.R., Courcelle, C.T. \& Courcelle, J. 2006. RuvABC is required to resolve holliday junctions that accumulate following replication on damaged templates in Escherichia coli. J Biol Chem. 281, 28811-28821.

Dower, W.J., Miller, J.F. \& Ragsdale, C.W. 1988. High efficiency transformation of E. coli by high voltage electroporation. Nucleic Acids Res. 16, 6127-6145.

Duggin, I.G. \& Bell, S.D. 2009. Termination structures in the Escherichia coli chromosome replication fork trap. J Mol Biol. 387, 532-539.

Fangman, W.L. \& Novick, A. 1968. Characterization of two bacterial mutants with temperature-sensitive synthesis of DNA. Genetics. 60, 1-17.

Friedman, K.L. \& Brewer, B.J. 1995. Analysis of replication intermediates by twodimensional agarose gel electrophoresis. Methods Enzymol. 262, 613-627.

Froger, A. \& Hall, J.E. 2007. Transformation of plasmid DNA into E. coli using the heat shock method. J Vis Exp. 253. 
Fujimura, F.K., Zyskind, J.W. \& Smith, D.W. 1979. The Escherichia coli dnaB protein is required for initiation of chromosomal DNA replication. Cold Spring Harb Symp Quant Biol. 43 Pt 1, 559-562.

Furukohri, A., Goodman, M.F. \& Maki, H. 2008. A dynamic polymerase exchange with Escherichia coli DNA polymerase IV replacing DNA polymerase III on the sliding clamp. J Biol Chem. 283, 11260-11269.

Gamas, P., Burger, A.C., Churchward, G., Caro, L., Galas, D. \& Chandler, M. 1986. Replication of pSC101: effects of mutations in the E. coli DNA binding protein IHF. Mol Gen Genet. 204, 85-89.

Georgescu, R.E., Kurth, I., Yao, N.Y., Stewart, J., Yurieva, O. \& O'Donnell, M. 2009. Mechanism of polymerase collision release from sliding clamps on the lagging strand. EMBO J.

Glover, B.P., Pritchard, A.E. \& McHenry, C.S. 2001. tau binds and organizes Escherichia coli replication proteins through distinct domains: domain III, shared by gamma and tau, oligomerizes DnaX. J Biol Chem. 276, 3584235846.

Greenfeder, S.A. \& Newlon, C.S. 1992. Replication forks pause at yeast centromeres. Mol Cell Biol. 12, 4056-4066.

Hanawalt, P. \& Brempelis, I. 1967. Selective Degradation of Newly-Replicated DNA after Inhibition of DNA synthesis in Escherichia coli. Proceedings of the 7th International Congress of Biochemistry, Japan. 650. 
Heller, R.C. \& Marians, K.J. 2006. Replication fork reactivation downstream of a blocked nascent leading strand. Nature. 439, 557-562.

Higuchi, K., Katayama, T., Iwai, S., Hidaka, M., Horiuchi, T. \& Maki, H. 2003. Fate of DNA replication fork encountering a single DNA lesion during oriC plasmid DNA replication in vitro. Genes Cells. 8, 437-449.

Holt, I.J., Lorimer H.E. \& Jacobs, I.T. 2000. Coupled leading and lagging strand synthesis of mammalian mitochondrial DNA. Trends Biochem Sci. 28, 355356

Horii, Z.I. \& Suzuki, K. 1968. Degradation of the DNA of Escherichia coli K12 rec(JC1569b) after irradiation with ultraviolet light. Photochem photobiol. 8, 93105.

Horiuchi, T., Maki, H. \& Sekiguchi, M. 1978. A new conditional lethal mutator (dnaQ49) in Escherichia coli K12. Molecular and General Genetics MGG. $163,277-283$.

Howard-Flanders, P., Theriot, L. \& Stedeford, J.B. 1969. Some properties of excision-defective recombination-deficient mutants of Escherichia coli K-12. J Bacteriol. 97, 1134-1141.

Howard-Flanders, P. \& Theriot, L. 1966. Mutants of Escherichia coli K-12 defective in DNA repair and in genetic recombination. Genetics. 53, 11371150. 
Hwang, D.S. \& Kornberg, A. 1992. Opening of the replication origin of Escherichia coli by DnaA protein with protein HU or IHF. J Biol Chem. 267, 23083-23086.

Indiani, C., Langston, L.D., Yurieva, O., Goodman, M.F. \& O'Donnell, M. 2009. Translesion DNA Polymerases Remodel the Replisome and Alter the Speed of the Replicative Helicase. Proc Natl Acad Sci U S A. X, XX-XX.

Indiani, C., Mclnerney, P., Georgescu, R., Goodman, M.F. \& O'Donnell, M. 2005. A sliding-clamp toolbelt binds high- and low-fidelity DNA polymerases simultaneously. Mol Cell. 19, 805-815.

Jaktaji, R.P. \& Lloyd, R.G. 2003. PriA supports two distinct pathways for replication restart in UV-irradiated Escherichia coli cells. Mol Microbiol. 47, 1091-1100.

Jensen, K.F. 1993. The Escherichia coli K-12 "wild types" W3110 and MG1655 have an rph frameshift mutation that leads to pyrimidine starvation due to low pyrE expression levels. J Bacteriol. 175, 3401-3407.

Kajander, O.A., Karhunen, P.J., Holt, I.J. \& Jacobs, H.T. 2001. Prominent mitochondrial DNA recombination intermediates in human heart muscle. EMBO Rep. 2, 1007-1012.

Keller, K.L., Overbeck-Carrick, T.L. \& Beck, D.J. 2001. Survival and induction of SOS in Escherichia coli treated with cisplatin, UV-irradiation, or mitomycin C are dependent on the function of the RecBC and RecFOR pathways of homologous recombination. Mutat Res. 486, 21-29. 
Khidhir, M.A., Casaregola, S. \& Holland, I.B. 1985. Mechanism of transient inhibition of DNA synthesis in ultraviolet-irradiated E. coli: inhibition is independent of recA whilst recovery requires RecA protein itself and an additional, inducible SOS function. Mol Gen Genet. 199, 133-140.

Kim, S., Dallmann, H.G., McHenry, C.S. \& Marians, K.J. 1996. Coupling of a replicative polymerase and helicase: a tau-DnaB interaction mediates rapid replication fork movement. Cell. 84, 643-650.

Kohiyama, M. 1968. DNA synthesis in temperature sensitive mutants of Escherichia coli. Cold Spring Harb Symp Quant Biol. 33, 317-324.

Kornberg, T. \& Gefter, M.L. 1971. Purification and DNA synthesis in cell-free extracts: properties of DNA polymerase II. Proc Natl Acad Sci U S A. 68, 761-764.

Kucherlapati, R.S., Eves, E.M., Song, K.Y., Morse, B.S. \& Smithies, O. 1984. Homologous recombination between plasmids in mammalian cells can be enhanced by treatment of input DNA. Proc Natl Acad Sci U S A. 81, 31533157.

Langston, L.D., Indiani, C. \& O'Donnell, M. 2009. Whither the replisome: emerging perspectives on the dynamic nature of the DNA replication machinery. Cell Cycle. 8, 2686-2691.

LeBowitz, J.H. \& McMacken, R. 1986. The Escherichia coli dnaB replication protein is a DNA helicase. J Biol Chem. 261, 4738-4748. 
Leu, F.P., Georgescu, R. \& O'Donnell, M. 2003. Mechanism of the E. coli tau processivity switch during lagging-strand synthesis. Mol Cell. 11, 315-327.

Little, J.W., Mount, D.W. \& Yanisch-Perron, C.R. 1981. Purified lexA protein is a repressor of the recA and lexA genes. Proc Natl Acad Sci U S A. 78, 41994203.

Lloyd, R.G. \& Sharples, G.J. 1993. Dissociation of synthetic Holliday junctions by E. coli RecG protein. Embo J. 12, 17-22.

Lloyd, R.G. 1991. Conjugational recombination in resolvase-deficient ruvC mutants of Escherichia coli K-12 depends on recG. J Bacteriol. 173, 54145418.

Lu, Y.B., Ratnakar, P.V., Mohanty, B.K. \& Bastia, D. 1996. Direct physical interaction between DnaG primase and DnaB helicase of Escherichia coli is necessary for optimal synthesis of primer RNA. Proc Natl Acad Sci U S A. 93, $12902-12907$.

Maki, S. \& Kornberg, A. 1988. DNA polymerase III holoenzyme of Escherichia coli. I. Purification and distinctive functions of subunits tau and gamma, the dnaZX gene products. J Biol Chem. 263, 6547-6554.

Marians, K.J. 2000. PriA-directed replication fork restart in Escherichia coli. Trends Biochem Sci. 25, 185-9.

Marians, K.J., Hiasa, H., Kim, D.R. \& McHenry, C.S. 1998. Role of the core DNA polymerase III subunits at the replication fork. Alpha is the only subunit required for processive replication. J Biol Chem. 273, 2452-2457. 
Martin-Parras, L., Hernandez, P., Martinez-Robles, M.L. \& Schvartzman, J.B. 1992. Initiation of DNA replication in ColE1 plasmids containing multiple potential origins of replication. J Biol Chem. 267, 22496-22505.

Martin-Parras, L., Lucas, I., Martinez-Robles, M.L., Hernandez, P., Krimer, D.B., Hyrien, O. \& Schvartzman, J.B. 1998. Topological complexity of different populations of pBR322 as visualized by two-dimensional agarose gel electrophoresis. Nucleic Acids Res. 26, 3424-3432.

Martin-Parras, L., Hernandez, P., Martinez-Robles, M.L. \& Schvartzman, J.B. 1991. Unidirectional replication as visualized by two-dimensional agarose gel electrophoresis. J Mol Biol. 220, 843-853.

Masker, W., Hanawalt, P. \& Shizuya, H. 1973. Role of DNA polymerase II in repair replication in Escherichia coli. Nat New Biol. 244, 242-243.

Mazin, A.V. \& Kowalczykowski, S.C. 1999. A novel property of the RecA nucleoprotein filament: activation of double- stranded DNA for strand exchange in trans. Genes Dev. 13, 2005-2016.

McGlynn, P. \& Lloyd, R.G. 2001. Action of RuvAB at replication fork structures. J Biol Chem. 276, 41938-41944.

McGlynn, P. \& Lloyd, R.G. 2002. Genome stability and the processing of damaged replication forks by RecG. Trends Genet. 18, 413-419.

McInerney, P., Johnson, A., Katz, F. \& O'Donnell, M. 2007. Characterization of a triple DNA polymerase replisome. Mol Cell. 27, 527-538. 
Mclnerney, P. \& O'Donnell, M. 2004. Functional Uncoupling of Twin Polymerases: MECHANISM OF POLYMERASE DISSOCIATION FROM A LAGGING-STRAND BLOCK. J Biol Chem. 279, 21543-21551.

Mclnerney, P. \& O'donnell, M. 2007. Replisome Fate upon Encountering a Leading Strand Block and Clearance from DNA by Recombination Proteins. J Biol Chem. 282, 25903-25916.

Michel, B. 2000. Replication fork arrest and DNA recombination. Trends Biochem Sci. 25, 173-178.

Niki, H., Ichinose, C., Ogura, T., Mori, H., Morita, M., Hasegawa, M., Kusukawa, N. \& Hiraga, S. 1988. Chromosomal genes essential for stable maintenance of the mini-F plasmid in Escherichia coli. J Bacteriol. 170, 5272-5278.

Nishitani, H. \& Lygerou, Z. 2004. DNA replication licensing. Front Biosci. 9, 21152132.

Norgard, M.V., Keem, K. \& Monahan, J.J. 1978. Factors affecting the transformation of Escherichia coli strain chi1776 by pBR322 plasmid DNA. Gene. 3, 279-292.

O'Donnell, M. 2006. Replisome architecture and dynamics in Escherichia coli. J Biol Chem. 281, 10653-10656.

Paz-Elizur, T., Skaliter, R., Blumenstein, S. \& Livneh, Z. 1996. Beta*, a UVinducible smaller form of the beta subunit sliding clamp of DNA polymerase III of Escherichia coli. I. Gene expression and regulation. J Biol Chem. 271, 2482-2490. 
Radman, M. 1975. SOS repair hypothesis: phenomenology of an inducible DNA repair which is accompanied by mutagenesis. Basic Life Sci. 5A, 355-367.

Ramdas, J., Mythili, E. \& Muniyappa, K. 1989. RecA protein promoted homologous pairing in vitro. Pairing between linear duplex DNA bound to HU Protein (nucleosome cores) and nucleoprotein filaments of recA proteinsingle-stranded DNA. J Biol Chem. 264, 17395-17400.

Remus, D., Beuron, F., Tolun, G., Griffith, J.D., Morris, E.P. \& Diffley, J.F. 2009. Concerted loading of Mcm2-7 double hexamers around DNA during DNA replication origin licensing. Cell. 139, 719-730.

Remus, D. \& Diffley, J.F. 2009. Eukaryotic DNA replication control: lock and load, then fire. Curr Opin Cell Biol. 21, 771-777.

Reuven, N.B., Arad, G., Maor-Shoshani, A. \& Livneh, Z. 1999. The mutagenesis protein UmuC is a DNA polymerase activated by UmuD', RecA, and SSB and is specialized for translesion replication. J Biol Chem. 274, 3176331766.

Reyes-Lamothe, R., Sherratt, D.J. \& Leake, M.C. 2010. Stoichiometry and architecture of active DNA replication machinery in Escherichia coli. Science. 328, 498-501.

Roberts, R.J. \& Strike, P. 1981. Efficiency of Escherichia coli repair processes on uv-damaged transforming plasmid DNA. Plasmid. 5, 213-220. 
Roberts, R.J. \& Strike, P. 1986. Repair in E. coli of transforming plasmid DNA damaged by psoralen plus near-ultraviolet irradiation. Mutat Res. 165, 8188.

Roychoudhury, A., Basu, S. \& Sengupta, D.N. 2009. Analysis of comparative efficiencies of different transformation methods of E. coli using two common plasmid vectors. Indian J Biochem Biophys. 46, 395-400.

Rupp, W.D. \& Howard-Flanders, P. 1968. Discontinuities in the DNA synthesized in an excision-defective strain of Escherichia coli following ultraviolet irradiation. J Mol Biol. 31, 291-304.

Saffran, W.A. \& Cantor, C.R. 1984. Mutagenic SOS repair of site-specific psoralen damage in plasmid pBR322. J Mol Biol. 178, 595-609.

Sassanfar, M. \& Roberts, J.W. 1990. Nature of the SOS-inducing signal in Escherichia coli. The involvement of DNA replication. J Mol Biol. 212, 79-96.

Scheuermann, R., Tam, S., Burgers, P.M., Lu, C. \& Echols, H. 1983. Identification of the epsilon-subunit of Escherichia coli DNA polymerase III holoenzyme as the dnaQ gene product: a fidelity subunit for DNA replication. Proc Natl Acad Sci U S A. 80, 7085-7089.

Schmid, S.E., Daune, M.P. \& Fuchs, R.P. 1982. Repair and mutagenesis of plasmid DNA modified by ultraviolet irradiation or N-acetoxy-N-2acetylaminofluorene. Proc Natl Acad Sci U S A. 79, 4133-4137.

Schutte, B.C. \& Cox, M.M. 1987. Homology-dependent changes in adenosine 5'triphosphate hydrolysis during recA protein promoted DNA strand 
exchange: evidence for long paranemic complexes. Biochemistry. 26, 56165625.

Sclafani, R.A. \& Holzen, T.M. 2007. Cell cycle regulation of DNA replication. Annu Rev Genet. 41, 237-280.

Seigneur, M., Ehrlich, S.D. \& Michel, B. 1997. Blocking rolling circle replication with a UV lesion creates a deletion hotspot. Mol Microbiol. 26, 569-580.

Setlow, R.B., Swenson, P.A. \& Carrier, W.L. 1963. Thymine dimers and Inhibition of DNA synthesis by ultraviolet irradiation of cells. Science. 142, 1464-1466.

Severini, A., Scraba, D.G. \& Tyrrell, D.L. 1996. Branched structures in the intracellular DNA of herpes simplex virus type 1. J Virol. 70, 3169-3175.

Strike, P., Humphreys, G.O. \& Roberts, R.J. 1979. Nature of transforming deoxyribonucleic acid in calcium-treated Escherichia coli. J Bacteriol. 138, 1033-1035.

Strike, P. \& Roberts, R.J. 1982. Resident enhanced repair: novel repair process action on plasmid DNA transformed into Escherichia coli K-12. J Bacteriol. $150,385-388$.

Stukenberg, P.T., Studwell-Vaughan, P.S. \& O'Donnell, M. 1991. Mechanism of the sliding beta-clamp of DNA polymerase III holoenzyme. J Biol Chem. 266, 11328-11334.

Summers, D.K. \& Sherratt, D.J. 1984. Multimerization of high copy number plasmids causes instability: ColE1 encodes a determinant essential for plasmid monomerization and stability. Cell. 36, 1097-1103. 
Svoboda, D.L. \& Vos, J.M. 1995. Differential replication of a single, UV-induced lesion in the leading or lagging strand by a human cell extract: fork uncoupling or gap formation. Proc Natl Acad Sci U S A. 92, 11975-11979. van der Ende, A., Baker, T.A., Ogawa, T. \& Kornberg, A. 1985. Initiation of enzymatic replication at the origin of the Escherichia coli chromosome: primase as the sole priming enzyme. Proc Natl Acad Sci U S A. 82, 39543958.

Van Houten, B., Gamper, H., Hearst, J.E. \& Sancar, A. 1988. Analysis of sequential steps of nucleotide excision repair in Escherichia coli using synthetic substrates containing single psoralen adducts. J Biol Chem. 263, 16553-16560.

Viguera, E., Hernandez, P., Krimer, D.B., Boistov, A.S., Lurz, R., Alonso, J.C. \& Schvartzman, J.B. 1996. The ColE1 unidirectional origin acts as a polar replication fork pausing site. J Biol Chem. 271, 22414-22421.

Wagner, J., Gruz, P., Kim, S.R., Yamada, M., Matsui, K., Fuchs, R.P. \& Nohmi, T. 1999. The dinB gene encodes a novel E. coli DNA polymerase, DNA pol IV, involved in mutagenesis. Mol Cell. 4, 281-286.

Wang, X., Peterson, C.A., Zheng, H., Nairn, R.S., Legerski, R.J. \& Li, L. 2001. Involvement of nucleotide excision repair in a recombination-independent and error-prone pathway of DNA interstrand cross-link repair. Mol Cell Biol. $21,713-720$. 
Watson, N. 1988. A new revision of the sequence of plasmid pBR322. Gene. 70, 399-403.

Webb, B.L., Cox, M.M. \& Inman, R.B. 1997. Recombinational DNA repair: the RecF and RecR proteins limit the extension of RecA filaments beyond single-strand DNA gaps. Cell. 91, 347-356.

Webb, B.L., Cox, M.M. \& Inman, R.B. 1999. ATP hydrolysis and DNA binding by the Escherichia coli RecF protein. J Biol Chem. 274, 15367-15374.

West, S.C. 1996. The RuvABC proteins and Holliday junction processing in Escherichia coli. J Bacteriol. 178, 1237-1241.

West, S.C., Cassuto, E. \& Howard-Flanders, P. 1982. Postreplication repair in E. coli: strand exchange reactions of gapped DNA by RecA protein. Mol Gen Genet. 187, 209-217.

Willetts, N.S. \& Clark, A.J. 1969. Characteristics of some multiply recombinationdeficient strains of Escherichia coli. J Bacteriol. 100, 231-239.

Woodgate, R., Rajagopalan, M., Lu, C. \& Echols, H. 1989. UmuC mutagenesis protein of Escherichia coli: purification and interaction with UmuD and UmuD'. Proc Natl Acad Sci U S A. 86, 7301-7305.

Yao, N., Leu, F.P., Anjelkovic, J., Turner, J. \& O'Donnell, M. 2000. DNA structure requirements for the Escherichia coli gamma complex clamp loader and DNA polymerase III holoenzyme. J Biol Chem. 275, 11440-11450. 
Yeung, A.T., Mattes, W.B., Oh, E.Y. \& Grossman, L. 1983. Enzymatic properties of purified Escherichia coli uvrABC proteins. Proc Natl Acad Sci U S A. 80, 6157-6161.

Yoshida, N. \& Sato, M. 2009. Plasmid uptake by bacteria: a comparison of methods and efficiencies. Appl Microbiol Biotechnol. 83, 791-798.

Yu, D., Ellis, H.M., Lee, E.C., Jenkins, N.A., Copeland, N.G. \& Court, D.L. 2000. An efficient recombination system for chromosome engineering in Escherichia coli. Proc Natl Acad Sci U S A. 97, 5978-5983. 


\title{
Appendix A
}

\section{Visualization of UV-induced Replication Intermediates in E. coli using Two- Dimensional Agarose-gel Analysis}

${ }^{*}$ This section has been published: Journal of Visualized Experiments. (2010) 46. pii 2220 (http://www.jove.com/video/2220)

\begin{abstract}
Inaccurate replication in the presence of DNA damage is responsible for the majority of cellular rearrangements and mutagenesis observed in all cell types and is widely believed to be directly associated with the development of cancer in humans. DNA damage, such as that induced by UV irradiation, severely impairs the ability of replication to duplicate the genomic template accurately. A number of gene products have been identified that are required when replication encounters DNA lesions in the template. However, a remaining challenge has been to determine how these proteins process lesions during replication in vivo. Using Escherichia coli as a model system, we describe a procedure in which two-dimensional agarose-gel analysis can be used to identify the structural intermediates that arise on replicating plasmids in vivo following UV-induced DNA damage. This procedure has been used to demonstrate that replication forks blocked by UV-induced damage undergo a transient reversal that is stabilized by RecA and several gene products associated with the RecF pathway. The technique demonstrates that these replication intermediates are
\end{abstract}


maintained until a time that correlates with the removal of the lesions by nucleotide excision repair and replication resumes.

\section{Materials and Methods}

Specific reagents and equipment are shown in Table A1.

\section{Growth and UV Irradiation.}

1.1) $200 \mu \mathrm{l}$ of a fresh overnight culture containing the plasmid pBR322 grown in Davis medium (Davis, 1949) supplemented with $0.4 \%$ glucose, $0.2 \%$ casamino acids, and $10 \mu \mathrm{g} / \mathrm{ml}$ thymine (DGCthy medium) and $100 \mu \mathrm{g} / \mathrm{ml}$ ampicillin is pelleted. The cell pellet is then resuspended in $200 \mu$ DGCthy medium lacking ampicillin and used to inoculate $20 \mathrm{ml}$ of DGCthy medium.

1.2) Cultures are grown without ampicillin selection in a shaking incubator at $37^{\circ} \mathrm{C}$ to an OD600 of $0.5\left(\sim 5 \times 10^{8}\right.$ cells $\left./ \mathrm{ml}\right)$. Growth without ampicillin avoids selection against abnormal or unproductive replication intermediates that may arise in some mutants. In addition, if using UV light to induce damage, the removal of the ampicillin from the media is necessary because it absorbs strongly at these wavelengths and shields the cells, reducing the effective dose of UV.

1.3) Working under yellow lights, the $20 \mathrm{~mL}$ culture is placed in a $15 \mathrm{~cm}$ diameter Petri dish on a rotating platform for agitation. Our cultures are placed at a distance from a 15-watt germicidal lamp that produces an exposure rate of $\sim 1$ 
$\mathrm{J} / \mathrm{m}^{2} / \mathrm{sec}$, which is measured using a UVC photometer. Cultures are irradiated with $50 \mathrm{~J} / \mathrm{m}^{2}$ and then immediately transferred into sterile, pre-warmed flasks and placed back into the shaking $37^{\circ} \mathrm{C}$ incubator for the duration of the experiment. This dose produces, on average, 1 cyclobutane pyrimidine dimer every $4.5 \mathrm{~kb}$ of ssDNA (Courcelle et al., 2003). The yellow lighting prevents photoreactivationreversal of cyclobutane pyrimidine dimers by photolyase.

\section{DNA isolation.}

2.1) At times when replication intermediates are to be examined, a $0.75 \mathrm{ml}$ aliquot of the culture is placed into $0.75 \mathrm{ml}$ ice cold NET30 Buffer $(100 \mathrm{mM} \mathrm{NaCl}$, $10 \mathrm{mM}$ Tris, $\mathrm{pH}$ 8.0, $30 \mathrm{mM}$ EDTA) and placed on ice until the end of the time course. The EDTA and cold temperature serves to effectively stop replication and nucleotide excision repair. We typically run a 90 minute time course with samples examined at 0, 15, 30, 45, 60 and 90 minutes post UV-irradiation.

2.2) Each sample is then pelleted, resuspended in $150 \mu \mathrm{l}$ of $1.5 \mathrm{mg} / \mathrm{ml}$ lysozyme and $0.2 \mathrm{mg} / \mathrm{ml}$ RNaseA in TE (10 mM Tris, $\mathrm{pH}$ 8.0, $1 \mathrm{mM}$ EDTA), and lysed at $37^{\circ} \mathrm{C}$ for $20 \mathrm{~min}$. At this time, $10 \mu \mathrm{l}$ of proteinase $\mathrm{K}(10 \mathrm{mg} / \mathrm{ml})$ and $10 \mu \mathrm{l}$ of $20 \%$ sarkosyl are added and the incubation is allowed to continue for $1 \mathrm{hr}$. Proteinase $\mathrm{K}$ and sarkosyl help to release DNA fragments that may be associated with the membrane or proteins before phenol extraction occurs. Since actively replicating $D N A$ is often bound to protein or membrane complexes, this helps increase the yield of replication fragments that are recovered. 
2.3) Samples are then extracted by adding 2 volumes of phenol to each sample and the tubes are gently inverted for 5 minutes. Then 2 volumes of chloroform/isoamyl alcohol (24/1) are added and the tubes are gently inverted again for 5 minutes.

2.4) The samples are centrifuged at $14,000 \mathrm{rpm}$ in a microcentrifuge for 5 minutes and the top aqueous phase of each sample is removed, and placed into a fresh tube. Then 4 volumes of chloroform/isoamyl alcohol (24/1) are added, the tubes are gently inverted for 5 minutes, and centrifuged again at $14,000 \mathrm{rpm}$ for 5 minutes.

2.5) The top, aqueous phase in each sample is then dialyzed for 1 hour by spotting $100 \mu \mathrm{l}$ of each sample on a $47 \mathrm{~mm}$ Whatman $0.025 \mu \mathrm{m}$ pore disk which floats on $250 \mathrm{ml}$ of $0.1 \mathrm{X}$ TE in a beaker. Because replicating structures with single strand regions or branch points are more susceptible to shearing, we typically cut our pipet tips off with a razor blade to make the mouth wider and minimize shearing forces. In general, pipetting should be kept to a minimum until after the DNA has been digested with restriction enzymes.

2.6) $80 \mu \mathrm{l}$ of each sample is then digested with 3 units of Pvull (New England Biolabs) which linearizes the plasmid just downstream from the origin of replication. The final volume is adjusted to $100 \mu \mathrm{l}$ with appropriate buffer.

2.7) Prior to loading the agarose gel, $100 \mu \mathrm{l}$ of chloroform and $20 \mu \mathrm{l}$ of $6 \mathrm{X}$ loading dye that contains Bromophenol Blue and Xylene Cyanol are added to each 
sample and mixed. Then, $40 \mu \mathrm{l}$ of the aqueous phase containing the loading dye is loaded into the gel. To minimize structural biases, structural artifacts, and DNA shearing, this isolation procedure does not include any steps to enrich for single strand regions, precipitate, or concentrate the DNA samples following cell lysis.

\section{D gel and southern analysis.}

3.1) The 2-dimensional agarose-gel analysis is modified from (Friedman and Brewer, 1995). For the 1st dimension, the restricted DNA samples are run through a $0.4 \%$ agarose gel in $1 \mathrm{X}$ TBE at $1 \mathrm{~V} / \mathrm{cm}$. One Liter of $10 \mathrm{X}$ TBE stock solution contains

$108 \mathrm{~g}$ Tris Base

$55 \mathrm{~g}$ Boric Acid

$40 \mathrm{ml}$ 0.5M EDTA (pH 8.0)

3.2) A lambda Hind III size marker is loaded in the first lane and the following samples are loaded in every other lane. We typically run the first dimension $\sim 12-$ 15 hrs. Skipping lanes makes it easier to slice the lanes out to cast in the second dimension. The low voltage and low percent agarose gel serves to separate the DNA fragments primarily based upon size.

3.3) For the second dimension, gel lanes are sliced out of the first dimension gel using a large butcher's knife. The first lane containing the lambda Hind III marker can be stained with ethidium bromide. Using the lambda Hind III marker as a guide, crop and discard the region of the gel that is below where the 
linearized plasmid is expected to run. Under these conditions, we find that linearized pBR322 runs slightly above the xylene cyanol stain.

3.4) To cast the second dimension, each lane is placed horizontally across the top of an empty gel caster. A solution of $1.0 \%$ agarose in $1 \mathrm{X}$ TBE is prepared and cooled to $55^{\circ} \mathrm{C}$. At this time, the gel solution is poured in to cast the second dimension, making sure to completely cover the gel slices. Once the gel has set, it is run at $6.5 \mathrm{~V} / \mathrm{cm}$ in an electrophoresis unit that allows the buffer to recirculate. We typically run the second dimension $\sim 5.5-7$ hrs. The high voltage and high percent agarose gel effectively separates the DNA fragments based on their shape, as well as size. Nonlinear shapes run more slowly through the second dimension.

3.5) Following electrophoresis, the gel is then rinsed in $\mathrm{H}_{2} \mathrm{O}$, washed twice in $400 \mathrm{ml}$ of $0.25 \mathrm{M}$ hydrochloric acid for 15 minutes per wash, rinsed with $\mathrm{H}_{2} \mathrm{O}$; , and then washed twice in $400 \mathrm{ml} 0.4 \mathrm{M} \mathrm{NaOH}$ for 30 minutes per wash. All washes are performed on a rotating platform. The acid washes serve to partially nick the DNA molecules into smaller fragments that transfer more efficiently. This step is necessary due to the large size and unusual shapes of the DNA replication intermediates.

3.6) The DNA in the gels is then transferred to a Hybond N+ nylon membrane (Spivak and Hanawalt, 1995). We use a downward alkali transfer system with $0.4 \mathrm{M} \mathrm{NaOH}$. Briefly, two sheets of blotting paper soaked in $0.4 \mathrm{M} \mathrm{NaOH}$ are placed on a large stack of paper towels. The nylon membrane is also soaked in 
$0.4 \mathrm{M} \mathrm{NaOH}$ and placed on top of the blotting paper. The gel is then carefully layered on top of this, followed by another piece of blotting paper, wetted in the $\mathrm{NaOH}$ solution. Finally, a long piece of wetted blotting paper is layered across the top and its two ends are placed into a dishes containing $1 \mathrm{~L}$ of $0.4 \mathrm{M} \mathrm{NaOH}$ solution to serve as a wick. We typically let the DNA transfer for 6-12 hrs.

3.7) The nylon membrane is removed, washed 20-30 sec in 5X SSC Buffer, and placed in a hybridization roller bottle containing $10.5 \mathrm{ml}$ Prehybridization Solution. Then, the membrane is incubated at $42^{\circ} \mathrm{C}$ with rotation for more than $6 \mathrm{hrs}$.

Prehybridization solution:

$5.0 \mathrm{ml}$ formamide

$0.5 \mathrm{ml} 20 \%$ SDS

$2.5 \mathrm{ml} 20 \times$ SSC$^{\star}$

$2.0 \mathrm{ml} 50 X$ Denhardt's*

$0.5 \mathrm{ml}$ Salmon Sperm DNA $(10 \mathrm{mg} / \mathrm{ml})$

*recipes for SSC and Denhardt's can be found in (Sambrook and Russell, 2001)

3.8) During the prehybridization period, $1 \mu \mathrm{g}$ of pBR322 plasmid is labeled with $32 \mathrm{P}$ by nick translation according to the protocol supplied by Roche using alpha labeled (32-P)-dCTP. The radiolabeled probe $(100 \mu \mathrm{l})$ is denatured by incubating at $98^{\circ} \mathrm{C}$ for 10 minutes in a screw cap microcentrifuge tube, and placed immediately on ice.

3.9) The denatured probe is added to $5.9 \mathrm{ml}$ hybridization solution.

Hybridization solution:

$3.0 \mathrm{ml}$ formamide

$1.5 \mathrm{ml} \mathrm{SSC}$

$1.0 \mathrm{ml} \mathrm{H} 2 \mathrm{O}$

$0.15 \mathrm{ml}$ 50X Denhardt's 
$0.10 \mathrm{ml} \mathrm{20 \%} \mathrm{SDS}$

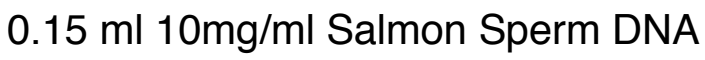

3.10) The prehybridization solution is poured out of the roller bottle and the hybridization solution is poured in. The roller bottle is then returned to the $42^{\circ} \mathrm{C}$ incubator and rotated for at least $12 \mathrm{hrs}$.

3.11) The hybridization solution is poured out of the roller bottle. Then, the blot is washed 4 times for 20 minutes in the roller bottle with $\sim 150 \mathrm{ml}$ of a wash solution containing $0.5 \mathrm{XSS}, 0.1 \% \mathrm{SDS}$ at $42^{\circ} \mathrm{C}$ with rotation.

3.12) Following the last wash, the membrane is placed on a paper towel until the liquid has visibly disappeared. The membrane is then wrapped in polyvinylchloride plastic wrap and exposed to a phosphorimager screen. We visualize and quantify the radioactivity using a Storm 840 and its associated ImageQuant Software (Molecular Dynamics).

\section{Discussion}

Typical results obtained from wild type cells in the presence and absence of UV-induced damage are shown in Figure A1. In the absence of damage, $\sim 1 \%$ of the total plasmid DNA can be found in the $Y$ arc when cells are rapidly growing in exponential phase. Following irradiation, a transient increase in $\mathrm{Y}$ shaped molecules is observed as blocked replication forks accumulate at damaged sites. The X-shaped replication intermediates also transiently accumulate and persist until a time that correlates with when the lesions are repaired (Courcelle et al., 2003). 
In place of the Southern analysis, the replication intermediates can be punched out of the gel with a plastic drinking straw, purified, and observed directly by electron microscopy (Donaldson et al., 2006). We have used this approach successfully to identify gene products required to process replication forks that encounter DNA damage and to identify abnormal replication intermediates that accumulate in these mutants (Al-Hadid et al., 2008; Belle et al., 2007; Chow and Courcelle, 2004; Chow and Courcelle, 2007; Courcelle et al., 2003; Donaldson et al., 2004). In addition, this approach can be easily modified to examine other forms of DNA damage.

\section{Acknowledgments}

Work in our lab is supported by CAREER award MCB0551798 from the National Science Foundation and AREA grant R15GM86839 from the NIGMS-NIH 
Table A1. Specific reagents and equipment

\begin{tabular}{|c|c|c|c|}
\hline $\begin{array}{c}\text { Name of the } \\
\text { reagent }\end{array}$ & Company & Catalogue number & Comments \\
\hline F40/GO 40WGold & GE & G15T8 & Yellow Lighting \\
\hline $\begin{array}{l}20 \text { watt germicidal } \\
\text { lamp }\end{array}$ & Sylvania & F20T12/GO & UV Lamp \\
\hline $\begin{array}{l}\text { Blak-Ray UV } \\
\text { Intensity Meter } \\
254 \mathrm{~nm}\end{array}$ & Daigger & EF28195T & UVC photometer \\
\hline $\begin{array}{l}0.025 \mu \mathrm{m} \text { pore } \\
\text { disks }\end{array}$ & Whatman & VSWP04700 & $\begin{array}{l}\text { Floating dialysis } \\
\text { disks }\end{array}$ \\
\hline Pvu II & Fermentas & ER0632 & $\begin{array}{c}\text { Restriction } \\
\text { Endonuclease }\end{array}$ \\
\hline Nick-translation kit & $\begin{array}{c}\text { Roche } \\
\text { Diagnostics }\end{array}$ & 976776 & $\begin{array}{l}\text { To make 32P- } \\
\text { labeled probe }\end{array}$ \\
\hline Blotting Paper & Whatman & $3030-704$ & $\begin{array}{l}\text { For Southern } \\
\text { transfer }\end{array}$ \\
\hline Nylon membrane & GE Healthcare & RPN203S & $\begin{array}{l}\text { For Southern } \\
\text { transfer }\end{array}$ \\
\hline
\end{tabular}




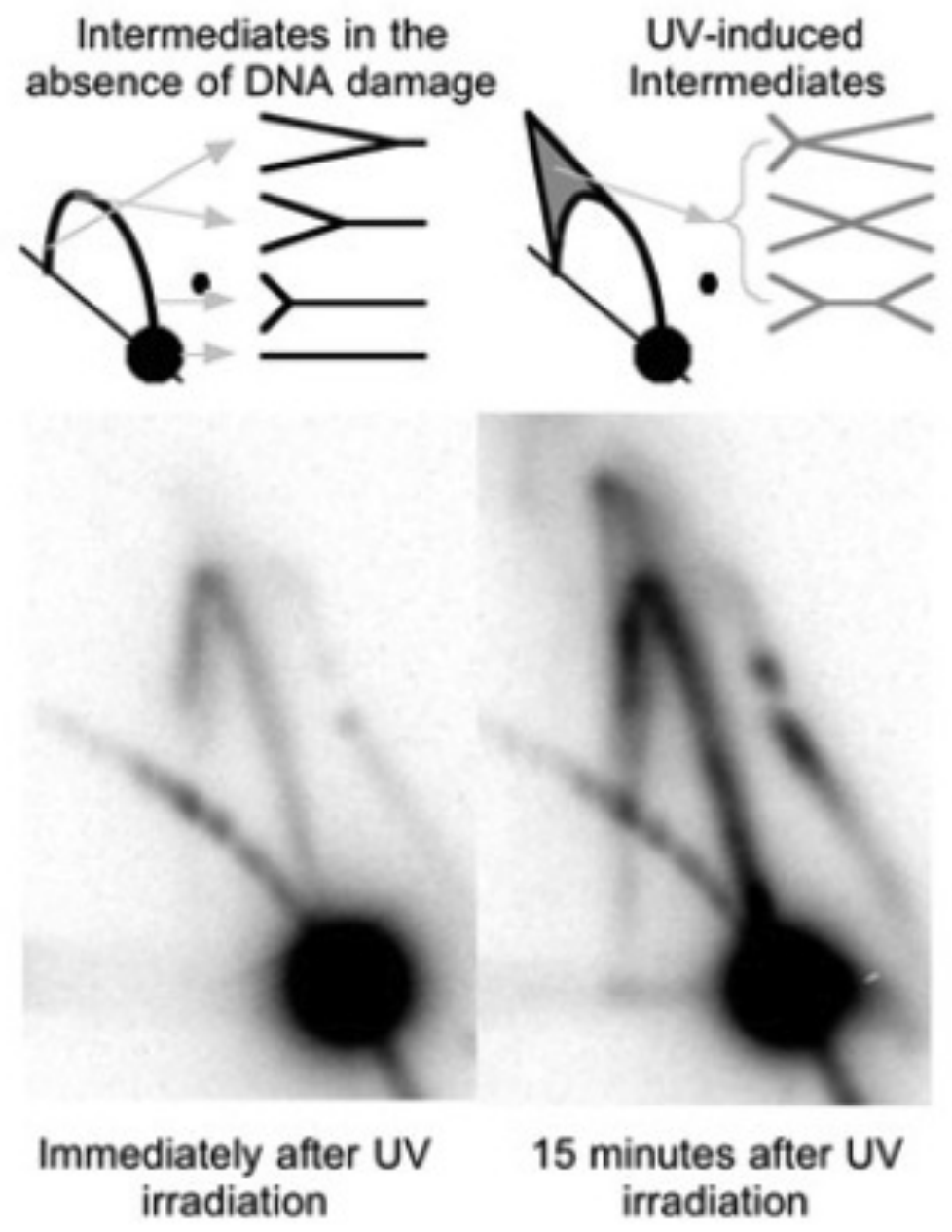

Figure A1. Plasmid replication intermediates observed in the presence and absence of UV-induced DNA damage. The migration pattern of Pvull digested pBR322 plasmid observed by 2D-agarose-gel analysis is diagrammed. Non-replicating linear plasmids run as a linear 4.4-kb fragment. Replicating plasmids form Y-shaped structures that migrate slower than the nonreplicating fragments due to their larger size and nonlinear shape. This migration pattern forms an arc that extends out from the linear region towards the well. Following UV-irradiation, double-Y or $\mathrm{X}$-shaped molecules are observed in the cone region that migrates more slowly than the $\operatorname{arc}$ of $\mathrm{Y}$ shaped molecules. An example of the Southern analysis of the 2D gel probed with 32P-labeled pBR322 is shown for cells immediately after UV irradiation and 15 minutes after UV irradiation (reproduced from ${ }^{2}$ with permission). 


\section{References}

Al-Hadid, Q., Ona, K., Courcelle, C.T. \& Courcelle, J. 2008. RecA433 cells are defective in recF-mediated processing of disrupted replication forks but retain recBCD-mediated functions. Mutat Res. 645, 19-26.

Belle, J.J., Casey, A., Courcelle, C.T. \& Courcelle, J. 2007. Inactivation of the DnaB helicase leads to the collapse and degradation of the replication fork: a comparison to UV-induced arrest. J Bacteriol. 189, 5452-5462.

Chow, K.H. \& Courcelle, J. 2004. RecO Acts with RecF and RecR to Protect and Maintain Replication Forks Blocked by UV-induced DNA Damage in Escherichia coli. J Biol Chem. 279, 3492-3496.

Chow, K.H. \& Courcelle, J. 2007. RecBCD and RecJ/RecQ initiate DNA degradation on distinct substrates in UV-irradiated Escherichia coli. Radiat Res. 168, 499-506.

Courcelle, J., Donaldson, J.R., Chow, K.H. \& Courcelle, C.T. 2003. DNA DamageInduced Replication Fork Regression and Processing in Escherichia coli. Science. 299, 1064-1067.

Davis, B.D. 1949. The Isolation of Biochemically Deficient Mutants of Bacteria by Means of Penicillin. Proc Natl Acad Sci U S A. 35, 1-10.

Donaldson, J.R., Courcelle, C.T. \& Courcelle, J. 2004. RuvAB and RecG Are Not Essential for the Recovery of DNA Synthesis Following UV-Induced DNA Damage in Escherichia coli. Genetics. 166, 1631-1640. 
Donaldson, J.R., Courcelle, C.T. \& Courcelle, J. 2006. RuvABC is required to resolve holliday junctions that accumulate following replication on damaged templates in Escherichia coli. J Biol Chem. 281, 28811-28821.

Friedman, K.L. \& Brewer, B.J. 1995. Analysis of replication intermediates by twodimensional agarose gel electrophoresis. Methods Enzymol. 262, 613-627.

Sambrook, J. \& Russell, D.W. 2001. Molecular Cloning - A laboratory manual. CSHL Press, Cold Spring Harbor.

Spivak, G. \& Hanawalt, P.C. 1995. Determination of damage and repair in specific DNA sequences. METHODS: A Companion to Methods in Enzymology. 7, 147-161. 


\title{
Appendix B
}

\section{Damage-Inducible Polymerases Contribute to the DNA Synthesis that Occurs Following Disruption of Pol III in Escherichia coli}

\author{
Introduction \\ E. coli contains five DNA polymerases (Hastings et al., 2010; Johnson and \\ O'Donnell, 2005). The primary function of Pol I (encoded by polA) is to process \\ Okazaki fragments and fill in gaps generated by base excision repair and \\ nucleotide excision repair (Smirnov et al., 1975). Pol III (encoded dnaE, dnaQ \\ and $h o l E)$, is the main replicative polymerase and is responsible for carrying out \\ replication of the genome (Horiuchi et al., 1978; Kornberg and Gefter, 1971). In \\ addition, E. coli also has three damage-inducible polymerases: Pol II (encoded \\ by polB), Pol IV (encoded by $\operatorname{din} B$ ) and Pol V (encoded by umuDC). These \\ polymerases are capable of inserting bases opposite to specific base adducts \\ that may otherwise block Pol III progression (Kornberg and Gefter, 1971; Masker \\ et al., 1973; Reuven et al., 1999; Wagner et al., 1999; Woodgate et al., 1989). \\ A remaining question has been when and to what extent these alternative \\ polymerases function. Some studies have proposed that these polymerases may \\ predominantly act on gaps in the lagging strand template (Reuven et al., 2001). \\ Others have suggested that they may replace Pol III and function at the \\ replication fork on either strand (Indiani et al., 2005; Indiani et al., 2009). In an \\ effort to begin answering this question, I used the thermosensitive allele of Pol III
}


used in Chapter 3 of this thesis, in conjunction with a strain lacking the three damage-inducible polymerases, to examine DNA synthesis rates and genomic DNA accumulation following Pol III disruption.

The rate of synthesis can be tracked in E. coli by the use of radiolabeled nucleotides. Under typical growth conditions, synthesis occurs at rates $>1 \mathrm{~kb} / \mathrm{s}$ (Johnson and O'Donnell, 2005). It has been suggested previously that higher concentrations of lower-affinity polymerases may allow them to compete with the replicative polymerase, Pol III, to interact with beta and tau and carry out replication (Hastings et al., 2010; Leu et al., 2003; Lopez et al., 2003; Sutton et al., 2001; Wagner et al., 2000). In order to counteract its lower affinity, the copy number of each component of the PolV heterodimer can increase over 30-fold following UV irradiation, reaching concentrations that allow the polymerase to displace Pol III in the later stages of the SOS response (Sommer et al., 1993; Woodgate and Ennis, 1991). However, in the absence of damage, it has been suggested that alternative polymerases may still contribute to DNA synthesis through competition with Pol III (Indiani et al., 2005). In another study by the same group, overexpression of PolV was shown to reduce the speed of the replicative helicase suggesting polymerase modularity during replication (Indiani et al., 2009). One could envision that over time, low-level polymerase switching could contribute significantly to mutagenesis.

In this appendix, I compared the rate of DNA synthesis and DNA accumulation that occurred in a thermosensitive mutant of the replicative 
polymerase, $d n a E$, to that occurring in the thermosensitive dnaE strain that also lacked the inducible polymerases. I observed that at least one of the three damage inducible polymerases contributes to the synthesis occurring after Pol III dissociation. I discuss the implications of these results and lend further support to the idea of polymerase modularity in the replisome.

\section{Materials and Methods}

Strain Construction. The strains used in this study are presented in Table A1.1 Our wild type strain has the genotype: lambda-, thyA36, deoC2, IN(rrnD-rrnE)1, rph and has been described previously (Jensen, 1993). Mutants were constructed using standard P1 transduction. Transductants were verified via selection using antibiotics and sensitivity to either temperature shift or UV when appropriate. Antibiotics used: Ampicillin $100 \mu \mathrm{g} / \mathrm{mL}$, Tetracycline $16 \mu \mathrm{g} / \mathrm{mL}$ for transductants.

\section{Tracking Rate of DNA Synthesis via [3H]-Thymidine Incorporation.}

Fresh overnight cultures were diluted 1:100 and grown in DGCthy medium supplemented with $0.1 \mu \mathrm{Ci} / \mathrm{ml}\left[{ }^{14} \mathrm{C}\right]$ thymine to an OD600 of 0.4 in a $30{ }^{\circ} \mathrm{C}$ shaking water bath at which time the culture was split in half. Half of the culture was immediately filtered and resuspended in fresh media containing $0.1 \mu \mathrm{Ci} / \mathrm{ml}$ $\left[{ }^{14} \mathrm{C}\right]$ thymine that had been pre-warmed to $42{ }^{\circ} \mathrm{C}$ while the other half was filtered and returned to fresh media containing $0.1 \mu \mathrm{Ci} / \mathrm{ml}\left[{ }^{14} \mathrm{C}\right]$ thymine that had been pre-warmed to $30^{\circ} \mathrm{C}$. Duplicate $0.5-\mathrm{mL}$ aliquots of the culture were pulse-labeled 
with $\left[{ }^{3} \mathrm{H}\right]$ thymidine $(1.0 \mu \mathrm{Ci} / 10 \mu \mathrm{g} / \mathrm{mL})$ for $2 \mathrm{~min}$ at the indicated times. Following pulse-labeling, the cells were lysed and the DNA was precipitated by addition of 5 $\mathrm{mL}$ of ice-cold $5 \%$ trichloroacetic acid. The precipitate was then collected on Fisherbrand $2.5-\mathrm{cm}$ glass fiber filters, and the amount of radioactivity in each sample was measured via liquid scintillation counter. Raw counts of $\left[{ }^{3} \mathrm{H}\right]$ thymidine and $\left[{ }^{14} \mathrm{C}\right]$ thymine were normalized to the -10 min time point in both treatments.

\section{Results and Discussion}

In order to begin to determine when and where alternative polymerases may be able to function in the absence of DNA damage in vivo, we compared the rate of DNA synthesis and genomic DNA accumulation in $d n a E$ polB dinB umuDC mutant to those observed in $d n a E$ mutants under both permissive and restrictive conditions. To this end, isogenic dnaE cultures either containing or lacking the damage-inducible polymerases were grown in media containing $\left[{ }^{14} \mathrm{C}\right]$ thymine to track genomic DNA accumulation. When the cultures reached an $\mathrm{OD}_{600} \sim 0.3$, the cultures were split in half and filtered. One half was returned to media prewarmed to the permissive temperature of $30^{\circ} \mathrm{C}$, while the other half was returned to media pre-warmed to the restrictive temperature of $42^{\circ} \mathrm{C}$. Immediately, aliquots of the cultures were taken and pulse-labeled with $\left[{ }^{3} \mathrm{H}\right]$ thymidine for 2 minutes to track the rate of synthesis. Pulse-labeling was repeated at various times throughout the 90 minute time course. 
We observed that under permissive conditions, dnaE cells continue to synthesize DNA at a constant rate and undergo two doublings within the 90minute time course (Figure B1A). Following disruption of Pol III, the amount of genomic DNA accumulation over time is reduced by about half, doubling once over the 90 minutes and the rate of DNA synthesis continues to decline eventually reaching background levels at the end of the 90-minute time course (Figure $\mathrm{B} 1 \mathrm{~A}$ and $\mathrm{B}$ ). By comparison, in $d n a E$ mutants lacking the three damageinducible polymerases, the rate of DNA synthesis remained constant under permissive conditions, however, the amount of DNA accumulation was reduced by approximately half, doubling once over 90 minutes. Following disruption of Pol III, mutants lacking the damage-inducible polymerases exhibited a more rapid decline in the rate of synthesis rates and the amount of genomic DNA accumulation ceased almost immediately (Figure B1A and B). Taken together, these results suggest that at least one of the translesion polymerases is able to substitute and continue DNA synthesis for a period of time in the absence of Pol III.

Curiously, the decrease in the rate of DNA accumulation at the permissive temperature in the $d n a E$ cells lacking the three damage inducible polymerases is equal to the rate seen in the $d n a E$ strain at the restrictive temperature. If not coincidental, this could be indicative of a number of possible phenomena. One possibility is that the alternative polymerases continue DNA synthesis on one strand, presumably the lagging, under conditions when Pol III is disrupted. This 
may account for why the genomic DNA accumulation is reduced to approximately one half that seen after Pol III inactivation.

It is also possible that following inactivation of Pol III, the translesion polymerases are able to continue synthesis on both strands, but at rate which is nearly half the normal rate for the initial period following inactivation. The reduced processivity and lower affinity of these polymerases, relative to Pol III, would be consistent with the steady decline in DNA synthesis rates over the time course (Becherel et al., 2002; Lenne-Samuel et al., 2002; Lopez et al., 2003; Sutton et al., 2001).

Yet another possibility is that the point mutation in the $d n a E$ strain impairs the ability of the polymerase to interact with the replisome specifically in either its leading or lagging strand orientation. In this scenario, the translesion polymerase would be able to compensate for the function of Pol III on the strand for which it is impaired. While speculative, such a possibility is attractive because it may explain the reduced accumulation rate observed in $d n a E$ strains missing the damage inducible polymerases.

It is unlikely that Pol I contributes significantly to synthesis because, as we observed in the disrupted $d n a E$ polB $\operatorname{din} B$ umuC mutant in which only Pol I is active, genomic DNA accumulation was undetectable. However, in order to draw more appropriate conclusions from these observations, a series of experiments are required. Firstly, it is important to note that the $d n a E$ polB $\operatorname{din} B$ umuDC mutant has a different genetic background than that of the $d n a E$ strain. In order 
to ensure that the nucleotide incorporation rates observed are not an artifact of the cell background, an isogenic $d n a E$ strain should be constructed and used in these experiments. If it were established that the background of the strain had no effect on incorporation rates, it would be important to determine whether one, two or all three of the alternative polymerases are responsible for the nucleotide incorporation observed. This could be achieved by observing the rate of synthesis following inactivation of DnaE in three isogenic mutants for the three alternative polymerases.

It has been shown that in eukaryotes as well as some bacteria, the replisome contains two different polymerases specific to either the leading- or lagging- strand (Dervyn et al., 2001; Karthikeyan et al., 2000). It would be of interest to determine whether a similar mechanism can occur in E. coli. Strandspecific sequencing of DNA isolated from these mutants could show whether the polymerases function predominantly on the leading or lagging strand. The differences observed in these mutants will provide the basis for genetic studies that address such questions. 
Table B1.1. E. coli strains used

\begin{tabular}{|c|c|c|}
\hline $\begin{array}{l}\text { Strain } \\
\text { number }\end{array}$ & Genotype & Source, Reference or Construction \\
\hline SR108 & $\begin{array}{l}\text { lambda-, thyA36, deoC2, } \\
\text { IN(rrnD-rrnE)1, rph }\end{array}$ & (Jensen, 1993) \\
\hline E486 & $\begin{array}{l}\text { dnaE486(ts), thr-1, leuB6, } \\
\text { fhuA21, lacY1, glnV44, } \\
\text { rfbC1, thyA6, rpsL67, } \\
\text { thiE1, deoC1, met-89 }\end{array}$ & (Wechsler and Gross, 1971) \\
\hline CL646 & $\begin{array}{l}\text { SR108 polB', } \operatorname{din} B^{-} \\
\text {AumuDC595 }\end{array}$ & (Courcelle et al., 2005) \\
\hline CL1881 & CL646 dnaE486(ts) & $\begin{array}{l}\text { CL } 646 \times \text { x } 1 \text { from E486 (Wechsler and } \\
\text { Gross, 1971) }\end{array}$ \\
\hline
\end{tabular}



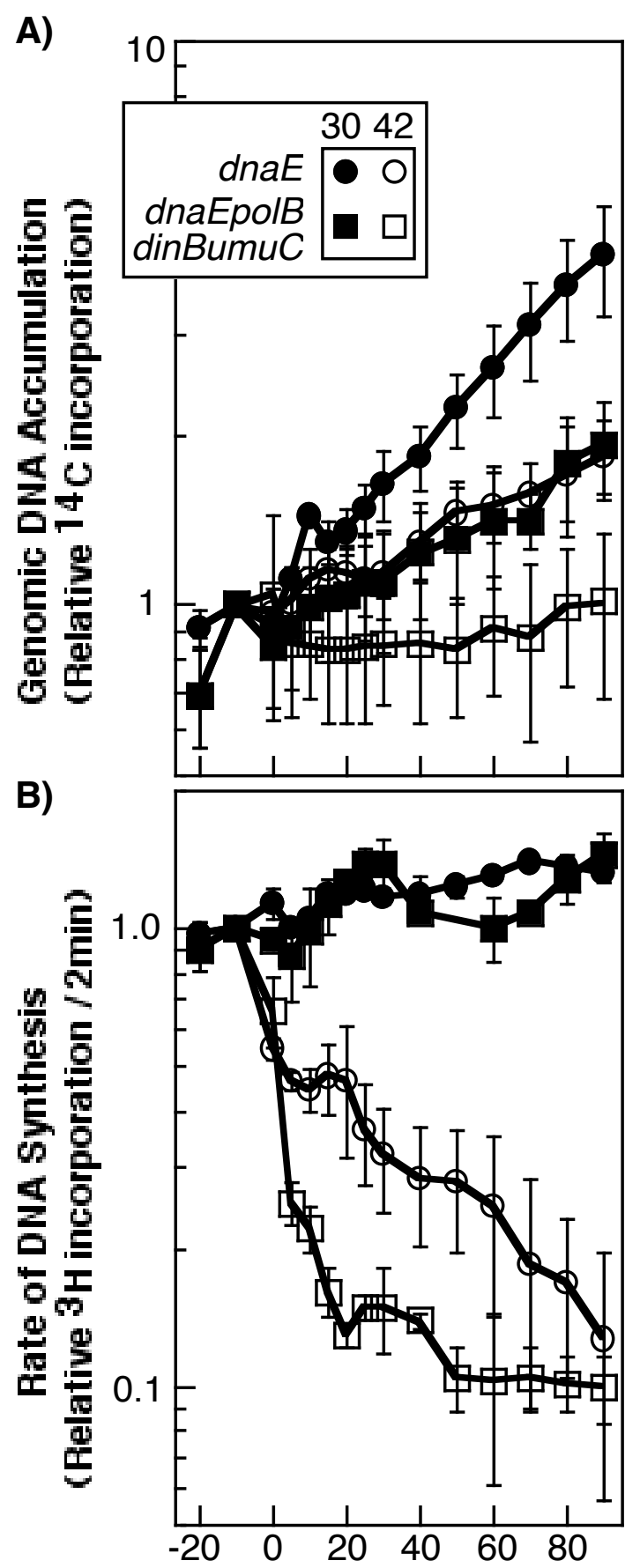

\section{Time following treatment (mins)}

Figure B1. Following inactivation of Pol III, the rate of DNA synthesis is dependent on at least one of the damage-inducible polymerases. Cultures grown in $\left[{ }^{14} \mathrm{C}\right]$ thymine at $30^{\circ} \mathrm{C}$ were pulse-labeled with $1 " \mathrm{Ci} / 10 \mathrm{~g} / \mathrm{ml}\left[{ }^{3} \mathrm{H}\right]$ thymidine for two minutes at the indicated times following mock treatment or a shift to $42^{\circ} \mathrm{C}$. The amount of radioactivity incorporated into the DNA, relative to pretreated cultures is plotted. Error bars represent standard error of two experiments. 


\section{References}

Becherel, O.J., Fuchs, R.P. \& Wagner, J. 2002. Pivotal role of the beta-clamp in translesion DNA synthesis and mutagenesis in E. coli cells. DNA Repair (Amst). 1, 703-708.

Dervyn, E., Suski, C., Daniel, R., Bruand, C., Chapuis, J., Errington, J., Janniere, L. \& Ehrlich, S.D. 2001. Two essential DNA polymerases at the bacterial replication fork. Science. 294, 1716-1719.

Hastings, P.J., Hersh, M.N., Thornton, P.C., Fonville, N.C., Slack, A., Frisch, R.L., Ray, M.P., Harris, R.S., Leal, S.M. \& Rosenberg, S.M. 2010.

Competition of Escherichia coli DNA polymerases I, II and III with DNA Pol IV in stressed cells. PLoS One. 5, e10862.

Horiuchi, T., Maki, H. \& Sekiguchi, M. 1978. A new conditional lethal mutator (dnaQ49) in Escherichia coli K12. Molecular and General Genetics MGG. $163,277-283$.

Indiani, C., Langston, L.D., Yurieva, O., Goodman, M.F. \& O'Donnell, M. 2009. Translesion DNA Polymerases Remodel the Replisome and Alter the Speed of the Replicative Helicase. Proc Natl Acad Sci U S A. X, XX-XX.

Indiani, C., Mclnerney, P., Georgescu, R., Goodman, M.F. \& O'Donnell, M. 2005. A sliding-clamp toolbelt binds high- and low-fidelity DNA polymerases simultaneously. Mol Cell. 19, 805-815. 
Jensen, K.F. 1993. The Escherichia coli K-12 "wild types" W3110 and MG1655 have an rph frameshift mutation that leads to pyrimidine starvation due to low pyrE expression levels. J Bacteriol. 175, 3401-3407.

Johnson, A. \& O'Donnell, M. 2005. Cellular DNA replicases: components and dynamics at the replication fork. Annu Rev Biochem. 74, 283-315.

Karthikeyan, R., Vonarx, E.J., Straffon, A.F., Simon, M., Faye, G. \& Kunz, B.A. 2000. Evidence from mutational specificity studies that yeast DNA polymerases delta and epsilon replicate different DNA strands at an intracellular replication fork. J Mol Biol. 299, 405-419.

Kornberg, T. \& Gefter, M.L. 1971. Purification and DNA synthesis in cell-free extracts: properties of DNA polymerase II. Proc Natl Acad Sci U S A. 68, 761-764.

Lenne-Samuel, N., Wagner, J., Etienne, H. \& Fuchs, R.P. 2002. The processivity factor beta controls DNA polymerase IV traffic during spontaneous mutagenesis and translesion synthesis in vivo. EMBO Rep. 3, 45-49.

Leu, F.P., Georgescu, R. \& O'Donnell, M. 2003. Mechanism of the E. coli tau processivity switch during lagging-strand synthesis. Mol Cell. 11, 315-327.

Lopez, D.S.F.J., Georgescu, R.E., Goodman, M.F. \& O'Donnell, M. 2003. Competitive processivity-clamp usage by DNA polymerases during DNA replication and repair. EMBO J. 22, 6408-6418.

Masker, W., Hanawalt, P. \& Shizuya, H. 1973. Role of DNA polymerase II in repair replication in Escherichia coli. Nat New Biol. 244, 242-243. 
Pham, P., Rangarajan, S., Woodgate, R. \& Goodman, M.F. 2001. Roles of DNA polymerases V and II in SOS-induced error-prone and error- free repair in Escherichia coli. Proc Natl Acad Sci U S A. 98, 8350-8354.

Reuven, N.B., Arad, G., Maor-Shoshani, A. \& Livneh, Z. 1999. The mutagenesis protein UmuC is a DNA polymerase activated by UmuD', RecA, and SSB and is specialized for translesion replication. J Biol Chem. 274, 3176331766.

Reuven, N.B., Arad, G., Stasiak, A.Z., Stasiak, A. \& Livneh, Z. 2001. Lesion bypass by the Escherichia coli DNA polymerase $\mathrm{V}$ requires assembly of a RecA nucleoprotein filament. J Biol Chem. 276, 5511-5517.

Smirnov, G.B., Sinzinis, B.I. \& Saenko, A.S. 1975. The role of DNA polymerase I in genetic recombination and viability of Escherichia coli. Basic Life Sci. 5A, 399-404.

Sommer, S., Knezevic, J., Bailone, A. \& Devoret, R. 1993. Induction of only one SOS operon, umuDC, is required for SOS mutagenesis in Escherichia coli. Mol Gen Genet. 239, 137-144.

Sutton, M.D., Farrow, M.F., Burton, B.M. \& Walker, G.C. 2001. Genetic interactions between the Escherichia coli umuDC gene products and the beta processivity clamp of the replicative DNA polymerase. J Bacteriol. 183, 2897-2909. 
Wagner, J., Fujii, S., Gruz, P., Nohmi, T. \& Fuchs, R.P. 2000. The beta clamp targets DNA polymerase IV to DNA and strongly increases its processivity. EMBO Rep. 1, 484-488.

Wagner, J., Gruz, P., Kim, S.R., Yamada, M., Matsui, K., Fuchs, R.P. \& Nohmi, T. 1999. The dinB gene encodes a novel E. coli DNA polymerase, DNA pol IV, involved in mutagenesis. Mol Cell. 4, 281-286.

Wentzell, B. \& McCalla, D.R. 1980. Formation and excision of nitrofuran-DNA adducts in Escherichia coli. Chem Biol Interact. 31, 133-150.

Woodgate, R. \& Ennis, D.G. 1991. Levels of chromosomally encoded Umu proteins and requirements for in vivo UmuD cleavage. Mol Gen Genet. 229, 10-16.

Woodgate, R., Rajagopalan, M., Lu, C. \& Echols, H. 1989. UmuC mutagenesis protein of Escherichia coli: purification and interaction with UmuD and UmuD'. Proc Natl Acad Sci U S A. 86, 7301-7305. 